(2) Open Access Full Text Article

REVIEW

\title{
Update on developments with SGLT2 inhibitors in the management of type 2 diabetes
}

This article was published in the following Dove Press journal:

Drug Design, Development and Therapy

II September 2014

Number of times this article has been viewed

\section{Michael A Nauck}

Department of Internal Medicine, Diabeteszentrum Bad Lauterberg, Bad Lauterberg im Harz, Germany
Correspondence: Michael A Nauck Department of Internal Medicine, Diabeteszentrum Bad Lauterberg Kirchberg 21, D-3743I Bad Lauterberg im Harz, Germany

Tel +49552481218

$\mathrm{Fax}+49552481398$

Emailm.nauck@diabeteszentrum.de
Abstract: The importance of the kidney's role in glucose homeostasis has gained wider understanding in recent years. Consequently, the development of a new pharmacological class of anti-diabetes agents targeting the kidney has provided new treatment options for the management of type 2 diabetes mellitus (T2DM). Sodium glucose co-transporter type 2 (SGLT2) inhibitors, such as dapagliflozin, canagliflozin, and empagliflozin, decrease renal glucose reabsorption, which results in enhanced urinary glucose excretion and subsequent reductions in plasma glucose and glycosylated hemoglobin concentrations. Modest reductions in body weight and blood pressure have also been observed following treatment with SGLT2 inhibitors. SGLT2 inhibitors appear to be generally well tolerated, and have been used safely when given as monotherapy or in combination with other oral anti-diabetes agents and insulin. The risk of hypoglycemia is low with SGLT2 inhibitors. Typical adverse events appear to be related to the presence of glucose in the urine, namely genital mycotic infection and lower urinary tract infection, and are more often observed in women than in men. Data from long-term safety studies with SGLT2 inhibitors and from head-to-head SGLT2 inhibitor comparator studies are needed to fully determine their benefit-risk profile, and to identify any differences between individual agents. However, given current safety and efficacy data, SGLT2 inhibitors may present an attractive option for T2DM patients who are failing with metformin monotherapy, especially if weight is part of the underlying treatment consideration.

Keywords: anti-diabetes agents, efficacy, hyperglycemia, safety, sodium glucose co-transporter type 2 inhibitors, type 2 diabetes mellitus

\section{Renal glucose handling in the kidney in glucose-tolerant individuals}

The human kidney regulates glucose homeostasis via gluconeogenesis, glucose uptake from the circulation, and by glucose reabsorption from the urine filtered in the renal glomeruli. ${ }^{1}$

Approximately 160-180 g/day of glucose is filtered by the kidneys. ${ }^{1}$ In healthy (ie, glucose-tolerant) individuals, virtually all glucose filtered by the glomeruli is reabsorbed by the proximal renal tubule and returned into the circulation, so almost no glucose is excreted into the urine. The ability of the proximal tubule to reabsorb glucose increases as the filtered glucose load increases, which can occur by increasing plasma glucose concentration or glomerular filtration rate (GFR), ${ }^{2}$ until the maximum glucose transport capacity (known as Tm glucose) is reached. Once this level is exceeded, surplus glucose cannot be reabsorbed and is excreted into the urine, resulting in urinary glucose excretion (UGE; ie, glucosuria). In a healthy adult, Tm glucose equates to a filtration 
rate of $260-350 \mathrm{mg} / \mathrm{min} / 1.73 \mathrm{~m},{ }^{2,3}$ which is equivalent to a plasma glucose concentration of approximately $200 \mathrm{mg} / \mathrm{dL}$ $(11.0 \mathrm{mmol} / \mathrm{L}) .{ }^{4}$ The plasma glucose concentration at which Tm glucose is reached is known as the renal threshold for glucose excretion.

Glucose reabsorption from the glomerular filtrate is mediated by sodium glucose co-transporter (SGLT) proteins in a process that is independent of insulin (Figures 1 and 2), unlike the action of the major facilitative glucose transporter (GLUT) GLUT4 that is responsible for glucose uptake into insulin-sensitive tissues, such as adipose tissue and muscle. SGLTs are membrane-bound proteins that actively transport glucose against its concentration gradient and, thus, require an energy source to drive the sodium pump. ${ }^{5}$ Details of the SGLT family are summarized in Table $1 .{ }^{5}$ Around $90 \%$ of filtered renal glucose is reabsorbed in the brush-border of cells in the first segment of the proximal convoluted tubule by SGLT2, a low-affinity, high-capacity transporter, and the remaining $10 \%$ is removed in the distal straight segment by SGLT1, a related high-affinity, low-capacity transporter., SGLT1 is also extensively expressed in the small intestine where it has a significant role in glucose absorption. ${ }^{5}$ A second group of glucose transporters, the facilitative glucose transporters or GLUTs, then enable the passive diffusion of glucose from the basolateral membrane of cells in the proximal convoluted tubule into the bloodstream, mainly via GLUT2 and to a minor degree via GLUT1..$^{5-7}$
SGLT2 is encoded by the SLC5A2 gene, and a range of loss-of-function mutations in this gene results in the rare disorder of familial renal glucosuria. ${ }^{8}$ Familial renal glucosuria is characterized by UGE in the presence of normal plasma glucose concentrations, without any signs of renal tubular dysfunction. ${ }^{8}$ Homozygous mutations in the gene encoding SGLT2 result in significant UGE $(>10-100 \mathrm{~g} / 1.73$ $\mathrm{m}^{2} /$ day), whereas heterozygous mutations generally result in lower degrees of UGE $\left(<10 \mathrm{~g} / 1.73 \mathrm{~m}^{2} /\right.$ day $) .{ }^{8}$ Nevertheless, most individuals affected by familial renal glucosuria are asymptomatic and only rarely suffer from hypoglycemia or hypovolemia, ${ }^{8}$ and most of the commonly cited descriptions of this syndrome do not mention an increased risk of genito-urinary infections. In comparison, loss-of-function mutations in the gene encoding SGLT1, SLC5A1, cause glucose-galactose malabsorption in the gut, ${ }^{9}$ with little or no glucosuria, which results in severe watery diarrhea in affected newborns; ${ }^{9}$ however, dietary tolerance to glucose appears to develop in adulthood, possibly due to development of gastrointestinal flora that aid in its metabolization. ${ }^{10}$

\section{Renal glucose handling in the kidney of an individual with diabetes mellitus}

Individuals with type 2 diabetes mellitus (T2DM) have increased renal glucose output in the post-absorptive state, causing increased release of glucose into the blood not only

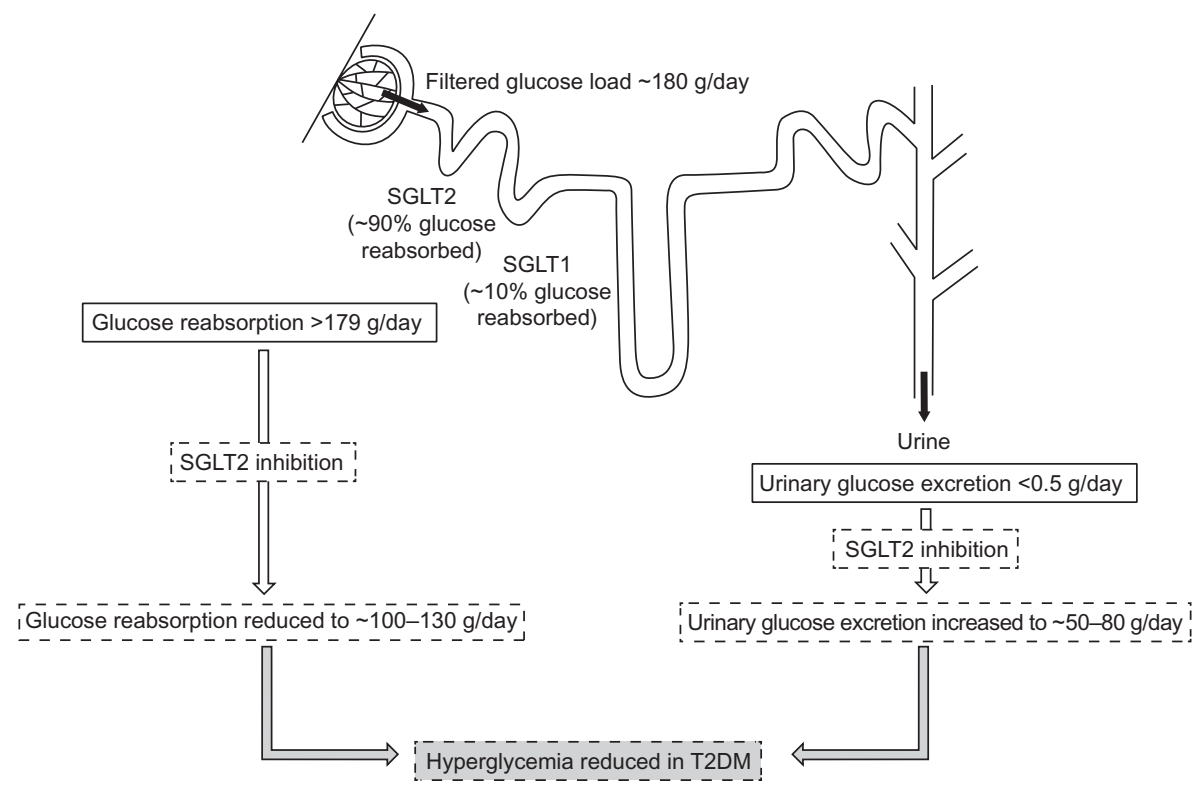

Figure I Renal tubular reabsorption of glucose.

Notes: Most of the glucose in the glomerular filtrate is reabsorbed by SGLT2 in the proximal convoluted tubule and the remainder is reabsorbed by SGLTI in the distal straight segment of the tubule, so virtually no glucose is lost in the urine. The facilitative glucose transporters (GLUTs) then enable passive diffusion of glucose from the renal tubule into the bloodstream. Pharmacological inhibition of SGLT2 reduces glucose reabsorption, causing glucose to remain in the filtrate for subsequent urinary excretion. Abbreviations: SGLT, sodium glucose co-transporter; T2DM, type 2 diabetes mellitus. 


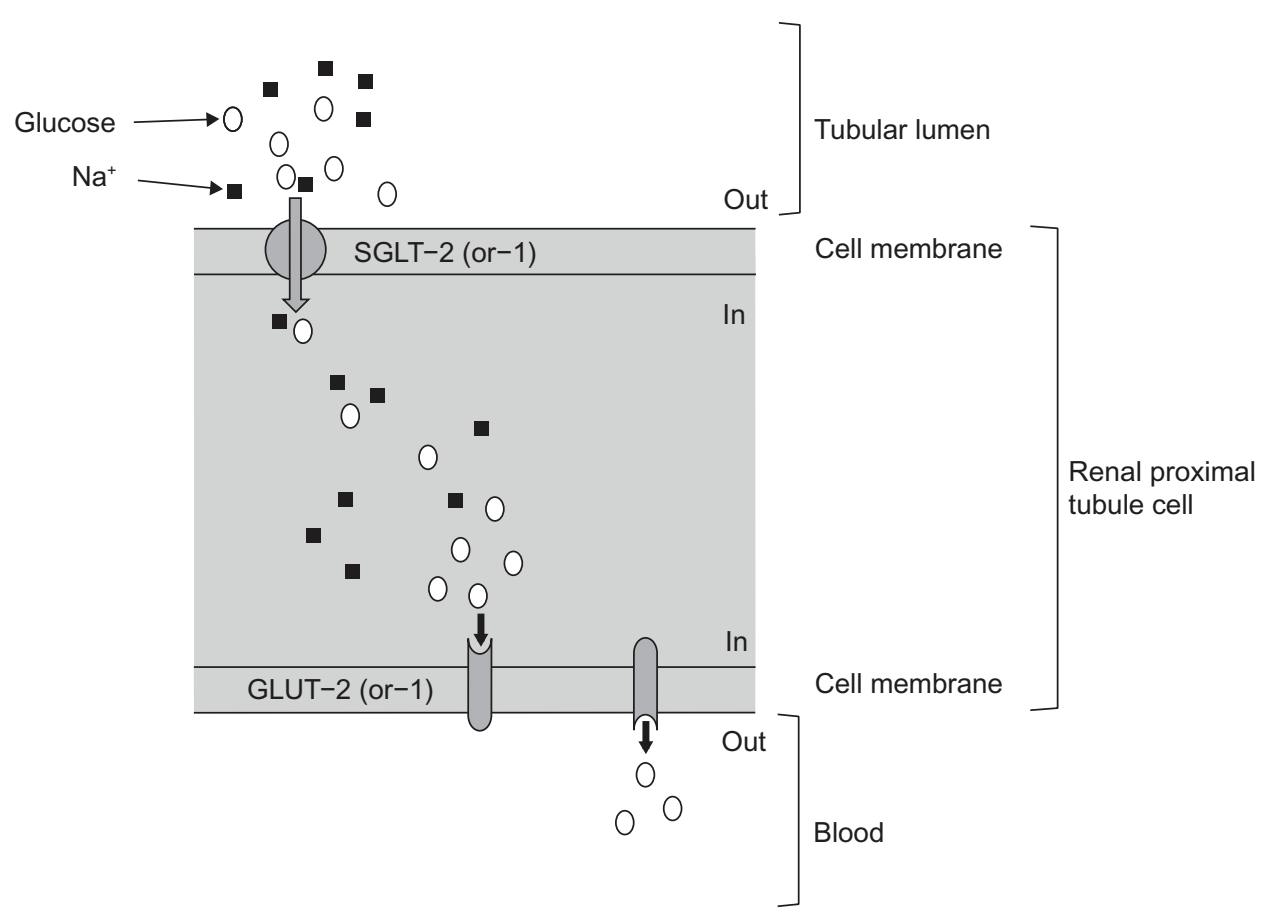

Figure 2 Renal glucose transport.

Notes: Glucose and sodium ( $1: 1)$ enter the renal tubule cells with assistance from glucose transport proteins. Active transport of glucose across the luminal membrane occurs via SGLT2 (and SGLTI) and is driven by coupling glucose transport with sodium co-transport. Glucose then diffuses passively across the basolateral membrane, facilitated by GLUT2 (and GLUTI).

Abbreviations: GLUT, facilitative glucose transporter; $\mathrm{Na}^{+}$, sodium; SGLT, sodium glucose co-transporter.

from the liver, but also with a significant contribution by the kidneys. ${ }^{11}$ Greater postprandial elevation of renal glucose release is also observed in individuals with T2DM versus those with normal glucose tolerance. ${ }^{12}$ Moreover, renal glucose uptake is increased in both post-absorptive and postprandial states in individuals with T2DM versus nondiabetic individuals. ${ }^{11,12}$

As demonstrated in an early study of individuals with type 1 DM (T1DM), hyperglycemia may occur without the expected degree of glucosuria, resulting from increased

Table I Sodium-glucose co-transporter (SGLT) family

\begin{tabular}{cll}
\hline SGLT member & Substrate & Distribution in human tissue \\
\hline SGLTI & $\begin{array}{l}\text { Glucose, } \\
\text { galactose } \\
\text { Glucose }\end{array}$ & $\begin{array}{l}\text { Intestine, trachea, kidney, heart, } \\
\text { brain, testis, prostate } \\
\text { Kidney, brain, liver, thyroid, } \\
\text { muscle, heart }\end{array}$ \\
SGLT3 & Glucose & $\begin{array}{l}\text { Intestine, testis, uterus, lung, } \\
\text { brain, thyroid } \\
\text { Intestine, kidney, liver, brain, }\end{array}$ \\
SGLT4 & Glucose, & $\begin{array}{l}\text { lung, trachea, uterus, pancreas } \\
\text { Kannose }\end{array}$ \\
SGLT5 & Glucose, & Kidney \\
SGLT6 & $\begin{array}{l}\text { galactose } \\
\text { D-chiro- }\end{array}$ & Brain, kidney, intestine \\
& inositol & \\
\hline
\end{tabular}

Note: Table adapted with permission from Wright EM, Loo DD, Hirayama BA Biology of human sodium glucose transporters. Physiol Rev. 20I I;9I (2):733-794. ${ }^{5}$ glucose reabsorption from the glomerular filtrate: the mean Tm glucose was reported to be up to $20 \%$ higher in individuals with T1DM than in healthy individuals. ${ }^{13}$ In addition, increased expression and activity of SGLT2 mRNA and protein have been demonstrated in vitro. ${ }^{14,15}$ There may also be over-expression of SGLT1 in the gastrointestinal tract in patients with diabetes. ${ }^{16}$ A recent study also demonstrated a change in renal glucose kinetics in response to SGLT2 inhibition in healthy subjects and those with T2DM, ${ }^{17}$ whereby administration of the SGLT2 inhibitor dapagliflozin (10 mg/day for 7 days) reduced Tm glucose by approximately $55 \%$ in both groups. ${ }^{17}$ Moreover, dapagliflozin reduced the plasma glucose threshold at which glucose excretion began to concentrations well below fasting levels (ie, 4.7-6.0 mmol/L [85-108 mg/dL]) in both groups: glucosuria threshold was reduced to $1.2 \pm 2.6 \mathrm{mmol} / \mathrm{L}(21 \pm 46 \mathrm{mg} / \mathrm{dL})$ in subjects with T2DM and to $2.0 \pm 2.2 \mathrm{mmol} / \mathrm{L}(37 \pm 40 \mathrm{mg} / \mathrm{dL})$ in healthy subjects $(P<0.001$ for both groups $){ }^{17}$

In healthy glucose-tolerant individuals, having a Tm glucose of approximately $200 \mathrm{mg} / \mathrm{dL}(11.0 \mathrm{mmol} / \mathrm{L})$ that is well above the normal filtered glucose load of approximately $100 \mathrm{mg} / \mathrm{dL}$ (5.5 mmol/L) allows the kidney to conserve this energy source for future use when glucose availability is scarce; however, this process may become maladaptive in 
individuals with DM. ${ }^{18}$ Instead of excreting excess glucose into the urine in the presence of hyperglycemia, the kidneys of a diabetic person continue to reabsorb glucose, due to an elevation of the Tm glucose. ${ }^{18}$ Consequently, hyperglycemia remains uncorrected and contributes to the ensuing problem of glucose toxicity. Thus, if SGLT2 activity promotes glucose conservation and hinders normalization of plasma glucose levels in DM, it is postulated that inhibition of SGLT2 might decrease the threshold for UGE (glucosuria) and reduce hyperglycemia ${ }^{18,19}$

\section{Early SGLT2 inhibitors}

Early investigations into renal glucose handling were carried out on phlorizin (Figure 3), a naturally occurring glucoside found in the root bark of fruit trees. ${ }^{20}$ Studies from the $1950 \mathrm{~s}$ revealed that phlorizin blocked sugar transport in several tissues, including the kidney and small intestine. ${ }^{21}$ This was later found to be due to inhibition of SGLT proteins: phlorizin is a competitive inhibitor of SGLT1 and SGLT2 but has greater affinity for SGLT2. ${ }^{5,20}$ In the $1980 \mathrm{~s}$, a rat model of diabetes was used to demonstrate that phlorizin-induced glucosuria was associated with normalization of plasma glucose without hypoglycemia. ${ }^{22,23}$ Phlorizin also normalized insulin sensitivity in partially pancreatectomized rats but did not affect insulin action in the control animals. ${ }^{22}$ The ensuing glucosuria reversed insulin resistance, and discontinuation of phlorizin led to the return of hyperglycemia and insulin resistance. ${ }^{22}$ However, phlorizin was unsuitable for clinical development in diabetes due to its poor oral bioavailability: phlorizin is metabolized to phloretin by glucosidase in the gut and, thus, must be given parenterally. Moreover, phloretin is a potent inhibitor of GLUT $1,{ }^{20}$ the suppression of which could result in reduced glucose transport to other tissues, such as the central nervous system. ${ }^{24}$

Consequently, pharmaceutical research has pursued phlorizin derivatives that possess increased stability/ bioavailability and SGLT2 selectivity, and both O- and C-glucoside entities have been evaluated (Figure 3 ). O-glucoside candidates, such as sergliflozin and T-1095, ${ }^{25}$ were investigated first, but were discontinued in early clinical development for reasons probably related to nonselective SGLT2 inhibition, ${ }^{26}$ and/or bioavailability issues. ${ }^{27} \mathrm{C}$-glucoside candidates possessed increased resistance to enzymatic breakdown ${ }^{28}$ and have fared more successfully during clinical development with a number of C-glucoside compounds progressing to marketing application and approval.

\section{General characteristics of SGLT2 inhibitors}

As the mode of action of SGLT2 is independent of insulin, SGLT2 inhibitors would be expected to act independently of pancreatic beta-cell function and insulin resistance. Consequently, there could be limited loss of potency in SGLT2 inhibitors (ie, maintained glucose lowering effect) when betacell function inevitably deteriorates over time, as is observed with other types of glucose-lowering agents. Furthermore, as inhibition of SGLT2 neither interferes with normal endogenous glucose production in response to hypoglycemia, ${ }^{29}$ nor stimulates insulin release, ${ }^{22,30}$ the mode of action of SGLT2 inhibitor therapy should not increase the risk of hypoglycemic episodes. The novel mechanism of action of SGLT2 inhibitor therapy also suggests that it can be given in combination with any of the existing glucose-lowering agents, including insulin, as they share no common mechanistic pathways.

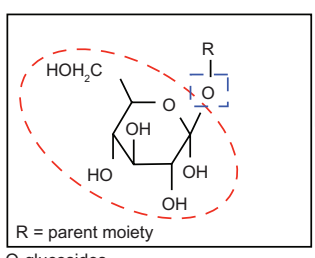

O-glucosides

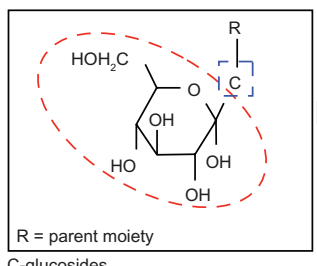

C-glucosides
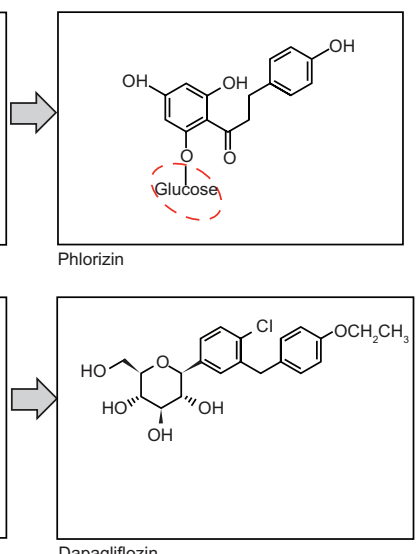
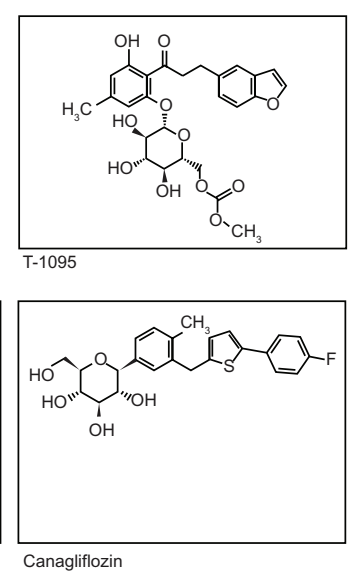

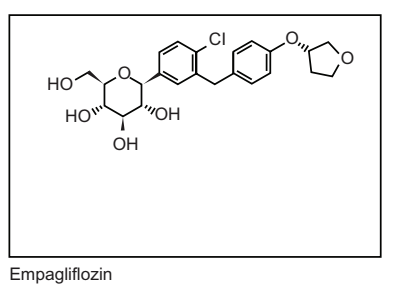

Figure 3 Structure of phlorizin and candidate SGLT2 inhibitors. Abbreviation: SGLT, sodium glucose co-transporter. 
As well as these predicted benefits, several potential safety issues may be anticipated from the known pharmacodynamic effects of SGLT2 inhibitors. For example, as SGLT2 inhibitors cause a modest osmotic diuresis, there may be a risk of hypotension and hypovolemia; although, lowering of blood pressure (BP) may be of benefit in some individuals with T2DM. The ability of SGLT2 inhibition to increase UGE depends upon the presence of a normal GFR, so the glycemic effectiveness of an SGLT2 inhibitor would be expected to be lower in patients with chronic kidney disease (CKD) and a reduced GFR. The continual presence of glucose in the urine caused by SGLT2 inhibition theoretically increases the risk of urinary tract infections and mycotic genital tract infections. Furthermore, given the renal tubular mechanism of action of SGLT2 inhibitors, this class of compounds has the hypothetical ability to alter the absorption and excretion of calcium and phosphate and, in so doing, potentially affect bone metabolism. Although the various SGLT2 inhibitors in clinical development have a structural similarity, they differ in their respective selectivity profiles for SGLT2 over SGLT1: empagliflozin has the highest degree of selectivity
( $>2,500$-fold), followed by tofogliflozin $(>1,875$-fold), dapagliflozin ( $>1,200$-fold), ipragliflozin ( $>550$-fold), and canagliflozin ( $>250$-fold). ${ }^{31}$ Inhibitors with lower selectivity for SGLT2 versus SGLT1 may incur safety issues arising from SGLT1 inhibition, such as diarrhea caused by glucosegalactose malabsorption. Although, recent data suggest that transient inhibition of SGLT1 by SGLT2 inhibitors may lower postprandial glucose by reducing intestinal glucose absorption. ${ }^{32}$

\section{Clinical data from SGLT2 inhibitor trials}

A summary of SGLT2 inhibitors currently known to be in clinical development is presented in Table 2. Phase II through IV clinical trials with SGLT2 inhibitors are listed in Table S1. At the time of writing, dapagliflozin and canagliflozin are marketed in the US and EU and empagliflozin gained recent approval from the European Medicines Agency and the US Food and Drug Administration. Outside of the US and EU marketing applications for ipragliflozin, luseogliflozin, and tofogliflozin were submitted to Japan's Phar-

Table 2 SGLT2 inhibitors in advanced clinical development

\begin{tabular}{|c|c|c|}
\hline Compound (sponsor) & Development status & Other information \\
\hline $\begin{array}{l}\text { Dapagliflozin } \\
\text { (Bristol-Myers Squibb, } \\
\text { AstraZeneca) }\end{array}$ & $\begin{array}{l}\text { Launched in Europe } \\
\text { EMA approval given in November } 2012 \\
\text { Launched in the US } \\
\text { FDA approval given in January } 2014\end{array}$ & $\begin{array}{l}\text { http://www.ema.europa.eu/ema/index.jsp?curl=pages/medicines/human/ } \\
\text { medicines/002322/human_med_00I546.jsp\&mid=WC0b0Iac05800Id I } 24 \\
\text { http://www.fda.gov/NewsEvents/Newsroom/PressAnnouncements/ } \\
\text { ucm380829.htm }\end{array}$ \\
\hline $\begin{array}{l}\text { Canagliflozin } \\
\text { (Mitsubishi Tanabe }\end{array}$ & $\begin{array}{l}\text { Launched in the US } \\
\text { FDA approval given in March } 2013\end{array}$ & $\begin{array}{l}\text { http://www.fda.gov/NewsEvents/Newsroom/PressAnnouncements/ } \\
\text { ucm345848.htm }\end{array}$ \\
\hline Pharma, Janssen) & $\begin{array}{l}\text { Launched in Europe } \\
\text { EMA approval given in November } 2013\end{array}$ & $\begin{array}{l}\text { http://www.ema.europa.eu/ema/index.jsp?curl=pages/medicines/human/ } \\
\text { medicines/002649/human_med_00I707.jsp\&mid=WC0b0Iac05800IdI } 24\end{array}$ \\
\hline $\begin{array}{l}\text { Empagliflozin } \\
\text { (Boehringer Ingelheim, } \\
\text { Eli Lilly) }\end{array}$ & $\begin{array}{l}\text { EMA approval given in May } 2014 \\
\text { FDA approval given in August } 2014\end{array}$ & $\begin{array}{l}\text { http://www.fda.gov/NewsEvents/Newsroom/PressAnnouncements/ } \\
\underline{\text { ucm 407637.htm }}\end{array}$ \\
\hline $\begin{array}{l}\text { Ipragliflozin } \\
\text { (Astellas, Kotobuki } \\
\text { Pharmaceutical) }\end{array}$ & $\begin{array}{l}\text { Launched in Japan } \\
\text { Japanese MHLW approval given in } \\
\text { January } 2014\end{array}$ & $\begin{array}{l}\text { http://www.astellas.com/en/corporate/news/detail/approval-of-suglat- } \\
\text { tablets-a-s.html }\end{array}$ \\
\hline $\begin{array}{l}\text { Luseogliflozin } \\
\qquad \text { (Taisho, Novartis) }\end{array}$ & $\begin{array}{l}\text { Pre-registration } \\
\text { Marketing application made to MHLW, } \\
\text { Japan in April } 2013\end{array}$ & $\begin{array}{l}\text { http://www.taisho-holdings.co.jp/en/ir/development/ } \\
\text { http://www.taisho-holdings.co.jp/en/release/2013/2013041801-e.pdf }\end{array}$ \\
\hline $\begin{array}{l}\text { Tofogliflozin } \\
\text { (Chugai, Kowa, Sanofi) }\end{array}$ & $\begin{array}{l}\text { Pre-registration } \\
\text { Marketing application made to MHLW, } \\
\text { Japan in June } 2013\end{array}$ & $\begin{array}{l}\text { http://www.chugai-pharm.co.jp/hc/ss/english/ir/reports_downloads/ } \\
\text { pipeline.html } \\
\text { http://www.chugai-pharm.co.jp/hc/ss/english/news/detail/20121026/50000. } \\
\text { html }\end{array}$ \\
\hline $\begin{array}{l}\text { Ertugliflozin [PF0497I729] } \\
\quad \text { (Pfizer, Merck and Co) }\end{array}$ & $\begin{array}{l}\text { Phase III trials commenced in October } \\
2013\end{array}$ & $\begin{array}{l}\text { http://clinicaltrials.gov/ct2/results?term=ertugliflozin } \\
\text { http://www.mercknewsroom.com/press-release/research-and- } \\
\text { development-news/merck-co-inc-and-pfizer-enter-worldwide- } \\
\text { collaboration-ag }\end{array}$ \\
\hline $\begin{array}{l}\text { Sotagliflozin [LX42II] } \\
\quad \text { (Lexicon Pharmaceuticals) }^{\mathrm{a}}\end{array}$ & $\begin{array}{l}\text { Phase III trials are expected to begin } \\
\text { in } 2014\end{array}$ & http://www.lexgen.com/pipeline/lx421I.html \\
\hline
\end{tabular}

Notes: aSotagliflozin [LX42II] is a dual SGLTI and SGLT2 inhibitor.

Abbreviations: EMA, European Medicines Agency; FDA, US Food and Drug Administration; MHLW, Ministry of Health, Labour and Welfare; SGLT, sodium glucose cotransporter. 
maceuticals and Medical Devices Agency, and ipragliflozin was recently approved. Developmental SGLT2 inhibitors are listed in Table S2. In addition, several fixed dose combination products utilizing SGLT2 inhibitors plus another class of oral anti-diabetes agents are currently in clinical development: dapagliflozin plus metformin (in $5 \mathrm{mg} / 850 \mathrm{mg}$ and $5 \mathrm{mg} / 1,000 \mathrm{mg}$ tablets) gained marketing authorization in the EU in early $2014,{ }^{33}$ and single-pill combination products containing dapagliflozin plus saxagliptin, canagliflozin plus metformin, and empagliflozin plus linagliptin or plus metformin, respectively, are in Phase III clinical trials.

The SGLT2 inhibitors currently marketed are indicated as monotherapy for patients with T2DM and inadequate glycemic control from diet and exercise (US and EU indications), ${ }^{34-37}$ who are unable to use metformin (EU-specific), ${ }^{35,37}$ and as an add-on therapy with other glucose-lowering agents, including insulin (EU-specific) ${ }^{35,37}$ In Europe, the recommended dose of dapagliflozin is $10 \mathrm{mg}$ once daily, whether given as a monotherapy or as an add-on therapy combined with other glucose-lowering agents. ${ }^{35}$ In the US, the recommended starting dose is $5 \mathrm{mg}$ once daily, which can be increased to $10 \mathrm{mg}$ once daily in patients without renal impairment who tolerate the drug and who require additional glycemic control..$^{36}$ The use of dapagliflozin is generally not recommended when eGFR is below $60 \mathrm{~mL} / \mathrm{min} / 1.73 \mathrm{~m}^{2}$. The recommended starting dose of canagliflozin is $100 \mathrm{mg}$ once daily, which can be increased to $300 \mathrm{mg}$ once daily in patients (without renal impairment) who require additional glycemic control, provided the estimated glomerular filtration rate (eGFR) is $60 \mathrm{~mL} / \mathrm{min} / 1.73 \mathrm{~m}^{2}$ or greater. ${ }^{34,37}$ Canagliflozin is generally not recommended when eGFR is below $45 \mathrm{ml} / \mathrm{min} / 1.73 \mathrm{~m}^{2}$. In pre-registration Phase III trials, empagliflozin was independently dosed at $10 \mathrm{mg}$ and $25 \mathrm{mg}$ once daily as monotherapy and as add-on combination therapy to other glucose-lowering agents, including insulin.

\section{Clinical efficacy}

A summary of efficacy data from key clinical trials of SGLT2 inhibitors (as registered in ClinicalTrials.gov) that are available, or expected to soon be available, in the US and EU is presented in Table S3. Selected efficacy data are also presented in Figure 4. Dapagliflozin, canagliflozin, and empagliflozin are the most advanced of the SGLT2 inhibitors in terms of clinical development, and have the largest amount of published clinical data currently available. Pooled analyses of Phase III study data and data from US and EU regulatory reports were also available for dapagliflozin and canagliflozin, whereas data for empagliflozin were principally obtained from publications of individual Phase III studies. Other SGLT2 inhibitors were earlier in clinical development and had fewer publications available at the time of writing, or had no clinical trials registered in ClinicalTrials.gov due to their current development occurring outside the US.

\section{Glycemic efficacy}

Several meta-analyses have demonstrated a significant improvement of glycemic control in patients with T2DM who were treated with SGLT2 inhibitors. ${ }^{60-62}$ The largest of these included data from 58 SGLT2 inhibitor trials, predominantly involving dapagliflozin and canagliflozin, and reported that this drug class had a favorable effect on reducing glycosylated hemoglobin $\left(\mathrm{HbA}_{1 \mathrm{c}}\right.$; mean difference versus placebo, $-0.7 \%$ [95\% confidence interval $\{\mathrm{CI}\}-0.7,-0.6]$; mean difference versus active comparator, $-0.1 \%[95 \% \mathrm{CI}-0.2$, 0.05]).$^{60}$ Dapagliflozin $10 \mathrm{mg}$ provided statistically significant and clinically relevant improvements in glycemic control compared with placebo (with mean placebo-corrected $\mathrm{HbA}_{1 \mathrm{c}}$ decrease in the different studies ranging from $-0.5 \%$ to $-0.7 \%$ at 24 weeks), when given as monotherapy or as add-on therapy to metformin, sulfonylurea, thiazolidinediones, or insulin. ${ }^{63}$ As add-on therapy to metformin, dapagliflozin 10 mg was shown to have non-inferior efficacy versus glipizide after 52 weeks. ${ }^{41}$ Dapagliflozin $10 \mathrm{mg}$ was also shown to have non-inferior efficacy versus metformin extended release when both were given as monotherapy for 24 weeks. ${ }^{39}$ Furthermore, the glucose-lowering effect of dapagliflozin as add-on therapy was maintained over periods of 48-102 weeks. ${ }^{42,64,65}$

Pooled data for canagliflozin $300 \mathrm{mg}$ and $100 \mathrm{mg}$ gave an overall mean change from baseline in $\mathrm{HbA}_{1 \mathrm{c}}$ relative to placebo of $-0.8 \%(95 \% \mathrm{CI}-0.9,-0.8)$ and $0.7 \%(95 \% \mathrm{CI}$ $-0.75,-0.6)$, respectively ${ }^{66}$ Individual studies over 52 weeks using canagliflozin as monotherapy, ${ }^{67}$ or with a background of metformin, ${ }^{46,47}$ or with metformin plus sulfonylurea, ${ }^{48}$ reported that efficacy in terms of reduced $\mathrm{HbA}_{1 \mathrm{c}}$ was maintained over this longer period. Furthermore, canagliflozin (300 mg) was superior in lowering $\mathrm{HbA}_{1 \mathrm{c}}$ when compared to glimepiride, ${ }^{46}$ or sitagliptin..${ }^{47,48}$

Empagliflozin $10 \mathrm{mg}$ and $25 \mathrm{mg}$ also led to statistically significant and clinically meaningful improvements in $\mathrm{HbA}_{1 \mathrm{c}}{ }^{53-57}$ In monotherapy and compared with placebo, adjusted mean differences in change from baseline $\mathrm{HbA}_{1 \mathrm{c}}$ at week 24 were $-0.7 \%(95 \% \mathrm{CI}-0.9,-0.6 ; P<0 \cdot 0001)$ for empagliflozin $10 \mathrm{mg},-0.9 \%(95 \% \mathrm{CI}-1.0,-0.7$; $P<0.0001)$ for empagliflozin $25 \mathrm{mg}$, versus $-0.7 \%$ (95\% CI 
$-0.9,-0.6 ; P<0.0001)$ for sitagliptin. ${ }^{53}$ Placebo-corrected changes in $\mathrm{HbA}_{1 \mathrm{c}}$ after 24 weeks for empagliflozin added to metformin were $-0.6 \%(95 \% \mathrm{CI}-0.7,-0.4 ; P<0.001)$ for empagliflozin $10 \mathrm{mg}$ and $-0.6 \%(95 \% \mathrm{CI}-0.8,-0.5$; $P<0.001$ ) for empagliflozin $25 \mathrm{mg} .{ }^{54}$

Larger reductions in $\mathrm{HbA}_{1 \mathrm{c}}$ were observed in patients with higher baseline levels of $\mathrm{HbA}_{1 \mathrm{c}}$ for each of these three SGLT2 inhibitors. ${ }^{38,45,53}$ Changes in $\mathrm{HbA}_{1 \mathrm{c}}$ and fasting plasma glucose from individual key trials using dapagliflozin, canagliflozin, and empagliflozin are presented in Table S3.

\section{Changes in body weight and composition}

Meta-analysis demonstrated SGLT2 inhibitors reduced body weight compared with other anti-diabetes agents (mean difference $-1.8 \mathrm{~kg}[95 \% \mathrm{CI}-3.5,-0.1]$ ). ${ }^{60}$ Body weight reductions of approximately $2-3 \mathrm{~kg}$ were observed

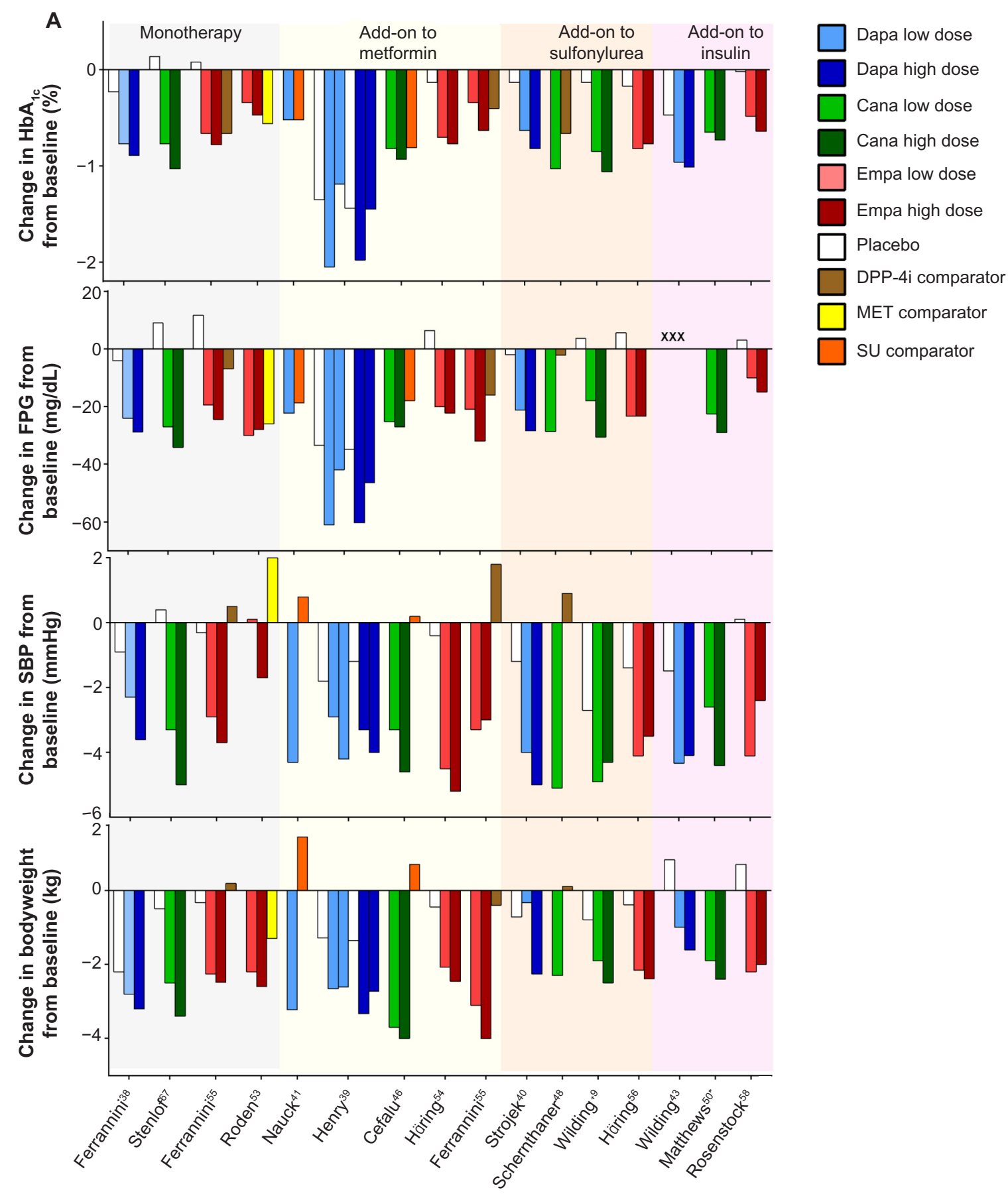

Figure 4 (Continued) 

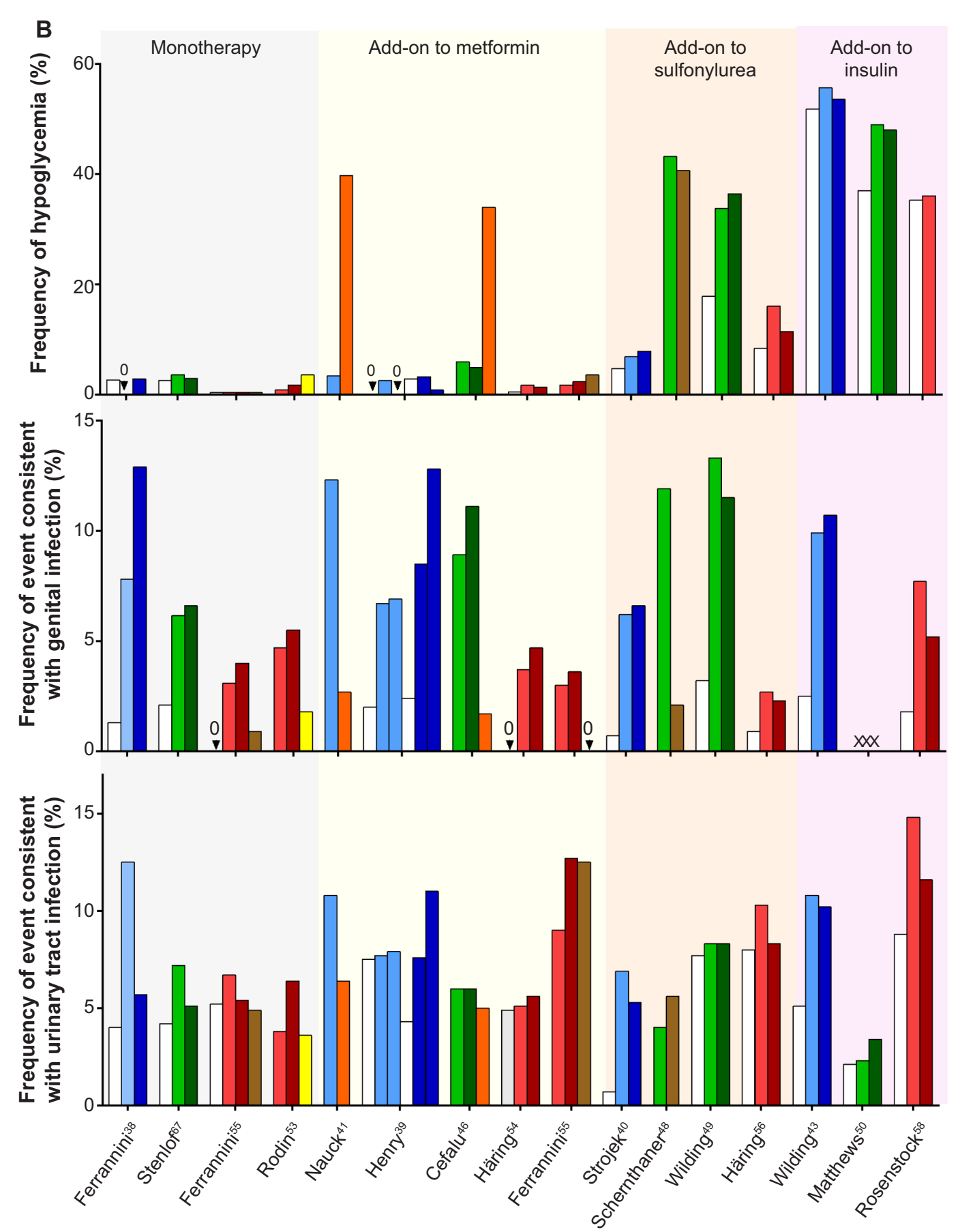

Figure 4 Efficacy and safety data from representative Phase III studies of dapagliflozin, canagliflozin, and empagliflozin.

Notes: (A) efficacy data; (B) safety data. Phase III studies were selected in which the SGLT2 inhibitor was given as monotherapy, or with background therapy of metformin, or sulfonylurea, or insulin. *Change versus placebo; $X$ Not reported.

Abbreviations: SGLT, sodium glucose co-transporter; FPG, fasting plasma glucose; SBP, systolic blood pressure; DPP-4i, dipeptidyl peptidase-4 inhibitor; MET, metformin; $\mathrm{SU}$, sulfonylurea; Dapa, dapagliflozin; Cana, canagliflozin; Empa, empagliflozin; HbA ${ }_{\mathrm{Ic}}$, glycosylated hemoglobin.

in most dapagliflozin Phase III studies, as stated in the European Medicines Agency (EMA) assessment report. ${ }^{63}$ The effect was maintained over 102 weeks in a study of dapagliflozin $10 \mathrm{mg}$ added to metformin therapy, with a body weight reduction $-4.5 \mathrm{~kg}$ versus $-2.1 \mathrm{~kg}$ for placebo plus metformin. ${ }^{68}$ Dual-energy X-ray absorptiometry revealed this reduction in body weight was principally due to a reduction in body fat mass, rather than a loss of fluid or lean tissue ${ }^{68}$ For canagliflozin, the change in body weight from baseline was generally consistent across placebo-controlled 
Phase III studies, but was lower where sulfonylurea was a background therapy: the US Food and Drug Administration (FDA) briefing document stated the placebo-subtracted mean reduction in body weight (excluding sulfonylurea background) was $-1.8 \%$ to $-3.8 \%$ for the $300 \mathrm{mg}$ dose and $-1.6 \%$ to $-2.4 \%$ for the $100 \mathrm{mg}$ dose.${ }^{69}$ For empagliflozin monotherapy, mean placebo-corrected changes in body weight from baseline after 24 weeks were $-1.9 \mathrm{~kg}(95 \% \mathrm{CI}-2.4,-1.4$; $P<0.0001)$ and $-2.1 \mathrm{~kg}(95 \% \mathrm{CI}-2.6,-1.7 ; P<0.0001)$ for $10 \mathrm{mg}$ and $25 \mathrm{mg}$ groups, respectively, versus $0.5 \mathrm{~kg}$ (95\% CI 0.04, 1.0; $P=0.0355$ ) for the sitagliptin comparator group. ${ }^{53}$ When empagliflozin was added to metformin the mean change in body weight after 24 weeks was greater for empagliflozin groups versus placebo (mean change standard error [SE] -2.1 [0.2] kg and -2.5 [0.2] $\mathrm{kg}$ for $10 \mathrm{mg}$ and $25 \mathrm{mg}$ groups, respectively, versus -0.45 [0.2] $\mathrm{kg}$ for placebo; $P<0.001$ for each dose versus placebo). ${ }^{54}$

\section{Blood pressure-lowering effects}

In a meta-analysis of six studies, SGLT2 inhibitors reduced systolic BP compared with other anti-diabetes agents (mean difference $-4.5 \mathrm{mmHg}$ [95\% CI $-5.7,-3.2 \mathrm{mmHg}]) .{ }^{60}$ A decrease in systolic BP was observed consistently across the dapagliflozin studies (Table S3). ${ }^{63}$ In a small study $(n=75)$ directly comparing dapagliflozin with an antihypertensive, treatment with placebo, dapagliflozin $(10 \mathrm{mg} /$ day $)$, or hydrochlorothiazide ( $25 \mathrm{mg}$ /day) resulted in adjusted changes from baseline in 24-hour ambulatory mean systolic BP of -0.9 (95\% CI -4.2 2.4), -3.3 (95\% CI -6.8, 0.2), and -6.6 (95\% CI $-9.9,-3.2) \mathrm{mmHg}$, respectively, at week $12 .{ }^{70}$ The study data suggest that dapagliflozin may have a diuretic-like capacity to lower BP in addition to beneficial effects on glycemic control. ${ }^{70}$

Canagliflozin demonstrated a dose-dependent and significant placebo-subtracted mean reduction in systolic BP, except when used as an add-on to sulfonylurea, ranging from $2.6-5.7 \mathrm{mmHg}$ and $3.5-7.9 \mathrm{mmHg}$ for the $100 \mathrm{mg}$ and $300 \mathrm{mg}$ doses, respectively. ${ }^{69}$ This was supported by a recent pooled analysis of six Phase III studies $(n=4,158)$ using canagliflozin, in which modest reductions in systolic $\mathrm{BP}$ were observed relative to placebo $(-3.3$ and $-4.5 \mathrm{mmHg}$ for $100 \mathrm{mg}$ and $300 \mathrm{mg}$, respectively). ${ }^{71}$

A pooled analysis of data from four Phase III trials $(\mathrm{n}=2,477)$ investigating empagliflozin $10 \mathrm{mg}$ or $25 \mathrm{mg}$ given for 24 weeks as monotherapy or as add-on therapy (with metformin, or metformin plus sulfonylurea, or pioglitazone \pm metformin) reported reductions in systolic blood pressure (SBP) for empagliflozin groups versus placebo (placebo-corrected change from baseline -3.4 $\mathrm{mmHg}$ and $-3.8 \mathrm{mmHg}$ for empagliflozin $10 \mathrm{mg}$ and 25 $\mathrm{mg}$, respectively).$^{72}$ A study of patients $(n=823)$ with T2DM and hypertension found that empagliflozin $10 \mathrm{mg}$ and 25 mg significantly reduced mean 24 hour SBP, measured via ambulatory BP monitoring, versus placebo $(-2.95$ and $-3.68 \mathrm{mmHg}$ versus $0.48 \mathrm{mmHg}$, respectively; $P<0.001$ versus placebo for each dose). ${ }^{73}$

\section{Clinical safety}

As defined for Table S3, a summary of safety data from key clinical trials of SGLT2 inhibitors is presented in Table S4 and selected safety data are presented in Figure 4.

\section{Urinary tract infections and genital tract infections}

In a meta-analysis of eight studies using canagliflozin and dapagliflozin that compared the SGLT2 inhibitors with other anti-diabetes agents, urinary tract infections were more common with SGLT2 inhibitors (odds ratio, 1.42 [95\% CI 1.06, 1.90]), as were genital tract infections (odds ratio, 5.06 [95\% CI 3.44, 7.45]). ${ }^{60}$ Safety data from a pooled retrospective analysis of data from the short-term, double-blind periods of 12 placebo-controlled trials $(n=4,545)$ using dapagliflozin reported that genital tract infections and lower urinary tract infections were more common with dapagliflozin than placebo; however, between-group differences were less marked for urinary tract infections (genital tract infection $4.1 \%-5.7 \%$ dapagliflozin versus $0.9 \%$ placebo; urinary tract infection $3.6 \%-5.7 \%$ dapagliflozin versus $3.7 \%$ placebo). ${ }^{74,75}$ Similar findings were reported from pooled analyses of canagliflozin and empagliflozin.

A pooled analysis of four 26 week Phase III studies $(n=2,313)$ of canagliflozin found higher proportions of subjects with urinary tract infections and genital tract infections occurred in the canagliflozin groups than with placebo (urinary tract infection $5.1 \%$ canagliflozin versus $4.0 \%$ placebo; genital tract infection $7.5 \%$ canagliflozin versus $1.9 \%$ placebo). ${ }^{76,77}$

A pooled analysis of four Phase III studies $(n=2,477)$ using empagliflozin found that empagliflozin was associated with an increased frequency of genital tract infections compared with placebo (approximately $4 \%$ versus $1 \%$, respectively), but this was not the case for urinary tract infections (frequency of approximately $8 \%-9 \%$ for each). ${ }^{78}$

For dapagliflozin, canagliflozin, and empagliflozin studies, events of genital tract infections and urinary tract infections were more common in women than in men in all treatment groups (Table S4), and patients usually experienced 
only a single episode, which was usually mild in intensity and responded to standard treatment. ${ }^{74-78}$

\section{Hypoglycemia}

The incidence of hypoglycemia during SGLT2 inhibitor treatment was generally low, except for groups receiving background therapy of sulfonylureas or insulin. A metaanalysis of SGLT2 inhibitor (dapagliflozin and canagliflozin) trials concluded that hypoglycemic risk was similar to that of other agents (odds ratio versus placebo, 1.28 [95\% CI $0.99,1.65 ; I^{2}=0 \%$ ]: odds ratio versus other anti-diabetes agents, 0.44 [95\% CI $0.35,0.54 ; P=93 \%]$ ). ${ }^{60}$ There were no major episodes of hypoglycemia when dapagliflozin was used as monotherapy, but an increased risk of hypoglycemic events, which were mainly minor in nature (defined as either a symptomatic episode with a capillary or plasma glucose measurement $<3.5 \mathrm{mmol} / \mathrm{L}$ [ $<63 \mathrm{mg} / \mathrm{dL}$ ] regardless of the need for external assistance or an asymptomatic capillary or plasma glucose measurement $<3.5 \mathrm{mmol} / \mathrm{L}$ [ $<63 \mathrm{mg} / \mathrm{dL}$ ], that does not qualify as a major episode), was observed when it was added to sulfonylurea or insulin. ${ }^{40,43,63}$

Similar findings were observed with canagliflozin, with a low risk of hypoglycemia among subjects treated with canagliflozin taken as monotherapy, or in combination with other anti-hyperglycemic agents not associated with hypoglycemia. An increased incidence of hypoglycemia was observed when canagliflozin was used in combination with insulin or sulfonylureas. ${ }^{34,49,50}$ The prescribing information for both canagliflozin and dapagliflozin recommend using a lower dose of insulin or insulin secretagogue to reduce the risk of hypoglycemia when used in combination with the respective SGLT2 inhibitor. ${ }^{34,36}$

The rate of hypoglycemia was also low with empagliflozin monotherapy and was comparable to placebo. ${ }^{53}$ For empagliflozin added to metformin plus sulfonylurea, the frequency of confirmed hypoglycemia was greater for empagliflozin versus placebo, but none of these events required assistance. ${ }^{56}$ When empagliflozin was added to basal insulin, no increased risk of hypoglycemia was reported versus placebo. ${ }^{58}$

\section{Renal safety and volume depletion events}

Approximately $375 \mathrm{~mL}$ of extra urinary volume is produced per day with dapagliflozin $10 \mathrm{mg}$ therapy. ${ }^{35} \mathrm{~A}$ pooled safety analysis of dapagliflozin using data from the double-blind periods of 12 placebo-controlled trials $(n>4,500)$ reported that volume depletion events occurred in $0.6 \%-1.2 \%$ for dapagliflozin groups $(2.5-10 \mathrm{mg})$ versus $0.4 \%$ for placebo groups ${ }^{79}$ indicating a slightly elevated risk and a need to maintain an adequate fluid intake. Hypotension occurred more frequently in dapagliflozin-treated groups than placebo groups for subjects who were elderly, had moderate renal impairment, or were treated with loop diuretics. ${ }^{63}$ Dapagliflozin treatment was not associated with increased risk of acute renal toxicity or deterioration of renal function. ${ }^{80}$ The estimated GFR (eGFR) decreased initially then returned to baseline by week 24 and was maintained to week 102 , while mean serum creatinine showed minimal change $( \pm 0.01 \mathrm{mg} / \mathrm{dL})$ from baseline to week 24 in all groups. ${ }^{80}$ As a safety measure, the dapagliflozin Summary of Product Characteristics recommends against its use in patients receiving loop diuretics or who are volume depleted, or who have moderate to severe renal impairment (defined as patients with creatinine clearance $<60 \mathrm{~mL} / \mathrm{min}$ or eGFR $<60 \mathrm{~mL} / \mathrm{min} / 1.73 \mathrm{~m}^{2}$ ), and encourages monitoring of volume status in cases where intercurrent conditions could lead to volume depletion..$^{35} \mathrm{~A} 104$-week Phase III study of dapagliflozin treatment in T2DM patients with moderate renal impairment reported events of renal impairment or renal failure were uncommon $(2.4 \%$ and $9.4 \%$ for dapagliflozin $5 \mathrm{mg}$ and $10 \mathrm{mg}$, respectively; $7.1 \%$ for placebo), and volume depletion events were more frequent with dapagliflozin $(9.6 \%$ and $12.9 \%$ for dapagliflozin $5 \mathrm{mg}$ and $10 \mathrm{mg}$, respectively; $6.0 \%$ for placebo). ${ }^{44}$

Analysis of a pooled dataset from the canagliflozin FDA briefing document stated that volume depletion-related adverse events, most commonly hypotension, occurred in $1.2 \%$ and $1.3 \%$ of canagliflozin $100 \mathrm{mg}$ and $300 \mathrm{mg}$ groups, respectively, versus $1.1 \%$ in placebo groups, ${ }^{69}$ furthermore, none of these events in the canagliflozin groups were serious or led to study discontinuation. ${ }^{69}$ In a pooled analysis of eight clinical trials (placebo- and active-controlled), volume depletion-related adverse events occurred in $2.3 \%$ and $3.4 \%$ of canagliflozin $100 \mathrm{mg}$ and $300 \mathrm{mg}$ groups, respectively, versus $1.5 \%$ in the comparator groups. ${ }^{34}$ Risk factors for these events were similar to those identified for dapagliflozin (eg, patient's age $\geq 75$ years, eGFR $<60 \mathrm{~mL} / \mathrm{min} / 1.73 \mathrm{~m}^{2}$, and use of loop diuretics). ${ }^{34}$ A Phase III trial of canagliflozin use in T2DM patients with stage 3 CKD (eGFR $\geq 30$ and $<50 \mathrm{~mL} / \mathrm{min} / 1.73 \mathrm{~m}^{2}$ ) reported larger decreases in eGFR from baseline in canagliflozin treatment groups (least square mean change, $-9.1 \%$ and $-10.1 \%$ for $100 \mathrm{mg}$ and $300 \mathrm{mg}$, respectively, versus $-4.5 \%$ for placebo). ${ }^{51}$ The reductions in eGFR with canagliflozin were largest at week 3 (the first post-baseline measurement) and then returned back toward baseline over the 26-week treatment period. ${ }^{51}$ A lower proportion of subjects in the canagliflozin $100 \mathrm{mg}$ 
and $300 \mathrm{mg}$ groups progressed to albuminuria (ie, from normoalbuminuria to micro- or macro-albuminuria, or from micro- to macro-albuminuria) versus those in the placebo group $(5.1 \%, 8.3 \%$, and $11.8 \%$, respectively; odds ratio [95\% CI], 0.33 [0.08, 1.48] for canagliflozin $100 \mathrm{mg}$ versus placebo, and $0.51[0.14,1.91]$ for canagliflozin $300 \mathrm{mg}$ versus placebo). ${ }^{51}$

A pooled analysis of empagliflozin data $(>11,000$ T2DM patients from Phase I, II, and III trials) reported that the percentage of patients with volume depletion events was similar with empagliflozin (10 mg dose group 1.4\%; $25 \mathrm{mg}$ dose group $1.5 \%$ ) and placebo (1.4\%). ${ }^{81}$ More patients receiving diuretics reported these events than those not receiving diuretics $\left(2.2 \%-2.7 \%\right.$ versus $0.9 \%-1.0 \%$, respectively). ${ }^{81}$ Treatment with empagliflozin in patients with T2DM and stage 2 or $3 \mathrm{CKD}$ (eGFR $\geq 60$ to $<90 \mathrm{~mL} / \mathrm{min} / 1.73 \mathrm{~m}^{2}$ and 30 to $<60 \mathrm{~mL} / \mathrm{min} / 1.73 \mathrm{~m}^{2}$, respectively) significantly reduced mean $\mathrm{HbA}_{1 \mathrm{c}}$ from baseline (placebo adjusted mean reduction in $\mathrm{HbA}_{1 \mathrm{c}}$ at week 24 was $-0.52 \%$ [95\% CI $\left.-0.72,-0.32\right]$ and $-0.68 \%$ [ $95 \%$ CI $-0.88,-0.49$ ] for stage 2 CKD receiving empagliflozin $10 \mathrm{mg}$ and $25 \mathrm{mg}$, respectively, and $-0.42 \%$ [95\% CI $-0.56,-0.28]$ for stage 3 CKD receiving empagliflozin $25 \mathrm{mg}$ [empagliflozin $10 \mathrm{mg}$ was not used]; $P<0.0001$ for each), ${ }^{59}$ and the effect was sustained at week 52 . However, empagliflozin $25 \mathrm{mg}$ did not reduce $\mathrm{HbA}_{1 \mathrm{c}}$ at week 24 or week 52 in patients with stage $4 \mathrm{CKD}$ (eGFR $\geq 15$ to $<30 \mathrm{~mL} /$ $\left.\min / 1.73 \mathrm{~m}^{2}\right) .{ }^{59}$ In patients with stage 2,3 , or $4 \mathrm{CKD}$, small decreases in eGFR were noted in the empagliflozin groups, which returned to baseline by the end of the 3 week follow-up after treatment completion. ${ }^{59}$ In patients with stage $3 \mathrm{CKD}$, fewer patients on empagliflozin $25 \mathrm{mg}$ than placebo shifted from no albuminuria at baseline to microalbuminuria, or from microalbuminuria at baseline to macroalbuminuria, at end of treatment (12.2\% with empagliflozin versus $22.2 \%$ with placebo, and $2.0 \%$ with empagliflozin versus $11.4 \%$ with placebo, respectively). ${ }^{59}$

\section{Venous thromboembolic events}

As volume depletion may increase the risk of hemoconcentration and venous thromboembolism (VTE), VTE events were monitored in trials using SGLT2 inhibitors.

Patients receiving dapagliflozin had a similar rate of VTE events to those in the comparator group $(0.3 \%$ for both groups) ${ }^{63}$ For canagliflozin, the rate of VTE in Phase III trials was also low $(0.2 \%$ and $0.3 \%$ for canagliflozin $100 \mathrm{mg}$ and $300 \mathrm{mg}$ groups, respectively, versus $0.2 \%$ for non-canagliflozin groups). ${ }^{69} \mathrm{VTE}$ data have not yet been reported for empagliflozin. ${ }^{82,83}$

\section{Bone safety}

There was no clear evidence that dapagliflozin induced bone demineralization or increased fracture rates in people with diabetes and normal or mildly impaired renal function (eGFR $>90 \mathrm{~mL} / \mathrm{min} / 1.73 \mathrm{~m}^{2}$ and $\geq 60$ to $<90 \mathrm{~mL} /$ $\min / 1.73 \mathrm{~m}^{2}$, respectively), ${ }^{63,84}$ but bone fractures were more common in dapagliflozin-treated patients with moderate renal impairment (eGFR $>30$ to $<60 \mathrm{~mL} / \mathrm{min} / 1.73 \mathrm{~m}^{2} ; 4.8 \%$ and $9.4 \%$ for $5 \mathrm{mg}$ and $10 \mathrm{mg}$ groups, respectively, versus $0 \%$ for placebo-treated subjects). ${ }^{63}$ A 102 week study $(n=140)$ did not identify any meaningful changes from baseline in markers of bone turnover or bone mineral density in patients receiving dapagliflozin added to metformin, when compared with placebo. ${ }^{68}$ No meaningful changes in bone density were observed with canagliflozin treatment over 26 weeks, according to the FDA briefing report, ${ }^{69}$ but there was an increase in overall bone fracture events with canagliflozin (2.5\% for $100 \mathrm{mg}$ and $2.3 \%$ for $300 \mathrm{mg}$ ) compared to control (1.7\%; includes placebo and active comparators, both with various background therapies). A 104-week trial (26-week double-blind phase +78 -week double-blind extension phase) evaluating canagliflozin in older patients (aged 55-80 years) with T2DM (ClinicalTrials.gov identifier: NCT01106651) included an assessment of bone density, which will be reported separately from the main efficacy/safety analysis. ${ }^{52}$ However, no discernible changes in bone density were observed at 26 weeks. ${ }^{85}$ In a pooled analysis of data from more than 11,000 patients with T2DM from Phase I, II, and III trials, empagliflozin was not associated with an increased frequency of bone fractures versus placebo (1.6\% and $1.1 \%$ for empagliflozin $10 \mathrm{mg}$ and $25 \mathrm{mg}$, respectively, versus $1.6 \%$ for placebo). ${ }^{86}$

\section{Cardiovascular safety}

SGLT2 inhibitors have favorable effects on cardiovascular (CV) risk factors by reducing hyperglycemia, body weight, and $\mathrm{BP},{ }^{87}$ but changes in lipid profiles have caused some concern, ${ }^{88}$ and information on major $\mathrm{CV}$ outcomes such as stroke, heart attack, and other vascular complications is currently limited. ${ }^{89}$ Several large, long-term studies with $\mathrm{CV}$ endpoints are ongoing and will provide data in the next 2-6 years (Table 3). ${ }^{90,91}$ Results from a meta-analysis on CV outcomes and death with SGLT2 inhibitors showed overall no evidence for an increased CV risk with SGLT2 inhibitor treatment. ${ }^{60}$ The EMA assessment report on dapagliflozin stated that an independently confirmed meta-analysis of Phase IIb/III studies did not show an increased CV risk in dapagliflozin-treated patients. ${ }^{63}$ The estimated hazard ratio 
Table 3 Registered cardiovascular clinical trials of SGLT2 inhibitors

\begin{tabular}{|c|c|}
\hline Trial details & Reference \\
\hline DECLARE TIMI58 - Dapagliflozin Effect on Cardiovascular Events & http://www.clinicaltrials.gov/ct2/show/ \\
\hline Full title: Dapagliflozin Effect on Cardiovascular Events: A Multicenter, Randomized, Double-Blind, & NCT01730534 \\
\hline \multicolumn{2}{|l|}{ Placebo-Controlled Trial to Evaluate the Effect of Dapagliflozin $10 \mathrm{mg}$ Once Daily on the Incidence } \\
\hline \multicolumn{2}{|l|}{ of Cardiovascular Death, Myocardial Infarction or Ischemic Stroke in Patients With Type 2 Diabetes } \\
\hline \multicolumn{2}{|l|}{ Primary outcome measure: Time to first event included in the composite endpoint of CV death, } \\
\hline \multicolumn{2}{|l|}{ MI or ischemic stroke } \\
\hline \multicolumn{2}{|l|}{ Patients: Aged $\geq 40$ years; T2DM; high risk for CV events } \\
\hline \multicolumn{2}{|l|}{ Estimated enrollment: 22,200 (recruiting) } \\
\hline \multicolumn{2}{|l|}{ Estimated study completion date: $2 \mathrm{Q} 2019$} \\
\hline CANVAS - Canagliflozin Cardiovascular Assessment Study & http://www.clinicaltrials.gov/ct2/show/ \\
\hline Full title: A Randomized, Multicenter, Double-Blind, Parallel, Placebo-Controlled Study of the Effects & NCT01032629 \\
\hline of JNJ 2843 I 754 on Cardiovascular Outcomes in Adult Subjects With Type 2 Diabetes Mellitus & $\mathrm{Neal}{ }^{90}$ \\
\hline \multirow{2}{*}{\multicolumn{2}{|c|}{$\begin{array}{l}\text { Primary outcome measure: Major adverse cardiovascular events, including CV death, nonfatal MI, } \\
\text { and nonfatal stroke }\end{array}$}} \\
\hline & \\
\hline \multicolumn{2}{|l|}{ Patients: Aged $\geq 30$ years; T2DM; high risk for CV events } \\
\hline \multicolumn{2}{|l|}{ Enrollment: 4,330} \\
\hline \multicolumn{2}{|l|}{ Estimated study completion date: $2 \mathrm{Q} 2017$} \\
\hline BI 10773 (Empagliflozin) Cardiovascular Outcome Event Trial in Type 2 Diabetes Mellitus Patients & http://www.clinicaltrials.gov/ct2/show/ \\
\hline (EMPA-REG-OUTCOME ${ }^{\mathrm{TM}}$ ) & NCT0II31676 \\
\hline Full title: A Phase III, Multicentre, International, Randomised, Parallel Group, Double Blind & Zinman ${ }^{91}$ \\
\hline \multicolumn{2}{|l|}{ Cardiovascular Safety Study of BI 10773 ( 10 mg and 25 mg Administered Orally Once Daily) Compared } \\
\hline \multicolumn{2}{|l|}{ to Usual Care in Type 2 Diabetes Mellitus Patients With Increased Cardiovascular Risk } \\
\hline \multicolumn{2}{|l|}{ Primary outcome measure: Time to the first occurrence of any of the following adjudicated } \\
\hline \multicolumn{2}{|l|}{ components of the primary composite endpoint: cardiovascular death (including fatal stroke and fatal MI), } \\
\hline \multicolumn{2}{|l|}{ non-fatal $\mathrm{Ml}$ and non-fatal stroke } \\
\hline \multicolumn{2}{|l|}{ Patients: Aged > 18 years; T2DM; confirmed history of MI, unstable angina, multi-vessel percutaneous } \\
\hline \multicolumn{2}{|l|}{ coronary intervention, multi-vessel coronary artery bypass grafting, ischemic or hemorrhagic stroke, } \\
\hline \multicolumn{2}{|l|}{ peripheral occlusive arterial disease } \\
\hline \multicolumn{2}{|l|}{ Estimated enrollment: 7,000} \\
\hline \multicolumn{2}{|l|}{ Estimated study completion date: $2 Q 2015$} \\
\hline Cardiovascular Outcomes Following Treatment with Ertugliflozin in Participants with & http://www.clinicaltrials.gov/ct2/show/ \\
\hline Type 2 Diabetes Mellitus and Established Vascular Disease & NCT0198688I \\
\hline \multicolumn{2}{|l|}{ Primary outcome measure: Time to the first occurrence of any component of the composite } \\
\hline \multicolumn{2}{|l|}{ endpoint of cardiovascular death, non-fatal MI, or non-fatal stroke } \\
\hline \multicolumn{2}{|l|}{ Patients: T2DM; established vascular disease } \\
\hline \multicolumn{2}{|l|}{ Estimated enrollment: 3,900 (currently recruiting) } \\
\hline Estimated study completion date: 2Q 2020 & \\
\hline
\end{tabular}

Abbreviations: CV, cardiovascular; MI, myocardial infarction; Q, quarter; T2DM, type 2 diabetes mellitus; SGLT, sodium glucose co-transporter.

for the primary composite endpoint (time to first event of the following adjudicated events: CV death, myocardial infarction, stroke, and hospitalization for unstable angina) using a Cox proportional hazards method was $0.674(95 \%$ CI $0.421,1.078) .{ }^{63}$ Similarly, a meta-analysis to assess CV safety for canagliflozin was presented in the FDA report, ${ }^{69}$ and included all Major Adverse Cardiovascular Events Plus (MACE-Plus; defined as a composite endpoint consisting of the following adjudicated events: CV death, nonfatal myocardial infarction, nonfatal stroke, and hospitalization for unstable angina) in nine Phase III trials (including interim data from the canagliflozin cardiovascular assessment study [CANVAS]). The estimated hazard ratio was 0.91 $(95 \%$ CI $0.68,1.22)$ for the risk of MACE-Plus comparing canagliflozin to all comparators (via the pre-specified primary Cox proportional hazards model fit to all trials including CANVAS) ${ }^{69}$

Changes in lipid profiles observed with SGLT2 inhibitor therapy have caused some concern. ${ }^{88}$ Dose-related increases in low-density lipoprotein cholesterol (LDL-C) were observed with canagliflozin, as shown in a pooled analysis of data from four 26-week placebo-controlled trials in which the mean percentage increases from baseline in LDL-C were $4.5 \%$ and $8.0 \%$ for $100 \mathrm{mg}$ and $300 \mathrm{mg}$ canagliflozin, respectively, relative to placebo. ${ }^{92}$ Canagliflozin labeling information recommends LDL-C should be monitored and treated according to standard care after initiating canagliflozin therapy. ${ }^{92}$ Statistically significant increases in high-density lipoprotein 
cholesterol (HDL-C) from baseline were observed with canagliflozin in four of eight placebo-controlled Phase III trials, but decreases in triglyceride levels with canagliflozin were small and were generally not statistically significant. ${ }^{93}$ For patients receiving dapagliflozin in Phase III trials, overall small mean changes in HDL-C $(+2.1 \%$ to $+9.3 \%)$, triglyceride $(-0.9 \%$ to $-10.6 \%)$, and LDL-C $(-0.5 \%$ to $+9.5 \%)$ were observed, but there was no clinically significant effect on lipid levels in the individual dapagliflozin studies concerned. ${ }^{94}$ For empagliflozin, a pooled analysis of four placebo-controlled Phase III trials reported small increases in HDL-C and LDL-C and small decreases in triglycerides with empagliflozin versus placebo after 24 weeks. ${ }^{72}$

\section{Malignancies}

A pooled analysis of data for all dapagliflozin doses from 19 Phase IIb/III trials revealed that the incidence rates for malignancies were similar for dapagliflozin (1.4\%) and placebo/comparator $(1.3 \%),{ }^{79}$ and there was no carcinogenicity or mutagenicity signal in animal data. ${ }^{35}$ However, breast and bladder cancer adverse events were numerically greater with dapagliflozin than placebo/comparator. ${ }^{35,63,79,95}$ The US prescribing information for dapagliflozin states that the drug should not be used in patients with active bladder cancer and should be used with caution in patients with a history of this disease. ${ }^{36}$ Furthermore, the dapagliflozin Summary of Product Characteristics does not recommend the use of dapagliflozin in patients being treated with pioglitazone, as epidemiological data suggest a small increased risk of bladder cancer with pioglitazone. ${ }^{35}$ Adverse events for breast and bladder cancer, plus renal cell cancer, were also monitored in the clinical studies for canagliflozin. ${ }^{69}$ The incidences of these tumor events were low and they occurred at a similar rate across treatment groups (breast cancer $0.38 \%-0.46 \%$ versus $0.4 \%$; bladder cancer $0.06 \%-0.09 \%$ versus $0.11 \%$; renal cell cancer $0.06 \%-0.09 \%$ versus $0.08 \%$ for canagliflozin $100 \mathrm{mg}$ and $300 \mathrm{mg}$ groups versus non-canagliflozin groups, respectively). ${ }^{69}$ No data on malignancy rates from trials using empagliflozin (or any of the other SGLT2 inhibitors) have been reported to date. Nevertheless, these safety signals raised concerns and further data are required to exclude the possibility of an elevated risk of certain types of cancer occurring with SGLT2 inhibitor treatment.

\section{Current and future roles for SGLT2 inhibitors}

Currently available published clinical trial data for SGLT2 inhibitors document their use as add-on therapy with metformin, insulin, sulfonylureas, dipeptidyl peptidase (DPP-4) inhibitors, or thiazolidinediones. SGLT2 inhibitors may also have a role as monotherapy; for example, in patients who are intolerant to metformin due to ensuing gastrointestinal side effects. Data from published trials indicate that various SGLT2 inhibitors have a similar ability to improve glucose control with a low risk of hypoglycemia, together with promoting modest reductions in BP and body weight. The properties of SGLT2 inhibitors present for the first time the possibility of a triple combination (ie, metformin, DPP-4 inhibitor, and SGLT2 inhibitor), with the expected net effect of weight reduction and freedom from hypoglycemic episodes. This could be particularly attractive in Europe, where triple oral combinations have not been popular (presumably, because at least one of the combination components introduced undesired adverse events, such as weight gain and/or hypoglycemia). At present, there is no evidence suggesting preference of any one SGLT2 inhibitor over another: any differences between individual SGLT2 inhibitors may be revealed when clinical head-to-head comparator studies are carried out, although no such studies are currently reported to be underway. A Phase I study comparing the pharmacodynamics of canagliflozin and dapagliflozin was recently completed and publication of the data is awaited (ClinicalTrials.gov identifier: NCT01877889), the primary outcome measure was the between-treatment difference in 24-hour mean renal threshold for glucose.

The effect of SGLT2 inhibition on preserving beta-cell function and improving insulin sensitivity has also been reported. Data from a study using an insulin-resistant animal model of T2DM found that sustained glucose lowering with dapagliflozin improved insulin sensitivity and pancreatic islet function and morphology. ${ }^{96}$ The authors suggested that reduction of hyperglycemia by dapagliflozin, through an insulin-independent mechanism, may improve core defects present in T2DM; however, further research is needed before firm conclusions can be drawn. ${ }^{96}$ Recently published and independent studies using dapagliflozin and empagliflozin in patients with T2DM reported increased insulin sensitivity following SGLT2 inhibitor therapy, ${ }^{97,98}$ and empagliflozininduced UGE also improved beta-cell function. ${ }^{98}$ SGLT2 inhibition with either of these agents increased to some extent endogenous glucose production, despite reducing fasting plasma glucose, and this may be at least partially explained by concentration change in the insulin to glucagon ratio which has been observed with SGLT2 inhibitor therapy. ${ }^{89,90}$ There is also preliminary evidence to suggest that SGLT2 inhibitors with lower selectivity towards SGLT1 (ie, canagliflozin) 
achieve intra-intestinal levels after oral dosing that may be sufficiently high to transiently inhibit intestinal SGLT1 and reduce intestinal glucose absorption, ${ }^{32,99}$ resulting in increased release of glucagon-like peptide- 1 and peptide YY..$^{32,100}$ These factors together may make SGLT2 inhibitors an attractive choice for T2DM patients who are failing with metformin and who need to lose weight.

Furthermore, SGLT2 inhibitors may have the potential to be used as an insulin-sparing agent in T2DM patients using insulin. ${ }^{43,58,64}$ A long-term study of dapagliflozin in T2DM patients using insulin reported the mean insulin dose increased by $18.3 \mathrm{IU} /$ day and body weight increased by $1.8 \mathrm{~kg}$ in the placebo group after 104 weeks, whereas insulin dose was stable and body weight decreased by $0.9 \mathrm{~kg}$ in the dapagliflozin groups. ${ }^{64} \mathrm{~A}$ similar trend was reported after 78 weeks of empagliflozin treatment. ${ }^{58}$ SGLT2 inhibitors could possibly be used transiently instead of insulin treatment in patients who are otherwise well controlled but who develop temporary acute hyperglycemia, due to factors such as short-term immobility, infectious diseases, etc. Additionally, SGLT2 inhibitors may have a role in improving glucose tolerance in pre-diabetic individuals. However, to allow the use of these agents in patients without established disease, clinical trials with SGLT2 inhibitors would need to show a reduced risk for relevant clinical endpoints (eg, CV, etc) as well as robust safety data.

Pilot studies using SGLT2 inhibitors in patients with T1DM are also in progress (ClinicialTrials.gov identifiers: NCT01498185, NCT01392560, NCT01742208), and preliminary results have been presented. ${ }^{101,102} \mathrm{~A}$ further possible use of SGLT2 inhibitors in T1DM is the concept that SGLT2 inhibition may have renal effects by lowering intra-glomerular pressure, which has recently been demonstrated with empagliflozin in patients with T1DM. ${ }^{103}$ This observation could explain the reduction of albuminuria with SGLT2 treatment described in Phase III studies. In addition, the Canagliflozin and Renal Events in Diabetes with Established Nephropathy Clinical Evaluation (CREDENCE; ClinicialTrials.gov identifier: NCT02065791) study has just commenced, and is a renal outcome study to investigate whether SGLT2 inhibition has renal potential beyond its glucose-lowering properties.

As a final point, it is of interest to note that current SGLT2 inhibitors only inhibit $30 \%-50 \%$ of the filtered glucose load, ie, $50-80 \mathrm{~g}$ of the $\sim 180 \mathrm{~g}$ filtered per day. The possible pharmacokinetic reasons for this imbalance are discussed in a report by Liu et al, ${ }^{104}$ and a novel hypothesis to explain this conundrum was recently postulated by Abdul-Ghani et al. ${ }^{105}$ Namely, complete inhibition of SGLT2 causes SGLT1 to reabsorb glucose at full capacity; therefore, only the fraction of filtered glucose that escapes SGLT1 will be excreted in the urine. ${ }^{105} \mathrm{~A}$ better understanding of renal SGLT2 inhibitor handling may help to develop future agents that can inhibit a larger proportion of filtered glucose and further reduce $\mathrm{HbA}_{1 \mathrm{c}}$ levels, ${ }^{104}$ for example, agents with the capacity to also partially inhibit renal SGLT1 and produce a more vigorous UGE than those that are highly specific for SGLT2 inhibition only. ${ }^{105}$

There is potentially much more to come from this novel class of drugs, and we wait with interest to see what further developments and therapeutic applications may arise.

\section{Acknowledgments}

Medical writing assistance, supported financially by Boehringer Ingelheim, was provided by Debra Brocksmith, MB ChB, PhD, of Envision Scientific Solutions during the preparation of this manuscript. Boehringer Ingelheim was given the opportunity to check the data used in the manuscript for factual accuracy only.

\section{Author contributions}

The author was fully responsible for all content and editorial decisions, was involved at all stages of manuscript development, and has approved the final version of the manuscript that reflects the author's interpretation and conclusions.

\section{Disclosure}

The author has received research grants to his institution from Berlin-Chemie/Menarini, Eli Lilly, Merck Sharp and Dohme, Novartis, AstraZeneca, Boehringer Ingelheim, GlaxoSmithKline, Lilly Deutschland, MetaCure, Roche Pharma, Novo Nordisk, and Tolerx for participation in multicenter clinical trials. He has received consulting fees and/or honoraria for membership in advisory boards and/or honoraria for speaking from Amylin, AstraZeneca, Berlin-Chemie/Menarini, Boehringer Ingelheim, Bristol-Myers Squibb, Diartis Pharmaceuticals, Eli Lilly, Hoffmann-LaRoche, GlaxoSmithKline, Intarcia Therapeutics, MannKind, Merck Sharp and Dohme, Novartis, Novo Nordisk, Sanofi, Takeda, Versartis, and Wyeth Research, including reimbursement for travel expenses.

\section{References}

1. Gerich JE. Role of the kidney in normal glucose homeostasis and in the hyperglycaemia of diabetes mellitus: therapeutic implications. Diabet Med. 2010;27(2):136-142.

2. Mather A, Pollock C. Glucose handling by the kidney. Kidney Int Suppl. 2011;(120):S1-S6.

3. Zelikovic I. Aminoaciduria and glycosuria. In: Avner ED, Harmon WE, Niaudet P, editors. Pediatric Nephrology. 5th edition. Philadelphia: Lippincott Williams \& Wilkins; 2004:701-728. 
4. Moe OW, Wright SH, Palacín M. Renal handling of organic solutes. In: Brenner BM, Rector, editors. Brenner and Rector's The Kidney. Philadelphia: Saunders Elsevier; 2008:214-247.

5. Wright EM, Loo DD, Hirayama BA. Biology of human sodium glucose transporters. Physiol Rev. 2011;91(2):733-794.

6. Hediger MA, Rhoads DB. Molecular physiology of sodium-glucose cotransporters. Physiol Rev. 1994;74(4):993-1026.

7. Dominguez JH, Camp K, Maianu L, Garvey WT. Glucose transporters of rat proximal tubule: differential expression and subcellular distribution. Am J Physiol. 1992;262(5 Pt 2):F807-F812.

8. Santer R, Kinner M, Lassen CL, et al. Molecular analysis of the SGLT2 gene in patients with renal glucosuria. J Am Soc Nephrol. 2003;14(11):2873-2882.

9. Turk E, Zabel B, Mundlos S, Dyer J, Wright EM. Glucose/galactose malabsorption caused by a defect in the $\mathrm{Na}+$ glucose cotransporter. Nature. 1991;350(6316):354-356.

10. Xin B, Wang H. Multiple sequence variations in SLC5A1 gene are associated with glucose-galactose malabsorption in a large cohort of Old Order Amish. Clin Genet. 2011;79(1):86-91.

11. Meyer C, Stumvoll M, Nadkarni V, Dostou J, Mitrakou A, Gerich J. Abnormal renal and hepatic glucose metabolism in type 2 diabetes mellitus. J Clin Invest. 1998;102(3):619-624.

12. Meyer C, Woerle HJ, Dostou JM, Welle SL, Gerich JE. Abnormal renal, hepatic, and muscle glucose metabolism following glucose ingestion in type 2 diabetes. Am J Physiol Endocrinol Metab. 2004;287(6):E1049-E1056.

13. Mogensen CE. Maximum tubular reabsorption capacity for glucose and renal hemodynamcis during rapid hypertonic glucose infusion in normal and diabetic subjects. Scand J Clin Lab Invest. 1971;28(1) 101-109.

14. Rahmoune H, Thompson PW, Ward JM, Smith CD, Hong G, Brown J. Glucose transporters in human renal proximal tubular cells isolated from the urine of patients with non-insulin-dependent diabetes. Diabetes. 2005;54(12):3427-3434

15. Vestri S, Okamoto MM, de Freitas HS, et al. Changes in sodium or glucose filtration rate modulate expression of glucose transporters in renal proximal tubular cells of rat. J Membr Biol. 2001;182(2): $105-112$.

16. Dyer J, Wood IS, Palejwala A, Ellis A, Shirazi-Beechey SP. Expression of monosaccharide transporters in intestine of diabetic humans. Am J Physiol Gastrointest Liver Physiol. 2002;282(2):G241-G248.

17. Defronzo RA, Hompesch M, Kasichayanula S, et al. Characterization of renal glucose reabsorption in response to dapagliflozin in healthy subjects and subjects with type 2 diabetes. Diabetes Care. 2013;36(10):3169-3176.

18. Abdul-Ghani MA, Norton L, Defronzo RA. Role of sodium-glucose cotransporter 2 (SGLT 2) inhibitors in the treatment of type 2 diabetes. Endocr Rev. 2011;32(4):515-531.

19. Abdul-Ghani MA, DeFronzo RA. Inhibition of renal glucose reabsorption: a novel strategy for achieving glucose control in type 2 diabetes mellitus. Endocr Pract. 2008;14(6):782-790.

20. Ehrenkranz JR, Lewis NG, Kahn CR, Roth J. Phlorizin: a review. Diabetes Metab Res Rev. 2005;21(1):31-38.

21. Alvarado F, Crane RK. Phlorizin as a competitive inhibitor of the active transport of sugars by hamster small intestine, in vitro. Biochim Biophys Acta. 1962;56:170-172.

22. Rossetti L, Smith D, Shulman GI, Papachristou D, DeFronzo RA. Correction of hyperglycemia with phlorizin normalizes tissue sensitivity to insulin in diabetic rats. $J$ Clin Invest. 1987;79(5):1510-1515.

23. Rossetti L, Shulman GI, Zawalich W, DeFronzo RA. Effect of chronic hyperglycemia on in vivo insulin secretion in partially pancreatectomized rats. J Clin Invest. 1987;80(4):1037-1044.

24. Thorens B, Mueckler M. Glucose transporters in the 21st Century. Am J Physiol Endocrinol Metab. 2010;298(2):E141-E145.

25. Oku A, Ueta K, Arakawa K, et al. T-1095, an inhibitor of renal Na+glucose cotransporters, may provide a novel approach to treating diabetes. Diabetes. 1999;48(9):1794-1800.
26. Isaji M. SGLT2 inhibitors: molecular design and potential differences in effect. Kidney Int Suppl. 2011;(120):S14-S19.

27. Chao EC, Henry RR. SGLT2 inhibition - a novel strategy for diabetes treatment. Nat Rev Drug Discov. 2010;9(7):551-559.

28. Hardman TC, Dubrey SW. Development and potential role of type-2 sodium-glucose transporter inhibitors for management of type 2 diabetes. Diabetes Ther. 2011;2(3):133-145.

29. McCrimmon RJ, Evans ML, et al. AICAR and phlorizin reverse the hypoglycemia-specific defect in glucagon secretion in the diabetic BB rat. Am J Physiol Endocrinol Metab. 2002;283(5):E1076-E1083.

30. Han S, Hagan DL, Taylor JR, et al. Dapagliflozin, a selective SGLT2 inhibitor, improves glucose homeostasis in normal and diabetic rats. Diabetes. 2008;57(6):1723-1729.

31. Grempler R, Thomas L, Eckhardt M, et al. Empagliflozin, a novel selective sodium glucose cotransporter-2 (SGLT-2) inhibitor: characterisation and comparison with other SGLT-2 inhibitors. Diabetes Obes Metab. 2012;14(1):83-90

32. Polidori D, Sha S, Mudaliar S, et al. Canagliflozin lowers postprandial glucose and insulin by delaying intestinal glucose absorption in addition to increasing urinary glucose excretion: results of a randomized, placebo-controlled study. Diabetes Care. 2013;36(8): 2154-2161.

33. European Medicines Agency [homepage on the internet]. Xigduo (dapagliflozin/metformin) authorisation details (EMEA/H/C/002672) 2014. Available from: http://www.ema.europa.eu/ema/index. jsp?curl=pages $/$ medicines $/$ human $/$ medicines $/ 002672 /$ human med_001721.jsp\&mid=WC0b01ac058001d124. Accessed February 10, 2014.

34. INVOKANA ${ }^{\mathrm{TM}}$ (canagliflozin) tablets, for oral use [prescribing information]. Janssen Pharmaceuticals Inc.; 2013. Available from: http://www. invokanahcp.com/prescribing-information.pdf. Accessed March 31, 2014.

35. Bristol-Myers Squibb-AstraZeneca EEIG [homepage on the Internet]. Summary of Product Characteristics: Forxiga $5 \mathrm{mg}$ film coated tablets 2012. Available from: http://ec.europa.eu/health/documents/ community-register/2012/20121112124487/anx_124487_en.pdf Accessed March 31, 2014.

36. AstraZeneca Pharamceuticals LP, Bristol-Myers Squibb Company. Highlights of prescribing information: FARXIGA (dapagliflozin) tablets, for oral use; 2014. Available from: http://packageinserts.bms. com/pi/pi_farxiga.pdf. Accessed February 11, 2014.

37. Janssen-Cilag International NV. Summary of Product Characteristics: Invokana, $100 \mathrm{mg}$ film-coated tablets; 2013. Available from: http://www.ema.europa.eu/docs/en_GB/document_library/EPAR__Product_Information/human/002649/WC500156456.pdf. Accessed January 20, 2014.

38. Ferrannini E, Ramos SJ, Salsali A, Tang W, List JF. Dapagliflozin monotherapy in type 2 diabetic patients with inadequate glycemic control by diet and exercise: a randomized, double-blind, placebo-controlled, phase 3 trial. Diabetes Care. 2010;33(10):2217-2224.

39. Henry RR, Murray AV, Marmolejo MH, Hennicken D, Ptaszynska A, List JF. Dapagliflozin, metformin XR, or both: initial pharmacotherapy for type 2 diabetes, a randomised controlled trial. Int J Clin Pract. 2012;66(5):446-456.

40. Strojek K, Yoon KH, Hruba V, Elze M, Langkilde AM, Parikh S. Effect of dapagliflozin in patients with type 2 diabetes who have inadequate glycaemic control with glimepiride: a randomized, 24-week, double-blind, placebo-controlled trial. Diabetes Obes Metab. 2011;13(10):928-938.

41. Nauck MA, Del Prato S, Meier JJ, et al. Dapagliflozin versus glipizide as add-on therapy in patients with type 2 diabetes who have inadequate glycemic control with metformin: a randomized, 52-week, double-blind, active-controlled noninferiority trial. Diabetes Care. 2011;34(9):2015-2022.

42. Rosenstock J, Vico M, Wei L, Salsali A, List JF. Effects of dapagliflozin, an SGLT2 inhibitor, on $\mathrm{HbA}(1 \mathrm{c})$, body weight, and hypoglycemia risk in patients with type 2 diabetes inadequately controlled on pioglitazone monotherapy. Diabetes Care. 2012;35(7):1473-1478. 
43. Wilding JP, Woo V, Soler NG, et al. Long-term efficacy of dapagliflozin in patients with type 2 diabetes mellitus receiving high doses of insulin: a randomized trial. Ann Intern Med. 2012;156(6):405-415.

44. Kohan DE, Fioretto P, Tang W, List JF. Long-term study of patients with type 2 diabetes and moderate renal impairment shows that dapagliflozin reduces weight and blood pressure but does not improve glycemic control. Kidney Int. 2014;85(4):962-971.

45. Stenlöf K, Cefalu WT, Kim KA, et al. Efficacy and safety of canagliflozin monotherapy in subjects with type 2 diabetes mellitus inadequately controlled with diet and exercise. Diabetes Obes Metab. 2013;15(4):372-382.

46. Cefalu WT, Leiter LA, Yoon KH, et al. Efficacy and safety of canagliflozin versus glimepiride in patients with type 2 diabetes inadequately controlled with metformin (CANTATA-SU): 52 week results from a randomised, double-blind, phase 3 non-inferiority trial. Lancet. 2013;382(9896):941-950.

47. Lavalle-González FJ, Januszewicz A, Davidson J, et al. Efficacy and safety of canagliflozin compared with placebo and sitagliptin in patients with type 2 diabetes on background metformin monotherapy: a randomised trial. Diabetologia. 2013;56(12):2582-2592.

48. Schernthaner G, Gross JL, Rosenstock J, et al. Canagliflozin compared with sitagliptin for patients with type 2 diabetes who do not have adequate glycemic control with metformin plus sulfonylurea: a 52-week randomized trial. Diabetes Care. 2013;36(9):2508-2515.

49. Wilding JP, Charpentier G, Hollander P, et al. Efficacy and safety of canagliflozin in patients with type 2 diabetes mellitus inadequately controlled with metformin and sulphonylurea: a randomised trial. Int J Clin Pract. 2013;67(12):1267-1282.

50. Matthews DR, Fulcher G, Perkovic V, et al. Efficacy and safety of canagliflozin (CANA), an inhibitor of sodium glucose co-transporter 2 (SGLT2), added-on to insulin therapy +/- oral agents in type 2 diabetes. Abstract 764. Diabetologia. 2012;55(Suppl 1):S314.

51. Yale JF, Bakris G, Cariou B, et al. Efficacy and safety of canagliflozin in subjects with type 2 diabetes and chronic kidney disease. Diabetes Obes Metab. 2013;15(5):463-473.

52. Bode B, Stenlöf K, Sullivan D, Fung A, Usiskin K. Efficacy and safety of canagliflozin treatment in older subjects with type 2 diabetes mellitus: a randomized trial. Hosp Pract (1995). 2013;41(2):72-84.

53. Roden M, Weng J, Eilbracht J, et al. Empagliflozin monotherapy with sitagliptin as an active comparator in patients with type 2 diabetes: a randomised, double-blind, placebo-controlled, phase 3 trial. Lancet Diabetes Endocrinol. 2013;1(3):208-219.

54. Häring HU, Merker L, Seewaldt-Becker E, Weimer M, Meinicke T. Empagliflozin as add-on to metformin for 24 weeks improves glycemic control in patients with type 2 diabetes (T2DM). Diabetes. 2013; 62(Suppl 1):Abstract 1092-P.

55. Ferrannini E, Berk A, Hantel S, et al. Long-term safety and efficacy of empagliflozin, sitagliptin, and metformin: an active-controlled, parallelgroup, randomized, 78-week open-label extension study in patients with type 2 diabetes. Diabetes Care. 2013;36(12):4015-4021.

56. Häring HU, Merker L, Seewaldt-Becker E, et al. Empagliflozin as add-on to metformin plus sulfonylurea in patients with type 2 diabetes. A 24-week, randomized, double-blind, placebo-controlled trial. Diabetes Care. 2013;36(11):3396-3404.

57. Kovacs CS, Seshiah V, Swallow R, et al. Empagliflozin improves glycaemic and weight control as add-on therapy to pioglitazone or pioglitazone plus metformin in patients with type 2 diabetes: a 24-week, randomized, placebo-controlled trial. Diabetes Obes Metab. 2014;16(2):147-158.

58. Rosenstock J, Jelaska A, Kim G, Broedl UC, Woerle HJ. Empagliflozin as add-on to basal insulin for 78 weeks improves glycemic control with weight loss in insulin-treated (T2DM). Diabetes. 2013;62(Suppl 1): Abstract 1102-P.

59. Barnett AH, Mithal A, Manassie J, et al. Efficacy and safety of empagliflozin added to existing antidiabetes treatment in patients with type 2 diabetes and chronic kidney disease: a randomised, double-blind, placebo-controlled trial. Lancet Diabetes Endocrinol. 2014;2(5):369-384.
60. Vasilakou D, Karagiannis T, Athanasiadou E, et al. Sodium-glucose cotransporter 2 inhibitors for type 2 diabetes: a systematic review and meta-analysis. Ann Intern Med. 2013;159(4):262-274.

61. Clar C, Gill JA, Court R, Waugh N. Systematic review of SGLT2 receptor inhibitors in dual or triple therapy in type 2 diabetes. BMJ Open. 2012;2(5): $\mathrm{e} 001007$.

62. Berhan A, Barker A. Sodium glucose co-transport 2 inhibitors in the treatment of type 2 diabetes mellitus: a meta-analysis of randomized double-blind controlled trials. BMC Endocr Disord. 2013;13(1):58.

63. European Medicines Agency [homepage on the Internet]. Forxiga (Dapagliflozin). EMA Assessment Report. Procedure no. EMEA/ H/C/002322; 2012. Available from: http://www.ema.europa.eu/ docs/en_GB/document_library/EPAR_-_Public_assessment_report/ human/002322/WC500136024.pdf. Accessed September 17, 2013.

64. Wilding JP, Woo V, Rohwedder K, Sugg J, Parikh S. Dapagliflozin in patients with type 2 diabetes receiving high doses of insulin: efficacy and safety over 2 years. Diabetes Obes Metab. Epub 2013 Aug 1.

65. Bailey CJ, Gross JL, Hennicken D, Iqbal N, Mansfield TA, List JF. Dapagliflozin add-on to metformin in type 2 diabetes inadequately controlled with metformin: a randomized, double-blind, placebo-controlled 102-week trial. BMC Med. 2013;11(1):43.

66. European Medicines Agency [homepage on the Internet]. Canagliflozin. EMA Assessment Report. Procedure no. EMEA/H/C/002649/0000; 2013. Available from: http://www.ema.europa.eu/docs/en_GB/ document_library/EPAR_-_Public_assessment_report/human/002649/ WC500156457.pdf. Accessed December 3, 2013.

67. Stenlöf K, Cefalu WT, Kim KA, et al. Long-term efficacy and safety of canagliflozin monotherapy in patients with type 2 diabetes inadequately controlled with diet and exercise: Findings from the 52-Week CANTATA-M study. Curr Med Res Opin. 2014;30(2):163-175.

68. Bolinder J, Ljunggren O, Johansson L, et al. Dapagliflozin maintains glycaemic control while reducing weight and body fat mass over 2 years in patients with type 2 diabetes mellitus inadequately controlled on metformin. Diabetes Obes Metab. Epub 2011 Aug 1.

69. US Food and Drug Administration [homepage on the Internet]. FDA Briefing Document. NDA 204042. Invokana (Canagliflozin) tablets; 2013. Available from: http://www.fda.gov/downloads/Advisory Committees/CommitteesMeetingMaterials/Drugs/Endocrinologicand MetabolicDrugsAdvisoryCommittee/UCM334550.pdf. Accessed March 31, 2014.

70. Lambers Heerspink HJ, de Zeeuw D, Wie L, Leslie B, List J. Dapagliflozin a glucose-regulating drug with diuretic properties in subjects with type 2 diabetes. Diabetes Obes Metab. 2013;15(9):853-862.

71. Weir MR, Januszewicz A, Gilbert RE, Lavalle Gonzalez FJ, Meininger G. Lower blood pressure (BP) with canagliflozin (cana) in subjects with type 2 diabetes mellitus (T2DM). Diabetes. 2013;62(Suppl 1): Abstract 1077-P.

72. Hach T, Gerich J, Salsali A, et al. Empagliflozin improves glycemic parameters and cardiovascular risk factors in patients with type 2 diabetes (T2DM): pooled data from four pivotal phase III trials Diabetes. 2013;62(Suppl 1):Abstract 69-LB.

73. Tikkanen I, Narko K, Zeller C, et al. Empagliflozin improves blood pressure in patients with type 2 diabetes (T2DM) and hypertension. Abstract 942. Diabetologia. 2013;56(Suppl S1):S377.

74. Johnsson KM, Ptaszynska A, Schmitz B, Sugg J, Parikh SJ, List JF. Vulvovaginitis and balanitis in patients with diabetes treated with dapagliflozin. J Diabetes Complications. 2013;27(5):479-484.

75. Johnsson KM, Ptaszynska A, Schmitz B, Sugg J, Parikh SJ, List JF. Urinary tract infections in patients with diabetes treated with dapagliflozin. J Diabetes Complications. 2013;27(5):473-478.

76. Nicolle LE, Capuano G, Fung A, Usiskin K. Urinary tract infection (UTI) with canagliflozin (CANA) in subjects with type 2 diabetes mellitus (T2DM). Diabetes. 2013;62(Suppl 1):Abstract 1139-P.

77. Nyirjesy P, Sobel J, Fung A, Gassmann-Meyer C, Ways K, Usiskin K. Genital mycotic infections with canagliflozin (CANA) in subjects with type 2 diabetes mellitus (T2DM). Diabetes. 2013;62(Suppl 1): Abstract 1069-P. 
78. Kim G, Gerich JE, Salsali A, et al. Empagliflozin (EMPA) increases genital infections but not urinary tract infections (UTIs) in pooled data from four pivotal phase III trials. Diabetes. 2013;62(Suppl 1): Abstract 74-LB

79. Ptaszynska A, Johnsson KM, Apanovitch A-M, Sugg J, Parikh S, List J. Safety of dapagliflozin in clinical trials for T2DM. Diabetes. 2012;61(Suppl 1):Abstract 1011-P.

80. Ptaszynska A, Chalamandaris AG, Sugg JE, Johnsson KM, Parikh S, List JL. Effect of dapagliflozin on renal function Diabetes. 2012;61(Suppl 1):Abstract 1098-P.

81. Toto RD, Wanner C, Gerich J, et al. No overall increase in volume depletion events with empagliflozin (EMPA) in a pooled analysis of more than 11,000 patients with type 2 diabetes (T2DM). J Am Soc Nephrol. 2013;24(Suppl):Abstract SA-PO373.

82. Liakos A, Karagiannis T, Athanasiadou E, et al. Efficacy and safety of empagliflozin for type 2 diabetes: a systematic review and meta-analysis. Diabetes Obes Metab. Epub 2014 April 26.

83. Gangadharan Komala M, Mather A. Empagliflozin for the treatment of Type 2 diabetes. Expert Rev Clin Pharmacol. 2014;7(3):271-279.

84. Ljunggren Ö, Bolinder J, Johansson L, et al. Dapagliflozin has no effect on markers of bone formation and resorption or bone mineral density in patients with inadequately controlled type 2 diabetes mellitus on metformin. Diabetes Obes Metab. 2012;14(11):990-999.

85. Bode B, Stenlof K, Sullivan D, Fung A, Usiskin K, Meininger G. Efficacy and safety of canagliflozin (CANA), a sodium glucose cotransporter 2 inhibitor (SGLT2), in older subjects with type 2 diabetes mellitus. Diabetologia. 2012;55(Suppl 1):S315 (Abstract 765).

86. Wanner C, Toto RD, Gerich J, et al. No increase in bone fractures with empagliflozin (EMPA) in a pooled analysis of more than 11,000 patients with type 2 diabetes (T2DM). J Am Soc Nephrol. 2013;24(Suppl):Abstract TH-PO452.

87. Basile JN. The potential of sodium glucose cotransporter 2 (SGLT2) inhibitors to reduce cardiovascular risk in patients with type 2 diabetes (T2DM). J Diabetes Complications. 2013;27(3):280-286.

88. Rodríguez-Gutiérrez R, Gonzalez-Saldivar G. Canagliflozin. Cleve Clin J Med. 2014;81(2):87-88.

89. Foote C, Perkovic V, Neal B. Effects of SGLT2 inhibitors on cardiovascular outcomes. Diab Vasc Dis Res. 2012;9(2):117-123.

90. Neal B, Perkovic V, de Zeeuw D, et al. Rationale, design, and baseline characteristics of the Canagliflozin Cardiovascular Assessment Study (CANVAS)-A randomized placebo-controlled trial. Am Heart J. 2013;166(2):217-223.

91. Zinman B, Inzucchi SE, Lachin J, et al. Design of the empagliflozin cardiovascular (CV) outcome event trial in type 2 diabetes (T2D). Can J Diabetes. 2013;37(Suppl 4):S29-S30.

92. Janssen Pharmaceuticals Inc. [homepage on the Internet]. INVOKANA $^{\mathrm{TM}}$ (canagliflozin) tablets, for oral use. Highlights of Prescribing Information (Revised 11/2013); 2013. Available from: http://www. invokanahcp.com/prescribing-information.pdf. Accessed February 27, 2014.
93. US Food and Drug Administration [homepage on the Internet] Invokana (Canagliflozin) Tablets. NDA 204042. FDA Briefing Document (January 10, 2013). FDA Briefing Document. 2013. Available from: http://www.fda.gov/downloads/AdvisoryCommittees/ CommitteesMeetingMaterials/Drugs/Endocrinologicand MetabolicDrugsAdvisoryCommittee/UCM334550.pdf. Accessed April 10, 2014

94. Ptaszynska A, Hardy E, Johnsson E, Parikh S, List J. Effects of dapagliflozin on cardiovascular risk factors. Postgrad Med. 2013;125(3):181-189.

95. US Food and Drug Administration [homepage on the Internet]. FDA Briefing Document. NDA 202293. Dapagliflozin tablets, 5 and $10 \mathrm{mg}$ 2011. Available from: http://www.fda.gov/downloads/ AdvisoryCommittees/CommitteesMeetingMaterials/drugs/ EndocrinologicandMetabolicDrugsAdvisoryCommittee/ucm 262994 pdf. Accessed March 31, 2014.

96. Macdonald FR, Peel JE, Jones HB, et al. The novel sodium glucose transporter 2 inhibitor dapagliflozin sustains pancreatic function and preserves islet morphology in obese, diabetic rats. Diabetes Obes Metab. 2010;12(11):1004-1012.

97. Merovci A, Solis-Herrera C, Daniele G, et al. Dapagliflozin improves muscle insulin sensitivity but enhances endogenous glucose production. J Clin Invest. 2014;124(2):509-514.

98. Ferrannini E, Muscelli E, Frascerra S, et al. Metabolic response to sodium-glucose cotransporter 2 inhibition in type 2 diabetic patients. J Clin Invest. 2014;124(2):499-508.

99. Powell DR, Smith M, Greer J, et al. LX4211 Increases serum glucagonlike peptide 1 and peptide YY levels by reducing sodium/glucose cotransporter 1 (SGLT1)-mediated absorption of intestinal glucose. $J$ Pharmacol Exp Ther. 2013;345(2):250-259.

100. Zambrowicz B, Freiman J, Brown PM, et al. LX4211, a dual SGLT1/ SGLT2 inhibitor, improved glycemic control in patients with type 2 diabetes in a randomized, placebo-controlled trial. Clin Pharmacol Ther. 2012;92(2):158-169.

101. Henry RR, Rosenstock J, Chalamandaris AG, Kasichayanula S, Bogle A, Griffen SC. Exploring the potential of dapagliflozin in type 1 diabetes: Phase 2a pilot study. Diabetes. 2013;62(Suppl 1):Abstract 70-LB.

102. Perkins BA, Cherney DZI, Partridge H, et al. Sodium-glucose cotransporter 2 inhibition and glycemic control in type 1 diabetes: Results of an 8-week open-label proof-of-concept trial. Diabetes Care. 2014;37(5):1480-1483.

103. Cherney DZ, Perkins BA, Soleymanlou N, et al. Renal hemodynamic effect of sodium-glucose cotransporter 2 inhibition in patients with type 1 diabetes mellitus. Circulation. 2014;129(5):587-597.

104. Liu JJ, Lee T, DeFronzo RA. Why Do SGLT2 inhibitors inhibit only $30 \%-50 \%$ of renal glucose reabsorption in humans? Diabetes. 2012;61(9):2199-2204.

105. Abdul-Ghani MA, Defronzo RA, Norton L. Novel hypothesis to explain why SGLT2 inhibitors inhibit only $30 \%-50 \%$ of filtered glucose load in humans. Diabetes. 2013;62(10):3324-3328. 


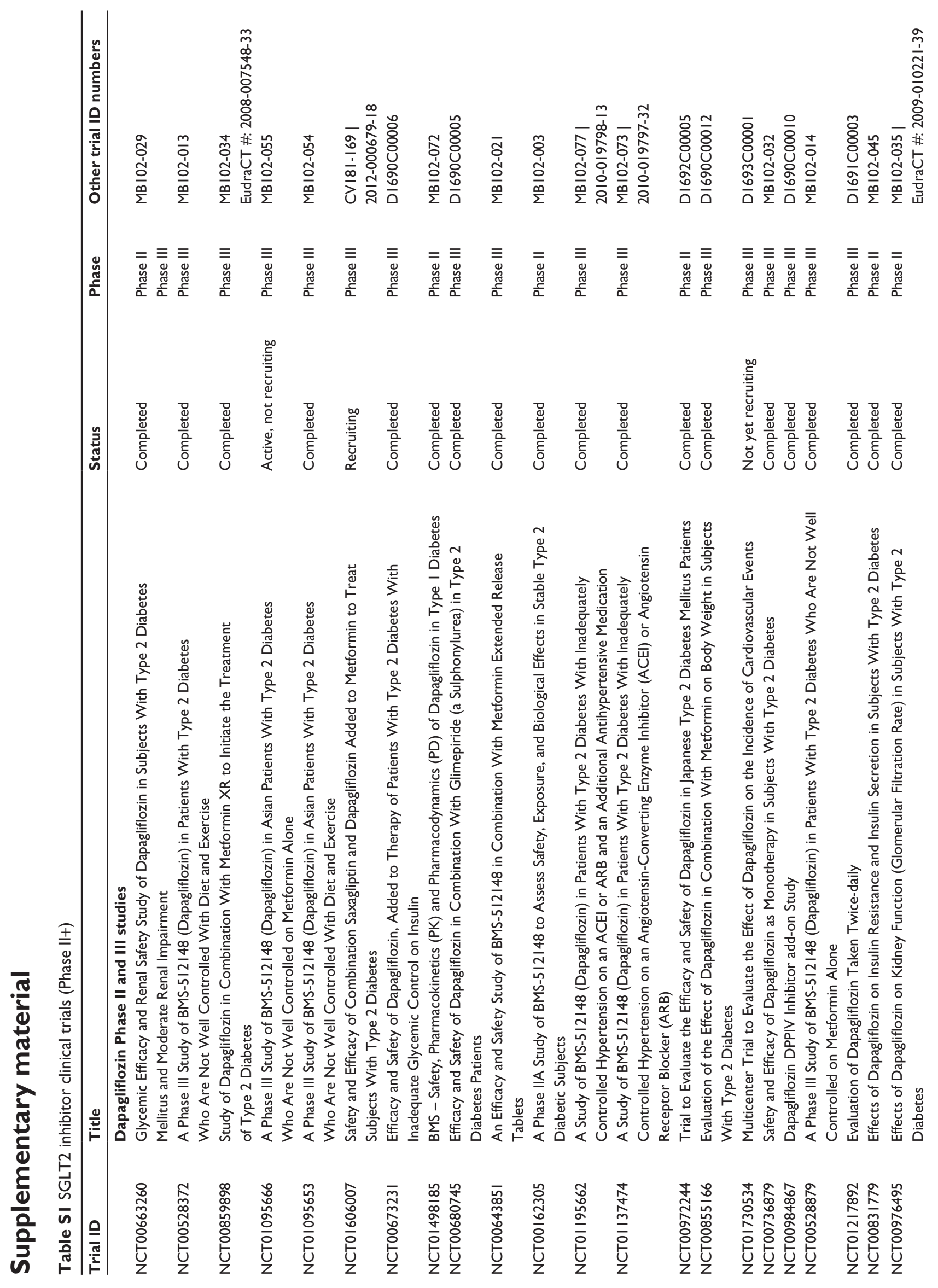




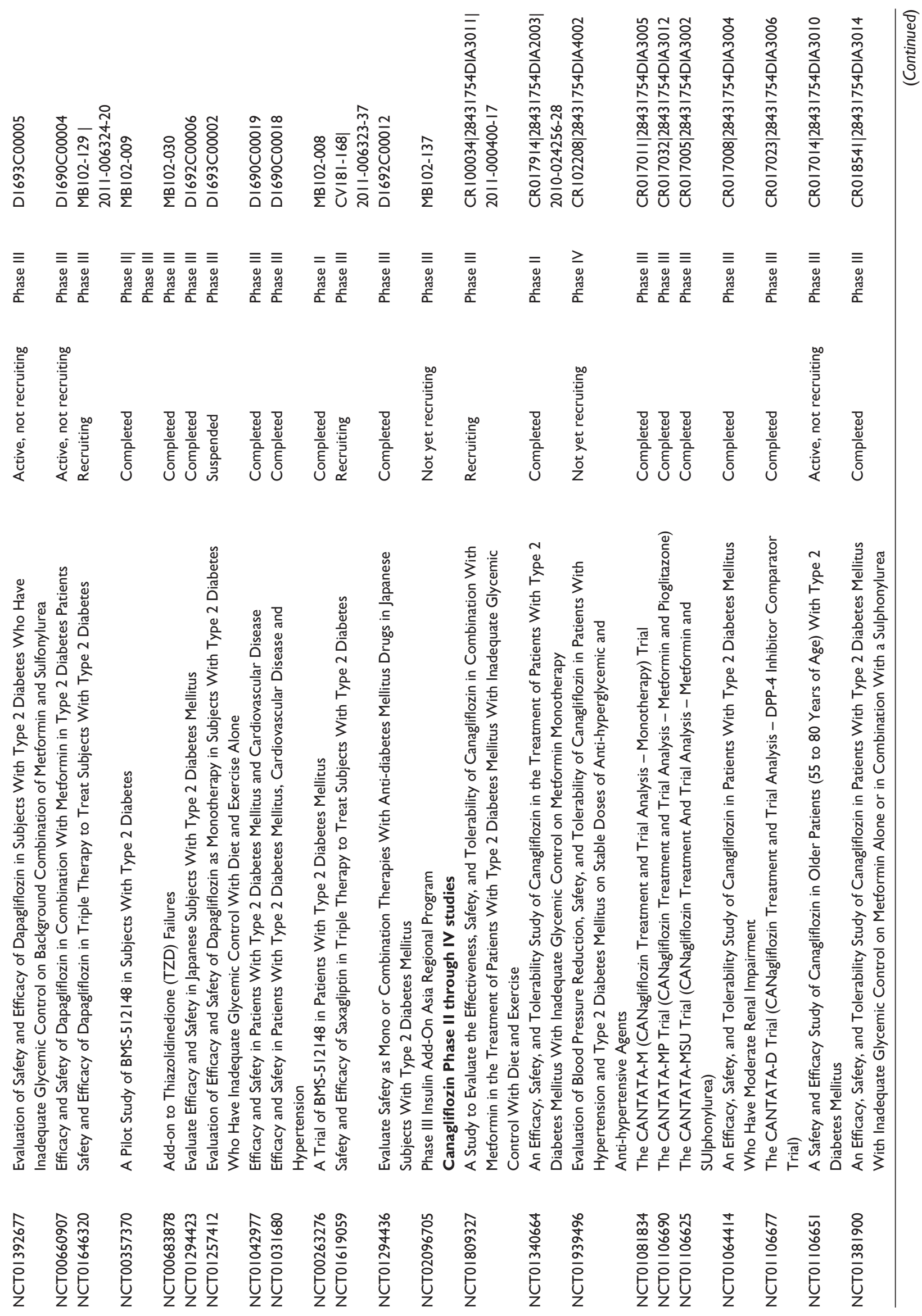



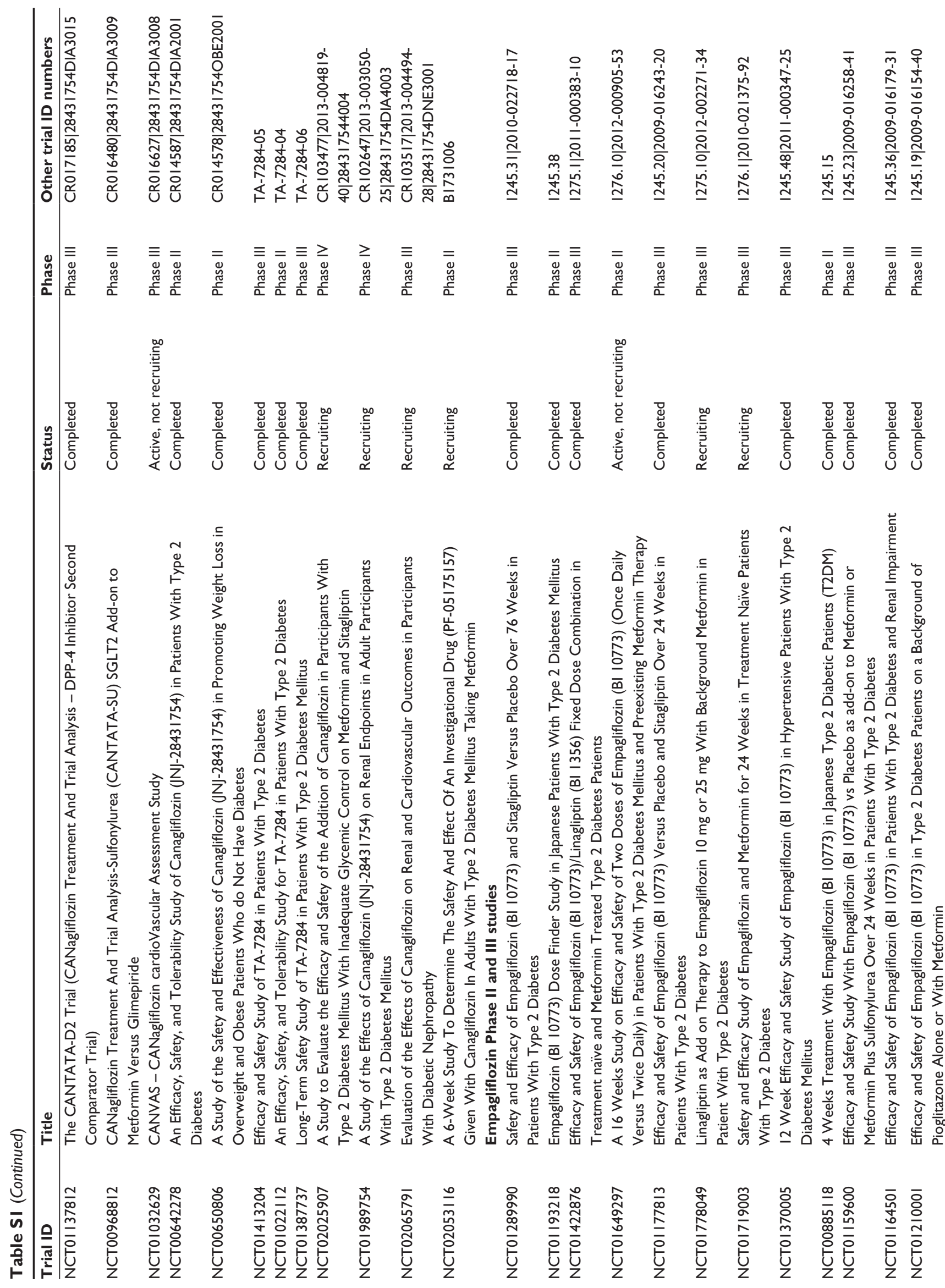

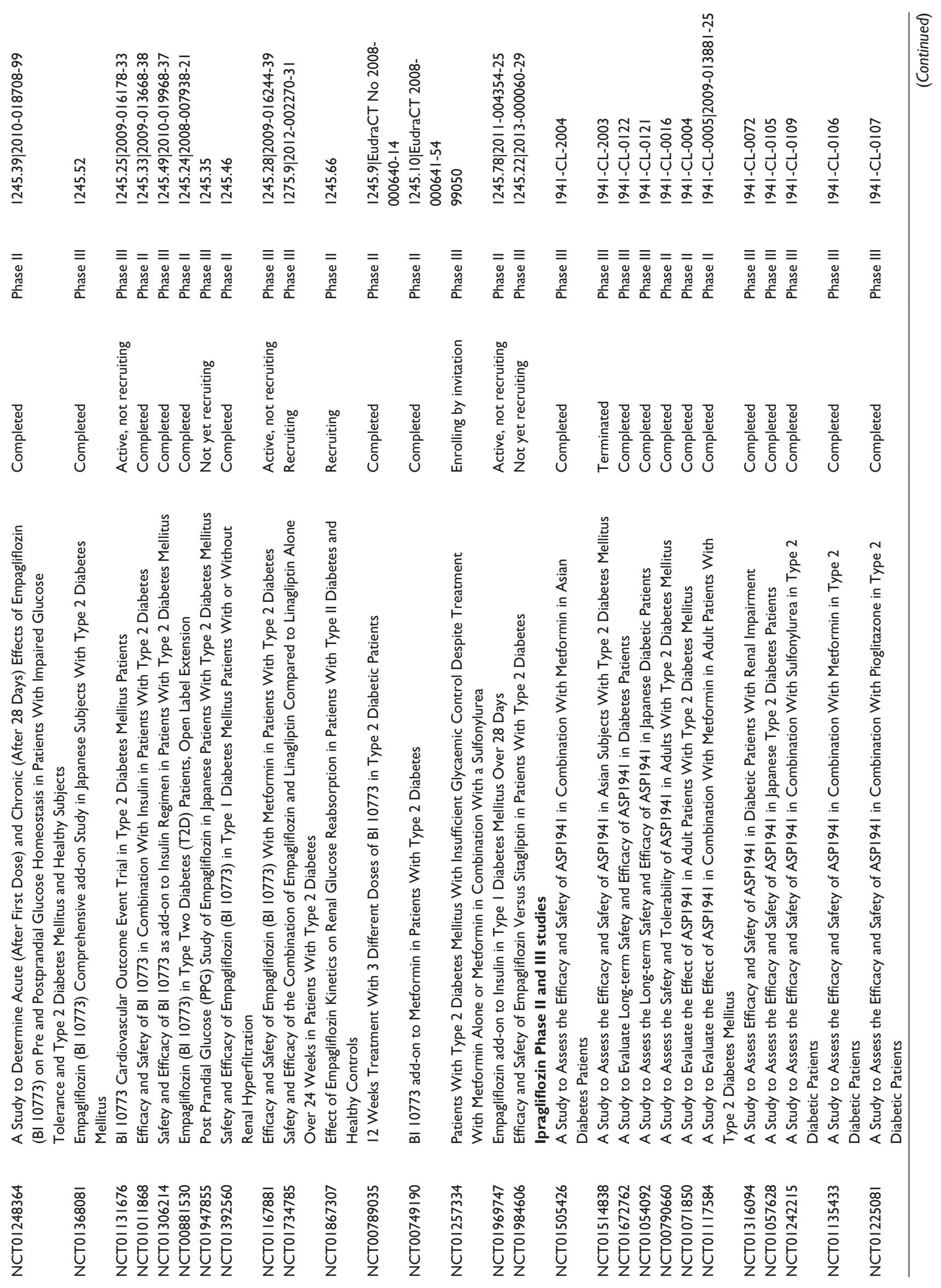

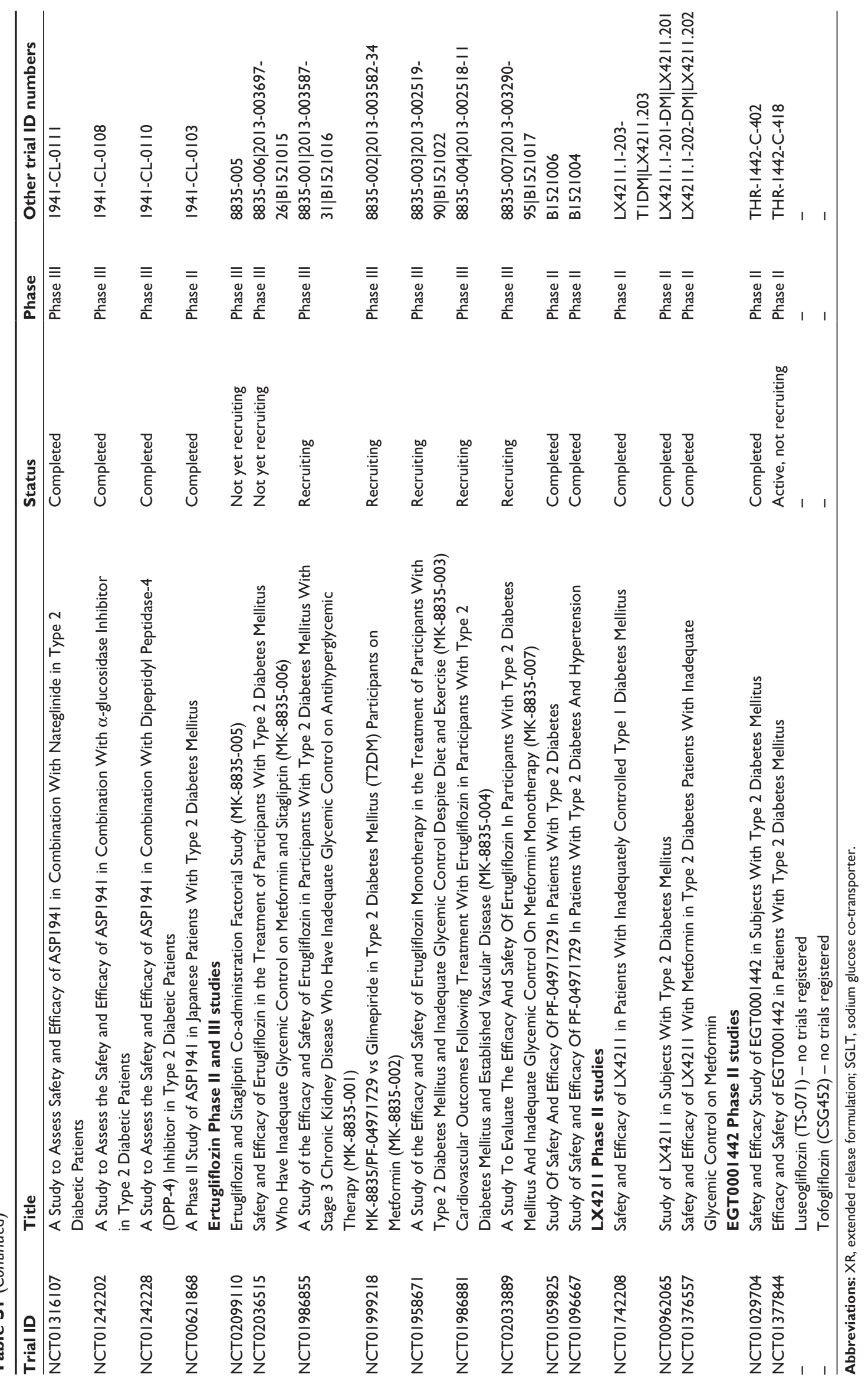


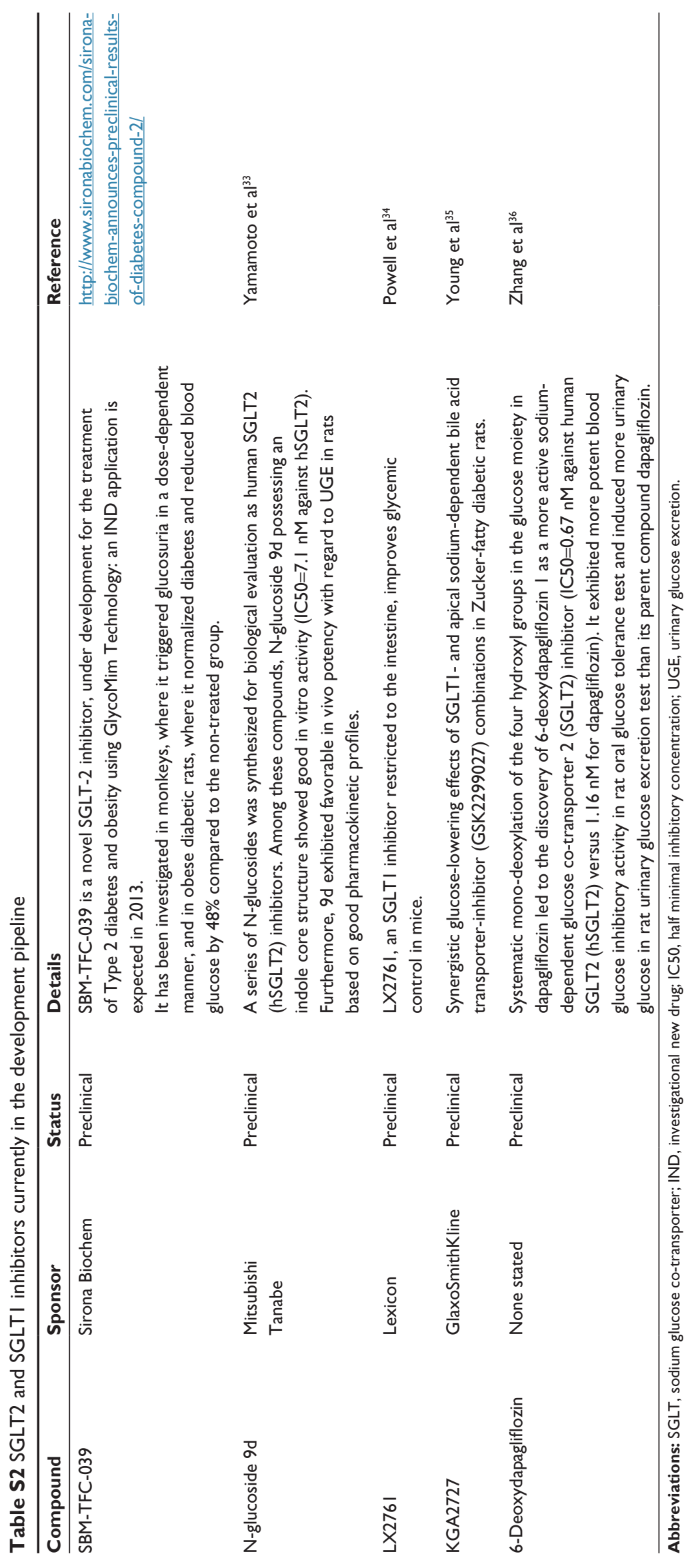


Table S3 Efficacy data from pivotal clinical trials of SGLT2 inhibitors ${ }^{\mathrm{a}}$

\begin{tabular}{|c|c|c|c|c|c|c|}
\hline \multirow[t]{2}{*}{$\begin{array}{l}\text { Reference \& NCT ID (Study } \\
\text { number or acronym) }\end{array}$} & \multirow[t]{2}{*}{ Study details } & \multirow[t]{2}{*}{ Regimen } & \multirow[t]{2}{*}{$\mathbf{N}$} & \multirow[t]{2}{*}{$\begin{array}{l}\text { Treatment and } \\
\text { dose, mg/day }\end{array}$} & \multicolumn{2}{|c|}{$\begin{array}{l}\text { Change in } \mathrm{HbA}_{\mathrm{Ic}} \text { from } \\
\text { baseline, } \%\end{array}$} \\
\hline & & & & & Mean & $\begin{array}{l}\text { SD or }(95 \% \mathrm{Cl}) \\
\text { or }[\mathrm{SEM}]\end{array}$ \\
\hline \multicolumn{7}{|l|}{ Dapagliflozin } \\
\hline \multirow[t]{8}{*}{$\begin{array}{l}\text { List Diabetes Care 2009' } \\
\text { NCT00263276 (MBI02008) }\end{array}$} & Phase II, I2 week & $\begin{array}{l}\text { Drug naïve, } \\
\text { diet/exercise }\end{array}$ & 389 & & & \\
\hline & & & 54 & Pbo & -0.2 & 0.1 \\
\hline & & & 59 & 2.5 & -0.7 & 0.1 \\
\hline & & & 58 & 5 & -0.7 & 0.1 \\
\hline & & & 47 & 10 & -0.9 & 0.1 \\
\hline & & & 59 & 20 & -0.6 & 0.1 \\
\hline & & & 56 & 50 & -0.9 & 0.1 \\
\hline & & & 56 & MET XR & -0.7 & 0.1 \\
\hline \multirow{5}{*}{$\begin{array}{l}\text { Wilding Diabetes Care 2009² } \\
\text { NCT00357370 (MBI02009) }\end{array}$} & Phase II, 12 week & OADs + INS & 71 & & & \\
\hline & & & & & & \\
\hline & & & 23 & Pbo & 0.1 & $(-0.2,0.4)$ \\
\hline & & & 24 & 10 & -0.6 & $(-0.9,-0.4)$ \\
\hline & & & 24 & 20 & -0.7 & $(-0.9,-0.4)$ \\
\hline \multirow{11}{*}{$\begin{array}{l}\text { Ferrannini Diabetes Care } 2010^{3} \\
\text { NCT00528372 (MBI020I3) }\end{array}$} & Phase III, 24 week & Drug naïve, & 485 & & & \\
\hline & & diet/exercise & & & & \\
\hline & & & 75 & Pbo & -0.2 & {$[0.1]$} \\
\hline & & & 65 & $2.5 \mathrm{AM}$ & -0.6 & {$[0.1]$} \\
\hline & & & 64 & $5 \mathrm{AM}$ & -0.8 & {$[0.1]$} \\
\hline & & & 70 & $10 \mathrm{AM}$ & -0.9 & {$[0.1]$} \\
\hline & & & 67 & $2.5 \mathrm{PM}$ & -0.8 & {$[0.1]$} \\
\hline & & & 68 & 5 PM & -0.8 & {$[0.1]$} \\
\hline & & & 76 & $10 \mathrm{PM}$ & -0.8 & {$[0.1]$} \\
\hline & & & 34 & $5\left(A_{1 c} \geq 10.1\right)$ & -2.9 & 1.4 \\
\hline & & & 39 & $10\left(A_{I c} \geq 10.1\right)$ & -2.7 & 1.3 \\
\hline \multirow[t]{5}{*}{$\begin{array}{l}\text { Bailey Diabetes Obes Metab 20I } 2^{4} \\
\text { NCT00736879 (MBI02032) }\end{array}$} & Phase III, 24 week & $\begin{array}{l}\text { Drug naïve, } \\
\text { diet/exercise }\end{array}$ & 282 & & & \\
\hline & & & 68 & Pbo & 0.0 & $(-0.2,0.3)$ \\
\hline & & & 72 & 1 & -0.7 & $(-1.0,-0.5)$ \\
\hline & & & 74 & 2.5 & -0.7 & $(-1.0,-0.5)$ \\
\hline & & & 68 & 5 & -0.8 & $(-1.1,-0.6)$ \\
\hline Bailey Lancet $2010^{5}$ & Phase III, 24 week & MET & 546 & & & \\
\hline \multicolumn{7}{|l|}{ NCT00528879 (MBI02014) } \\
\hline & & & 137 & Pbo & -0.3 & $(-0.4,-0.2)$ \\
\hline & & & 137 & 2.5 & -0.7 & $(-0.9,-0.6)$ \\
\hline & & & 137 & 5 & -0.7 & $(-0.8,-0.5)$ \\
\hline & & & 135 & 10 & -0.8 & $(-1.0,-0.7)$ \\
\hline \multirow{4}{*}{$\begin{array}{l}\text { Bolinder J Clin Endocrinol } \\
\text { Metab 20I2 }{ }^{6} \text { NCT00855I66 } \\
\text { (DI690C000I2) }\end{array}$} & Phase III, 24 week, & MET & 182 & & & \\
\hline & $\mathrm{BMI} \geq 25$ & & & & & \\
\hline & & & 91 & Pbo & -0.1 & - \\
\hline & & & 91 & 10 & -0.4 & - \\
\hline Henry Int J Clin Pract $2012^{7}$ & $\begin{array}{l}\text { Phase III, } 24 \text { week } \\
\text { (both) }\end{array}$ & MET XR & & & & \\
\hline \multirow[t]{3}{*}{ NCT0064385 I (MBI0202I) } & & & 201 & $\mathrm{Pbo}+\mathrm{MET}$ & -1.4 & $(-1.5,-1.2)$ \\
\hline & & & 194 & $5+$ MET & -2.1 & $(-2.2,-1.9)$ \\
\hline & & & 203 & $5+\mathrm{Pbo}$ & -1.2 & $(-1.4,-1.0)$ \\
\hline \multirow[t]{3}{*}{ NCT00859898 (MBI02034) } & & & 208 & $\mathrm{Pbo}+\mathrm{MET}$ & -1.4 & $(-1.6,-1.3)$ \\
\hline & & & 211 & $10+$ MET & -2.0 & $(-2.1,-1.8)$ \\
\hline & & & 219 & $10+\mathrm{Pbo}$ & -1.5 & $(-1.6,-1.3)$ \\
\hline
\end{tabular}




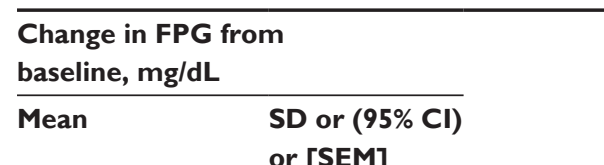

Change in body weight

from baseline, $\mathrm{kg}$

Mean SD or $(95 \% \mathrm{Cl})$ or [SEM]

Change in SBP from baseline, $\mathrm{mmHg}$

Mean

SD or $(95 \% \mathrm{Cl})$ or [SEM]

Supine

-6
-16
-19
-21
-24
-31
-18

$-1.1$

$-2.4$

$-2.2$

$-2.3$

$-3.0$

$-3.1$

$-1.5$

$-1.9$

$-4.5$

$-4.3$

$-10$

$-4$

$-15$

$-24$

$-29$

$-26$

$-27$

$-30$

$-77$

$-84$

4

$-11$

$-22$

$-28$

$-6$

$-18$

$-21$

$-23$

2

$-15$

$-34$

$-61$

$-42$

$-35$

$-60$

$-46$
$(1,34)$

$(-14,18)$

$(-26,6)$

[4]

[4]

[4]

[4]

[4]

[4]

[4]

53

61

$(-4,12)$

$(-19,-3)$

$(-30,-14)$

$(-37,-20)$

$(-1 \mathrm{I},-\mathrm{I})$

$(-23,-12)$

$(-29,-16)$

$(-29,-18)$

$-$

-

$(-39,-28)$

$(-66,-56)$

$(-47,-37)$

$(-40,-30)$

$(-65,-55)$

$(-5 I,-4 I)$
$(-1.8,-0.4)$

$(-3.1,-1.7)$

$(-2.9,-1.6)$

$(-3.0,-1.5)$

$(-3.6,-2.3)$

$(-3.8,-2.4)$

$(-2.1,-0.8)$

$(-2.9,-0.9)$

$(-5.5,-3.5)$

$(-5.3,-3.3)$

[0.4]

[0.5]

[0.5]

[0.5]

[0.5]

[0.5]

[0.4]

3.4

3.5

$(-1.7,-0.2)$

$(-3.4,-1.9)$

$(-3.4,-1.9)$

$(-3.5,-1.9)$

$(-1.4,-0.4)$

$(-2.7,-1.8)$

$(-3.5,-2.6)$

$(-3.3,-2.4)$

$(-1.4,-0.3)$

$(-3.5,-2.4)$

$(-1.8,-0.8)$

$(-3.1,-2.2)$

$(-3.1,-2.2)$

$(-1.8,-0.9)$

$(-3.8,-2.9)$

$(-3.2,-2.3)$
2

$-3$

$-3$

$-6$

$-4$

$-3$

$-0$

2

$-1$

$-6$

Seated

$-1$

$-5$

-2 [2]

-4 [2]

$-4 \quad$ [2]

$-5$

-2 [I]

-6 [2]

$-3 \quad$ [2]

Seated

I [ [I]

$-4 \quad[1]$

$-3 \quad$ [2]

$-5 \quad$ [2]

Seated

0

-2 [I]

$-4 \quad[1]$

$-5 \quad$ [I]

Seated

0

$-3$

-2 [I]

$-3 \quad[1]$

$-4 \quad[I]$

$-1 \quad[1]$

$-3 \quad$ [I]

$-4$
[6]

$[3]$

[2]

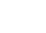

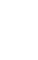

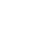

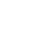

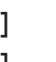

2]

I]
[1]
2]


Table S3 (Continued)

\begin{tabular}{|c|c|c|c|c|c|c|}
\hline \multirow[t]{2}{*}{$\begin{array}{l}\text { Reference \& NCT ID (Study } \\
\text { number or acronym) }\end{array}$} & \multirow[t]{2}{*}{ Study details } & \multirow[t]{2}{*}{ Regimen } & \multirow[t]{2}{*}{$\mathbf{N}$} & \multirow[t]{2}{*}{$\begin{array}{l}\text { Treatment and } \\
\text { dose, } \mathrm{mg} / \mathrm{day}\end{array}$} & \multicolumn{2}{|c|}{$\begin{array}{l}\text { Change in } \mathbf{H b A}_{\mathrm{Ic}} \text { from } \\
\text { baseline, } \%\end{array}$} \\
\hline & & & & & Mean & $\begin{array}{l}\text { SD or }(95 \% \mathrm{Cl}) \\
\text { or }[\mathrm{SEM}]\end{array}$ \\
\hline Strojek Diabetes Obes Metab $201 \mathrm{I}^{8}$ & Phase III, 24 week & SU (GLIM) & 597 & & & \\
\hline \multicolumn{7}{|l|}{ NCT00680745 (DI690C00005) } \\
\hline & & & 145 & Pbo & -0.1 & - \\
\hline & & & 154 & 2.5 & -0.6 & - \\
\hline & & & 142 & 5 & -0.6 & - \\
\hline & & & 151 & 10 & -0.8 & - \\
\hline Nauck Diabetes Care 201 ${ }^{9}$ & Phase III, 52 week & MET & & & & \\
\hline \multicolumn{7}{|l|}{ NCT00660907 (DI690C00004) } \\
\hline & & & 406 & DAPA 2.5-10 & -0.5 & $(-0.6,0.4)$ \\
\hline & & & 408 & GLIP 5-20 & -0.5 & $(-0.6,0.4)$ \\
\hline Rosenstock Diabetes Care & Phase III, 48 week & TZD (PIO) & 420 & & & \\
\hline \multicolumn{7}{|l|}{$2012^{10}$ NCT00683878 } \\
\hline \multicolumn{7}{|l|}{ (MBI02030) } \\
\hline & & & 139 & Pbo & -0.5 & {$[0.1]$} \\
\hline & & & $|4|$ & 5 & -1.0 & {$[0.1]$} \\
\hline & & & 140 & 10 & -1.2 & {$[0.1]$} \\
\hline Wilding Ann Intern Med 2012"1 & Phase III, 48 week & INS & 800 & & & \\
\hline \multirow[t]{6}{*}{ NCT0067323I (DI690C00006) } & & $\geq 30$ units/day & & & & \\
\hline & & \pm OADs & & & & \\
\hline & & & 193 & Pbo & -0.5 & - \\
\hline & & & 202 & 2.5 & -0.8 & - \\
\hline & & & 211 & 5 & -1.0 & - \\
\hline & & & 194 & 10 & -1.0 & - \\
\hline Kohan Kidney Int $2013^{12}$ & Phase III, I04 week & AHAs including & & & & \\
\hline \multirow[t]{4}{*}{ NCT00663260 (MBI02029) } & Renal impairment & INS & & & & \\
\hline & & 24 week data & 50 & Pbo & -0.3 & {$[0.1]$} \\
\hline & & 24 week data & 63 & 5 & -0.4 & {$[0.1]$} \\
\hline & & 24 week data & 65 & 10 & -0.4 & {$[0.1]$} \\
\hline \multirow{8}{*}{$\begin{array}{l}\text { Jabbour Diabetes Care } 2013^{13} \\
\text { NCT00984867 (DI690C000I0) }\end{array}$} & Phase III, 24 week & DDP4 inhibitor & & & & \\
\hline & & $(\mathrm{SITA}) \pm \mathrm{MET}$ & & & & \\
\hline & & & 224 & Pbo & 0.0 & $(-0.1,0.1)$ \\
\hline & & & 223 & 10 & -0.5 & $(-0.6,0.4)$ \\
\hline & & Stratum I & 111 & $\mathrm{Pbo}+\mathrm{SITA}$ & 0.1 & $(-0.1,0.3)$ \\
\hline & & Stratum I & 110 & $10+$ SITA & -0.5 & $(-0.6,-0.3)$ \\
\hline & & Stratum 2 & 113 & Pbo + SITA + MET & -0.0 & $(-0.2,0.1)$ \\
\hline & & Stratum 2 & 113 & $10+$ SITA + MET & -0.4 & $(-0.6,-0.3)$ \\
\hline \multicolumn{7}{|l|}{ Canagliflozin } \\
\hline \multirow{5}{*}{$\begin{array}{l}\text { Stenlöf Diabetes Obes Metab 20I314 } \\
\text { NCT0I08I834 (CANTATA-M) }\end{array}$} & Phase III, 26 week & Drug naïve, & 584 & & & \\
\hline & & diet/exercise & & & & \\
\hline & & & 192 & Pbo & 0.1 & - \\
\hline & & & 195 & 100 & -0.8 & - \\
\hline & & & 197 & 300 & -1.0 & - \\
\hline Cefalu Lancet $2013^{15}$ & Phase III, 52 week & MET & 1,450 & & & \\
\hline \multicolumn{7}{|l|}{ NCT009688I2 (CANTATA-SU) } \\
\hline & & & 483 & 100 & -0.8 & {$[0.0]$} \\
\hline & & & 485 & 300 & -0.9 & {$[0.0]$} \\
\hline & & & 482 & GLIM I-8 & -0.8 & {$[0.0]$} \\
\hline
\end{tabular}




\begin{tabular}{|c|c|c|c|c|c|}
\hline \multicolumn{2}{|c|}{$\begin{array}{l}\text { Change in FPG from } \\
\text { baseline, } \mathrm{mg} / \mathrm{dL}\end{array}$} & \multicolumn{2}{|c|}{$\begin{array}{l}\text { Change in body weight } \\
\text { from baseline, } \mathrm{kg}\end{array}$} & \multicolumn{2}{|c|}{ Change in SBP from baseline, $\mathrm{mmHg}$} \\
\hline \multirow[t]{2}{*}{ Mean } & $\begin{array}{l}\text { SD or }(95 \% \mathrm{CI}) \\
\text { or }[\mathrm{SEM}]\end{array}$ & Mean & $\begin{array}{l}\text { SD or }(95 \% \mathrm{Cl}) \\
\text { or }[\mathrm{SEM}]\end{array}$ & Mean & $\begin{array}{l}\text { SD or }(95 \% \mathrm{Cl}) \\
\text { or }[\mathrm{SEM}]\end{array}$ \\
\hline & & & & Seated & \\
\hline-2 & - & -0.7 & - & -1 & - \\
\hline-17 & - & -1.2 & - & -5 & - \\
\hline-21 & - & -1.6 & - & -4 & - \\
\hline-28 & - & -2.3 & - & -5 & - \\
\hline-22 & $(-26,-19)$ & -3.2 & $(-3.6,-2.9)$ & -4 & - \\
\hline \multirow{2}{*}{-19} & $(-22,-18)$ & 1.4 & $(I . I, I .8)$ & 1 & - \\
\hline & & & & Seated & \\
\hline-13 & {$[4]$} & 3.0 & {$[0.4]$} & 2 & {$[1]$} \\
\hline-23 & {$[3]$} & 1.4 & {$[0.4]$} & -1 & {$[\mathrm{I}]$} \\
\hline-33 & [3] & 0.7 & {$[0.4]$} & -2 & {$[1]$} \\
\hline Not & & & & Seated & \\
\hline \multicolumn{6}{|c|}{ reported } \\
\hline- & - & 0.8 & - & -1 & $(-4,1)$ \\
\hline- & - & -1.0 & - & -5 & $(-7,-3)$ \\
\hline- & - & -1.0 & - & -4 & $(-6,-2)$ \\
\hline- & - & -1.6 & - & -4 & $(-6,-2)$ \\
\hline 3 & [7] & 0.7 & {$[0.5]$} & - & - \\
\hline-10 & [6] & -1.3 & {$[0.4]$} & - & - \\
\hline \multirow[t]{7}{*}{-9} & [6] & -1.7 & {$[0.4]$} & - & - \\
\hline & & & & Seated SBP & \\
\hline & & & & at week 8 & \\
\hline & & & & in patients & \\
\hline & & & & with seated & \\
\hline & & & & baseline SBP & \\
\hline & & & & $\geq 130 \mathrm{mmHg}$ & \\
\hline 4 & $(-1,8)$ & -0.3 & $(-0.6,0.1)$ & -5 & $(-7,-3)$ \\
\hline-24 & $(-28,-20)$ & -2.1 & $(-2.5,-1.8)$ & -6 & $(-8,-4)$ \\
\hline 5 & $(-2,12)$ & -0.1 & $(-0.5,0.4)$ & -4 & $(-7,-1)$ \\
\hline-22 & $(-29,-15)$ & -1.9 & $(-2.4,-1.5)$ & -7 & $(-10,-4)$ \\
\hline 3 & $(-3,9)$ & -0.5 & $(-1.0,0.1)$ & -6 & $(-8,-3)$ \\
\hline-26 & $(-32,-20)$ & -2.4 & $(-2.9,-1.8)$ & -5 & $(-8,-2)$ \\
\hline 9 & - & -0.5 & - & 0 & {$[\mathrm{I}]$} \\
\hline-27 & & -2.5 & & -3 & {$[1]$} \\
\hline-34 & & -3.4 & & -5 & {$[1]$} \\
\hline-25 & [2] & -3.7 & {$[0.2]$} & -3 & {$[\mathrm{I}]$} \\
\hline-27 & [2] & -4.0 & {$[0.2]$} & -5 & {$[1]$} \\
\hline-18 & [2] & 0.7 & {$[0.2]$} & 0 & {$[1]$} \\
\hline
\end{tabular}


Table S3 (Continued)

\begin{tabular}{|c|c|c|c|c|c|c|}
\hline \multirow[t]{2}{*}{$\begin{array}{l}\text { Reference \& NCT ID (Study } \\
\text { number or acronym) }\end{array}$} & \multirow[t]{2}{*}{ Study details } & \multirow[t]{2}{*}{ Regimen } & \multirow[t]{2}{*}{$\mathbf{N}$} & \multirow[t]{2}{*}{$\begin{array}{l}\text { Treatment and } \\
\text { dose, } \mathrm{mg} / \text { day }\end{array}$} & \multicolumn{2}{|c|}{$\begin{array}{l}\text { Change in } \mathbf{H b A}_{\mathrm{Ic}} \text { from } \\
\text { baseline, } \%\end{array}$} \\
\hline & & & & & Mean & $\begin{array}{l}\text { SD or }(95 \% \mathrm{Cl}) \\
\text { or }[\mathrm{SEM}]\end{array}$ \\
\hline \multirow{6}{*}{$\begin{array}{l}\text { Lavalle-González Diabeto } \\
2013^{16} \text { NCTOI I } 06677 \\
\text { (CANTATA-D) }\end{array}$} & Phase III, 52 week & MET & - & & & \\
\hline & & & & & & \\
\hline & & & & & & \\
\hline & & & 368 & 100 & -0.7 & {$[0.1]$} \\
\hline & & & 367 & 300 & -0.9 & {$[0.1]$} \\
\hline & & & 366 & SITA 100 & -0.7 & {$[0.1]$} \\
\hline \multirow{5}{*}{$\begin{array}{l}\text { Schernthaner Diabetes } \\
\text { Care } 2013^{17} \text { NCTOI I378I2 } \\
\text { (CANTATA-D2) }\end{array}$} & Phase III, 52 week & $\mathrm{MET}+\mathrm{SU}$ & 755 & & & \\
\hline & & & & & & \\
\hline & & & & & & \\
\hline & & & 377 & 300 & -1.0 & - \\
\hline & & & 378 & SITA 100 & -0.7 & - \\
\hline \multirow{9}{*}{$\begin{array}{l}\text { Wilding Int J Clin Pract } 2013^{18} \\
\text { NCT0I I } 06625 \\
\text { (CANTATA-MSU) }\end{array}$} & Phase III, 26 week & $\mathrm{MET}+\mathrm{SU}$ & 469 & & & \\
\hline & (+26 week extension) & & & & & \\
\hline & & & & & & \\
\hline & & 26 week & 156 & Pbo & -0.1 & - \\
\hline & & 26 week & 157 & 100 & -0.9 & - \\
\hline & & 26 week & 156 & 300 & -1.1 & - \\
\hline & & 52 week & 119 & Pbo & 0.0 & - \\
\hline & & 52 week & 127 & 100 & -0.7 & - \\
\hline & & 52 week & 128 & 300 & -1.0 & - \\
\hline \multirow{6}{*}{$\begin{array}{l}\text { Forst Diabetes Obes Metab } \\
2014^{19} \text { NCT0I I } 06690 \\
\text { (CANTATA-MP) }\end{array}$} & Phase III, 26 week & MET + TZD & 342 & & & \\
\hline & ( +26 week extension) & (PIO) & & & & \\
\hline & & & & & & \\
\hline & & & 115 & Pbo & -0.3 & - \\
\hline & & & 113 & 100 & -0.9 & - \\
\hline & & & 114 & 300 & -1.0 & - \\
\hline \multirow{6}{*}{$\begin{array}{l}\text { Matthews Diabetologia } 2012^{20} \\
\text { NCT0I032629 } \\
\text { (CANVAS, INS sub-study) }\end{array}$} & Phase III, Sub-study & INS & $\mathrm{I}, 708$ & & & \\
\hline & efficacy duration & $\geq 20$ units/day & & & & \\
\hline & 18 week & & & & & \\
\hline & & & 565 & Pbo & $\Delta$ vs Pbo & - \\
\hline & & & 566 & 100 & -0.7 & $(-0.7,-0.6)$ \\
\hline & & & 587 & 300 & -0.7 & $(-0.8,-0.7)$ \\
\hline \multirow{11}{*}{$\begin{array}{l}\text { Rosenstock Diabetes } \\
\text { Care } 2012^{21} \text { NCT00642278 }\end{array}$} & Phase II, 12 week & MET & 451 & & & \\
\hline & & & & & & \\
\hline & & & 65 & Pbo & -0.2 & [SEM shown \\
\hline & & & & & & graphically; no \\
\hline & & & & & & data reported] \\
\hline & & & 64 & 50 & -0.8 & - \\
\hline & & & 64 & 100 & -0.8 & - \\
\hline & & & 65 & 200 & -0.7 & - \\
\hline & & & 64 & 300 & -0.9 & - \\
\hline & & & 64 & $300 \mathrm{BD}$ & -1.0 & - \\
\hline & & & 65 & SITA I00 & -0.7 & - \\
\hline \multirow{6}{*}{$\begin{array}{l}\text { Yale Diabetes Obes Metab } 2013^{22} \\
\text { NCT0I0644I4 }\end{array}$} & Phase III, 26 week, & AHAs & 269 & & & \\
\hline & CKD & & & & & \\
\hline & & & 90 & Pbo & -0.0 & Difference \\
\hline & & & & & & vs Pbo \\
\hline & & & 90 & 100 & -0.3 & $(-0.5,-0.1)$ \\
\hline & & & 89 & 300 & -0.4 & $(-0.6,-0.2)$ \\
\hline
\end{tabular}




\begin{tabular}{l} 
Change in FPG from \\
baseline, $\mathrm{mg} / \mathrm{dL}$ \\
\hline Mean SD or $(95 \% \mathrm{Cl})$
\end{tabular}

or [SEM]

Change in body weight

from baseline, $\mathrm{kg}$

Mean SD or $(95 \% \mathrm{Cl})$

or [SEM]

[0.2]

[0.2]

[0.2]

$-3.7$

$-1.2$
$-2.3$

0.1

$-0.8$

$-1.9$

$-2.5$

$-1.0$

$-2.0$

$-3.1$

-27
-33

$\Delta$ vs
Pbo
-23
-29

4

-16
-25
-27
-25
-23
-13

I

$-15$

$-12$
$-0.2$

$-2.6$

$-3.8$

$(-28,-17)$

$(-34,-24)$

[SEM shown graphically; no data reported]

-
-
-
-
-

Difference

vs $\mathrm{Pbo}$

$(-29,-2)$

$(-25,1)$

$\begin{array}{ll}- & -0.2 \\ - & -2.6 \\ - & -3.8\end{array}$

$\Delta$ vs

Pbo

$-1.9 \%$

$-2.4 \%$

$-1.1$

$-2.3$

$-2.6$

$-2.7$

$-3.4$

$-3.4$

$-0.6$

0.2

$-1.2$

$-1.4$
$-$

$-$

$-$

$-$

$-$

$-$

$-$

$-$

$-$

$-$

$-$

$-$

$(-2.2,-1.6)$

$(-2.7,-2.1)$

[SEM shown graphically; no data reported]

-
-
-
-
-
-

Change in SBP from baseline, $\mathrm{mmHg}$

Mean

SD or $(95 \% \mathrm{Cl})$ or [SEM]

$-5$

I

[I]

[I]

[I]

$\begin{array}{ll}-5 & {[1]} \\ -1 & {[I]}\end{array}$
I]

(n)

\section{I]}

]


Table S3 (Continued)

\begin{tabular}{|c|c|c|c|c|c|c|}
\hline \multirow[t]{2}{*}{$\begin{array}{l}\text { Reference \& NCT ID (Study } \\
\text { number or acronym) }\end{array}$} & \multirow[t]{2}{*}{ Study details } & \multirow[t]{2}{*}{ Regimen } & \multirow[t]{2}{*}{$\mathbf{N}$} & \multirow[t]{2}{*}{$\begin{array}{l}\text { Treatment and } \\
\text { dose, } \mathrm{mg} / \mathrm{day}\end{array}$} & \multicolumn{2}{|c|}{$\begin{array}{l}\text { Change in } \mathbf{H b A}_{\mathrm{Ic}} \text { from } \\
\text { baseline, } \%\end{array}$} \\
\hline & & & & & Mean & $\begin{array}{l}\text { SD or }(95 \% \mathrm{Cl}) \\
\text { or }[\mathrm{SEM}]\end{array}$ \\
\hline \multirow{5}{*}{$\begin{array}{l}\text { Bode Hosp Pract } 2013^{23} \\
\text { NCT0I I0665I }\end{array}$} & Phase III, 26 week & AHAs & 714 & & & [SEM shown \\
\hline & Elderly & & & & & $\begin{array}{l}\text { graphically; no } \\
\text { data reported] }\end{array}$ \\
\hline & & & 237 & Pbo & -0.0 & - \\
\hline & & & 241 & 100 & -0.6 & - \\
\hline & & & 236 & 300 & -0.7 & - \\
\hline \multicolumn{7}{|l|}{ Empagliflozin } \\
\hline Roden Lancet Diab Endo $2013^{24}$ & Phase III, 24 week & Drug naïve & 899 & & & \\
\hline \multicolumn{7}{|l|}{ NCT0II778I3 (I245.20) } \\
\hline & & & 228 & Pbo & 0.1 & $(-0.0,0.2)$ \\
\hline & & & 224 & 10 & -0.7 & $(-0.8,-0.6)$ \\
\hline & & & 224 & 25 & -0.8 & $(-0.9,-0.7)$ \\
\hline & & & 223 & SITA 100 & -0.7 & $(-0.8,-0.6)$ \\
\hline Häring Diabetes $2013^{25}$ & Phase III, 24 week & MET & 637 & & & \\
\hline \multicolumn{7}{|l|}{ NCT0II 59600 (I245.23) } \\
\hline & & & 207 & Pbo & -0.1 & {$[0.1]$} \\
\hline & & & 217 & 10 & -0.7 & {$[0.1]$} \\
\hline & & & 213 & 25 & -0.8 & {$[0.1]$} \\
\hline Ferrannini Diabetes Care $2013^{26}$ & Phase Ilb, 78 week & Monotherapy or & & & & \\
\hline \multirow[t]{9}{*}{ NCT0088I530 (I245.24) } & & MET monotherapy & & & & \\
\hline & & or MET + SITA & & & & \\
\hline & & & 80 & 10 & -0.3 & $(-0.5,-0.1)$ \\
\hline & & & 88 & 25 & -0.5 & $(-0.7,-0.3)$ \\
\hline & & & 56 & MET & -0.6 & $(-0.8,-0.3)$ \\
\hline & & & 137 & $10+$ MET & -0.3 & $(-0.5,-0.2)$ \\
\hline & & & 139 & $25+$ MET & -0.6 & $(-0.8,-0.5)$ \\
\hline & & & 56 & SITA & -0.4 & $(-0.6,-0.2)$ \\
\hline & & & & $100+$ MET & & \\
\hline Häring Diabetes Care $2013^{27}$ & Phase III, 24 week & $\mathrm{MET}+\mathrm{SU}$ & 666 & & & \\
\hline \multirow{4}{*}{ NCTOII 59600 (I 245.23) } & & & & & & \\
\hline & & & 225 & Pbo & -0.2 & {$[0.1]$} \\
\hline & & & 225 & 10 & -0.8 & {$[0.1]$} \\
\hline & & & 216 & 25 & -0.8 & {$[0.1]$} \\
\hline \multirow{6}{*}{$\begin{array}{l}\text { Kovacs Diabetes Obes } \\
\text { Metab 201328 } \\
\text { NCT0I } 210001 \text { (1245.19) }\end{array}$} & Phase III, 24 week & TZD (PIO) & 498 & & & \\
\hline & & \pm MET & & & & \\
\hline & & & & & & \\
\hline & & & 165 & Pbo & -0.1 & {$[0.1]$} \\
\hline & & & 165 & 10 & -0.6 & {$[0.1]$} \\
\hline & & & 168 & 25 & -0.7 & {$[0.1]$} \\
\hline Rosenstock Diabetes $2013^{29}$ & Phase Ilb, & INS & 494 & & & \\
\hline \multirow[t]{4}{*}{ NCTOI0II868 (I245.33) } & 78 week & $\begin{array}{l}\text { (dose not } \\
\text { stated) }\end{array}$ & & & & \\
\hline & & & 170 & Pbo & 0.0 & {$[0.1]$} \\
\hline & & & 169 & 10 & -0.5 & {$[0.1]$} \\
\hline & & & 155 & 25 & -0.6 & {$[0.1]$} \\
\hline \multirow{7}{*}{$\begin{array}{l}\text { Ferrannini Diabetes Obes Metab } \\
2013^{30} \text { NCT00789035 (I245.9) }\end{array}$} & Phase Ilb, & Drug naïve or & 406 & & & \\
\hline & 12 week & 4-week washout & & & & \\
\hline & & & 82 & Pbo & 0.1 & $(-0.09,0.27)$ \\
\hline & & & 81 & 5 & -0.4 & $(-0.6 \mathrm{I},-0.25)$ \\
\hline & & & 81 & 10 & -0.5 & $(-0.66,-0.30)$ \\
\hline & & & 82 & 25 & -0.6 & $(-0.8 \mathrm{I},-0.45)$ \\
\hline & & & 80 & MET(O/L) & -0.7 & $(-0.92,-0.57)$ \\
\hline
\end{tabular}




\begin{tabular}{|c|c|c|c|c|c|}
\hline \multicolumn{2}{|c|}{$\begin{array}{l}\text { Change in FPG from } \\
\text { baseline, } \mathrm{mg} / \mathrm{dL}\end{array}$} & \multicolumn{2}{|c|}{$\begin{array}{l}\text { Change in body weight } \\
\text { from baseline, } \mathrm{kg}\end{array}$} & \multicolumn{2}{|c|}{ Change in SBP from baseline, $\mathrm{mmHg}$} \\
\hline \multirow[t]{2}{*}{ Mean } & $\begin{array}{l}\text { SD or }(95 \% \mathrm{Cl}) \\
\text { or }[\mathrm{SEM}]\end{array}$ & Mean & $\begin{array}{l}\text { SD or }(95 \% \mathrm{Cl}) \\
\text { or }[\mathrm{SEM}]\end{array}$ & Mean & $\begin{array}{l}\text { SD or }(95 \% \mathrm{Cl}) \\
\text { or [SEM] }\end{array}$ \\
\hline & $\begin{array}{l}\text { [SEM shown graphically; } \\
\text { no data reported] }\end{array}$ & & $\begin{array}{l}\text { [SEM shown graphically; } \\
\text { no data reported] }\end{array}$ & & \\
\hline 7 & - & -0.1 & - & 1 & {$[1]$} \\
\hline-18 & - & -2.2 & - & -4 & {$[1]$} \\
\hline-20 & - & -2.8 & - & -7 & {$[I]$} \\
\hline 12 & $(8,16)$ & -0.3 & $(-0.7,0.0)$ & 0 & $(-2,1)$ \\
\hline-20 & $(-23,-16)$ & -2.3 & $(-2.6,-1.9)$ & -3 & $(-5,-1)$ \\
\hline-25 & $(-28,-2 I)$ & -2.5 & $(-2.8,-2.1)$ & -4 & $(-5,-2)$ \\
\hline-7 & $(-11,-3)$ & 0.2 & $(-0.2,0.5)$ & 1 & $(-1,2)$ \\
\hline 6 & [2] & -0.5 & {$[0.2]$} & 0 & {$[1]$} \\
\hline-20 & [2] & -2.1 & {$[0.2]$} & -5 & {$[\mathrm{I}]$} \\
\hline-22 & [2] & -2.5 & {$[0.2]$} & -5 & {$[1]$} \\
\hline-30 & $(-37,-24)$ & -2.2 & $(-3.1,-1.4)$ & 0 & $(-3,3)$ \\
\hline-28 & $(-34,-2 I)$ & -2.6 & $(-3.5,-1.8)$ & -2 & $(-5,2)$ \\
\hline-26 & $(-34,-18)$ & -1.3 & $(-2.3,-0.3)$ & 2 & $(-2,6)$ \\
\hline-21 & $(-26,-16)$ & -3.1 & $(-3.9,-2.4)$ & -3 & $(-6,-1)$ \\
\hline-32 & $(-37,-27)$ & -4.0 & $(-4.8,-3.3)$ & -3 & $(-5,-1)$ \\
\hline-16 & $(-24,-8)$ & -0.4 & $(-1.5,0.7)$ & 2 & $(-2,5)$ \\
\hline 6 & [2] & -0.4 & {$[0.2]$} & -1 & {$[\mathrm{I}]$} \\
\hline-23 & [2] & -2.2 & {$[0.2]$} & -4 & {$[1]$} \\
\hline-23 & [2] & -2.4 & {$[0.2]$} & -4 & {$[1]$} \\
\hline 6 & [3] & 0.3 & {$[0.2]$} & 1 & {$[\mathrm{I}]$} \\
\hline-17 & [3] & -1.6 & {$[0.2]$} & -3 & {$[\mathrm{I}]$} \\
\hline-22 & [3] & -1.5 & {$[0.2]$} & -4 & {$[1]$} \\
\hline 3 & [3] & 0.7 & {$[0.5]$} & 0 & {$[\mathrm{I}]$} \\
\hline-10 & [3] & -2.2 & {$[0.5]$} & -4 & {$[\mathrm{I}]$} \\
\hline-15 & [3] & -2.0 & {$[0.5]$} & -2 & {$[\mathrm{I}]$} \\
\hline & & & & Not re & \\
\hline I & $(-6,-8)$ & -0.8 & $(-1.3,-0.2)$ & - & - \\
\hline-23 & $(-30,-16)$ & -1.8 & $(-2.3,-1.3)$ & - & - \\
\hline-29 & $(-36,-22)$ & -2.3 & $(-2.8,-1.8)$ & - & - \\
\hline-31 & $(-38,-24)$ & -2.0 & $(-2.5,-1.5)$ & - & - \\
\hline-30 & $(-38,-22)$ & -1.3 & $(-1.8,-0.8)$ & - & - \\
\hline
\end{tabular}


Table S3 (Continued)

\begin{tabular}{|c|c|c|c|c|c|c|}
\hline \multirow[t]{2}{*}{$\begin{array}{l}\text { Reference \& NCT ID (Study } \\
\text { number or acronym) }\end{array}$} & \multirow[t]{2}{*}{ Study details } & \multirow[t]{2}{*}{ Regimen } & \multirow[t]{2}{*}{$\mathbf{N}$} & \multirow[t]{2}{*}{$\begin{array}{l}\text { Treatment and } \\
\text { dose, } \mathrm{mg} / \mathrm{day}\end{array}$} & \multicolumn{2}{|c|}{$\begin{array}{l}\text { Change in } \mathbf{H b A}_{\mathrm{Ic}} \text { from } \\
\text { baseline, } \%\end{array}$} \\
\hline & & & & & Mean & $\begin{array}{l}\text { SD or }(95 \% \mathrm{Cl}) \\
\text { or }[\mathrm{SEM}]\end{array}$ \\
\hline \multirow[t]{8}{*}{$\begin{array}{l}\text { Rosenstock Diabetes Obes Metab } \\
2013^{31} \text { NCT00749I90 (I245.I0) }\end{array}$} & $\begin{array}{l}\text { Phase Ilb, } \\
12 \text { week }\end{array}$ & MET & 495 & & & \\
\hline & & & 71 & Pbo & 0.2 & $(0.0,0.3)$ \\
\hline & & & 71 & I & -0.1 & $(-0.2,0.1)$ \\
\hline & & & 71 & 5 & -0.2 & $(-0.4,-0.1)$ \\
\hline & & & 71 & 10 & -0.6 & $(-0.7,-0.4)$ \\
\hline & & & 70 & 25 & -0.6 & $(-0.7,-0.4)$ \\
\hline & & & 70 & 50 & -0.5 & $(-0.6,-0.3)$ \\
\hline & & & 71 & SITA I00 (O/L) & -0.5 & $(-0.7,-0.3)$ \\
\hline \multirow{11}{*}{$\begin{array}{l}\text { Barnett Lancet Diab Endo } \\
2014^{32} \text { NCTOI I6450 I } \\
(\text { I } 245.36)\end{array}$} & Phase III, & AHAs & & (Efficacy data & & \\
\hline & $\begin{array}{l}52 \text { week, } \\
\text { CKD }\end{array}$ & & & $\begin{array}{l}\text { reported at } \\
\text { week 24) }\end{array}$ & & \\
\hline & & Stage 2 & 95 & Pbo & 0.1 & $(-0.1,0.2)$ \\
\hline & & CKD & & & & \\
\hline & & & 98 & 10 & -0.5 & $(-0.6,-0.3)$ \\
\hline & & & 97 & 25 & -0.6 & $(-0.8,-0.5)$ \\
\hline & & Stage 3 & 187 & Pbo & 0.1 & $(-0.5,0.2)$ \\
\hline & & CKD & & & & \\
\hline & & & 187 & 25 & -0.4 & $(-0.5,-0.3)$ \\
\hline & & Stage 4 CKD & 37 & Pbo & -0.2 & 0.8 \\
\hline & & & 37 & 25 & 0.0 & 1.6 \\
\hline
\end{tabular}

Notes: a Data are presented as published (from randomized double-blind arms of each trial unless otherwise stated).

Abbreviations: AHA, anti-hyperglycemic agent; AM, ante meridiem (in the morning); BD, bis in die (twice per day); BMI, body mass index; CANTATA, canagliflozin treatment and trial analysis; CANTATA-D2, dipeptidyl peptidase 4 inhibitor second comparator; CANTATA-M, metformin; CANTATA-MSU, metformin + sulfonylurea; CANTATA-SU, sulfonylurea; CANVAS, canagliflozin cardiovascular assessment study; Cl, confidence interval; CKD, chronic kidney disease; DAPA, dapagliflozin; DPP4, dipeptidyl peptidase 4; FPG, fasting plasma glucose; GLIM, glimepiride; GLIP, glipizide; $\mathrm{HbA}_{\mathrm{Ic}}$ (or $\mathrm{A}_{\mathrm{Ic}}$ ), glycated hemoglobin; INS, insulin; MET, metformin; NCT ID, National Clinical Trials (US) identification (number); OAD, oral anti-diabetes drug; O/L, open label; Pbo, placebo; PIO, pioglitazone; PM, post meridiem (in the afternoon); SBP, systolic blood pressure; SD, standard deviation; SEM, standard error of the mean; SGLT2, sodium glucose co-transporter type 2; SITA, sitagliptin; SU, sulfonylurea; TZD, thiazolidinedione; $\mathrm{XR}$, extended release formulation; vs, versus. 


\begin{tabular}{|c|c|c|c|c|c|}
\hline \multicolumn{2}{|c|}{$\begin{array}{l}\text { Change in FPG from } \\
\text { baseline, } \mathrm{mg} / \mathrm{dL}\end{array}$} & \multicolumn{2}{|c|}{$\begin{array}{l}\text { Change in body weight } \\
\text { from baseline, kg }\end{array}$} & \multicolumn{2}{|c|}{ Change in SBP from baseline, $\mathrm{mmHg}$} \\
\hline Mean & $\begin{array}{l}\text { SD or }(95 \% \mathrm{Cl}) \\
\text { or }[\mathrm{SEM}]\end{array}$ & Mean & $\begin{array}{l}\text { SD or }(95 \% \mathrm{Cl}) \\
\text { or }[\mathrm{SEM}]\end{array}$ & Mean & $\begin{array}{l}\text { SD or }(95 \% \mathrm{Cl}) \\
\text { or }[\mathrm{SEM}]\end{array}$ \\
\hline 5 & $(-2,12)$ & -1.2 & $(-1.8,-0.5)$ & -2 & 15 \\
\hline-2 & $(-9,5)$ & -1.6 & $(-2.2,-0.9)$ & -2 & 12 \\
\hline-16 & $(-23,-9)$ & -2.3 & $(-2.9,-1.7)$ & -3 & 15 \\
\hline-22 & $(-29,-16)$ & -2.7 & $(-3.4,-2.1)$ & -4 & 13 \\
\hline-27 & $(-34,-20)$ & -2.6 & $(-3.2,-2.0)$ & -9 & 13 \\
\hline-28 & $(-35,-21)$ & -2.9 & $(-3.5,-2.2)$ & -3 & 15 \\
\hline-13 & $(-22,-3)$ & -0.8 & $(-1.5,-0.2)$ & -2 & 12 \\
\hline 6 & $(-1,12)$ & -0.33 & $(-0.80,0.14)$ & 1 & $(-2,3)$ \\
\hline-14 & $(-21,-7)$ & -1.76 & $(-2.2 \mathrm{I},-1.3 \mathrm{I})$ & -3 & $(-5,1)$ \\
\hline-18 & $(-25,-11)$ & -2.33 & $(-2.78,-1.88)$ & -5 & $(-7,-2)$ \\
\hline II & $(4,18)$ & -0.08 & $(-0.43,0.27)$ & 0 & $(-1,2)$ \\
\hline-9 & $(-16,-2)$ & -0.98 & $(-1.33,-0.63)$ & -4 & $(-6,-2)$ \\
\hline II & II & -0.1 & 1.9 & 1 & 16 \\
\hline 4 & 108 & -1.4 & 5.0 & -7 & 17 \\
\hline
\end{tabular}


Table S4 Safety data from pivotal clinical trials of SGLT2 inhibitors ${ }^{\mathbf{a}}$

\begin{tabular}{llllllll}
\hline $\begin{array}{l}\text { Reference \& NCT ID (Study } \\
\text { number or acronym) }\end{array}$ & $\begin{array}{l}\text { Study } \\
\text { detail }\end{array}$ & Regimen & N & $\begin{array}{l}\text { Treatment and } \\
\text { dose, mg/day }\end{array}$ & $\begin{array}{l}\text { Adverse } \\
\text { events }\end{array}$ & $\begin{array}{l}\text { Serious adverse } \\
\text { events }\end{array}$ & $\begin{array}{l}\text { Total } \\
\text { Total }\end{array}$
\end{tabular}

\section{Dapagliflozin}

List Diabetes Care 2009' NCT00263276 (MBI02008)

Wilding Diabetes Care $2009^{2}$ NCT00357370 (MBI02009)

Ferrannini Diabetes Care $2010^{3}$ NCT00528372 (MBI020I3)

Bailey Diabetes Obes Metab 2012 ${ }^{4}$ Phase III, NCT00736879 (MBI02032)

Bailey Lancet $2010^{5}$ NCT00528879 (MBI020 I4)

Bolinder J Clin Endocrinol Metab $2012^{6}$ NCT00855166

(DI690C00012)
Phase II Drug naïve,

12 week diet/exercise

Phase III, Drug naïe,

24 week diet/exercise

12 week
Drug naïve,

diet/exercise

MET

Phase III, 24 week

Phase III, 24 week, $\mathrm{BMI} \geq 25$

389

\section{$\mathrm{Pbo}$}

2.5

10

20

50

MET XR

$\begin{array}{llll}29 & 54 & 0 & 0 \\ 35 & 59 & 1 & 2 \\ 35 & 60 & 0 & 0 \\ 32 & 68 & 1 & 2 \\ 40 & 68 & 1 & 2 \\ 35 & 63 & 1 & 2 \\ 38 & 68 & 1 & 2\end{array}$

65

64

70

67

68

76

34

39

282

$68 \quad \mathrm{~Pb}$

$72 \quad$ ।

$\begin{array}{ll}74 & 2.5\end{array}$

$68 \quad 5$

546

2.5
5

5

Pbo 45

$2.5 \mathrm{AM}$

5 AM

10 AM

$2.5 \mathrm{PM}$

5 PM

10 PM

$5\left(A_{1 \mathrm{c}} \geq 10.1\right)$

$10\left(A_{l c} \geq 10.1\right)$

\section{Pbo}

45

45

44

45

27

28 $\begin{array}{llll}45 & 60.0 & 3 & 4.0\end{array}$

$41 \quad 63.1 \quad 0 \quad 0$

$\begin{array}{llll}37 & 57.8 & \text { I } & 1.6\end{array}$

48

$68.6 \quad 1 \quad 1.4$

$67.2 \quad$ I $\quad 1.5$

64.7 । I.5

$59.2 \quad$ I $\quad$ I.3

$\begin{array}{lll}79.4 & 0 & 0\end{array}$

$\begin{array}{lll}71.8 & 0 & 0\end{array}$

$\begin{array}{ll}137 & \text { Pbo } \\ 137 & 2.5 \\ 137 & 5 \\ 135 & 10\end{array}$

182
$41 \quad 60.3 \quad 0 \quad 0$

$\begin{array}{llll}42 & 58.3 & 2 & 2.8\end{array}$

$\begin{array}{llll}43 & 58.1 & 2 & 2.7\end{array}$

$39 \quad 57.4 \quad 0 \quad 0$
4.3

(1)

4.2 
Number of patients with an adverse event of special interest

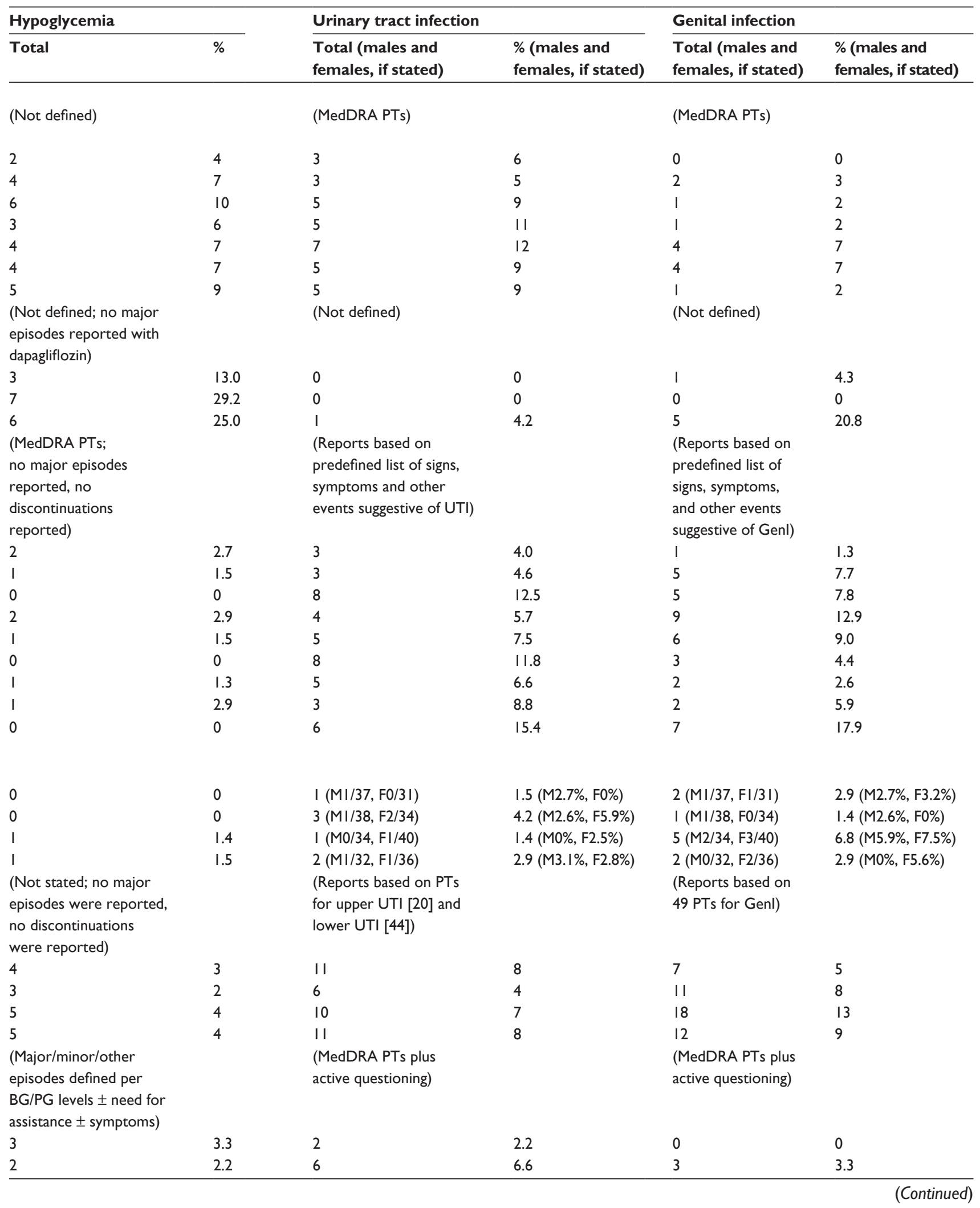


Table S4 (Continued)

\begin{tabular}{llllllll}
\hline $\begin{array}{l}\text { Reference \& NCT ID (Study } \\
\text { number or acronym) }\end{array}$ & $\begin{array}{l}\text { Study } \\
\text { detail }\end{array}$ & Regimen & N & $\begin{array}{l}\text { Treatment and } \\
\text { dose, mg/day }\end{array}$ & $\begin{array}{l}\text { Adverse } \\
\text { events }\end{array}$ & $\begin{array}{l}\text { Serious adverse } \\
\text { events }\end{array}$ \\
\cline { 3 - 7 } & & & Total & $\%$ & Total $\%$
\end{tabular}

\begin{tabular}{ll}
\hline Henry Int J Clin Pract 20I27 & Phase III, MET XR \\
& 24 week \\
& (both)
\end{tabular}

NCT0064385I (MBI0202I)

NCT00859898 (MBI02034)

Strojek Diabetes Obes Metab $201 I^{8}$ NCT00680745

(DI690C00005)

Nauck Diabetes Care 201 I9 NCT00660907 (DI690C00004)

Rosenstock Diabetes Care 2012 10 NCT00683878 (MBI02030)

Wilding Ann Intern Med 2012" NCT0067323I (DI690C00006)

\section{Phase III,}

SU (GLIM)

24 week

Phase III, MET

52 week

Phase III,

48 week

Phase III,

48 week

INS

$\geq 30$ units/day

\pm OADs

$\begin{array}{ll}145 & \text { Pbo } \\ 154 & 2.5 \\ 142 & 5 \\ 151 & 10\end{array}$

406

DAPA $2.5-10$

318

$78.3 \quad 35$

8.6

408

GLIP 5-20

318

$77.9 \quad 46$

II.3

420

$\begin{array}{ll}139 & \text { Pbo } \\ 141 & 5 \\ 140 & 10 \\ 800 & \end{array}$

$\begin{array}{llll}93 & 66.9 & 4 & 2.9 \\ 96 & 68.1 & 6 & 4.3 \\ 99 & 70.7 & 2 & 1.4\end{array}$

$\begin{array}{llllll}193 & \text { Pbo } & 144 & 73.1 & 26 & 13.2 \\ 202 & 2.5 & 153 & 75.7 & 27 & 13.4 \\ 211 & 5 & 153 & 72.2 & 19 & 9.0 \\ 194 & 10 & 145 & 74.0 & 23 & 11.7\end{array}$


Number of patients with an adverse event of special interest

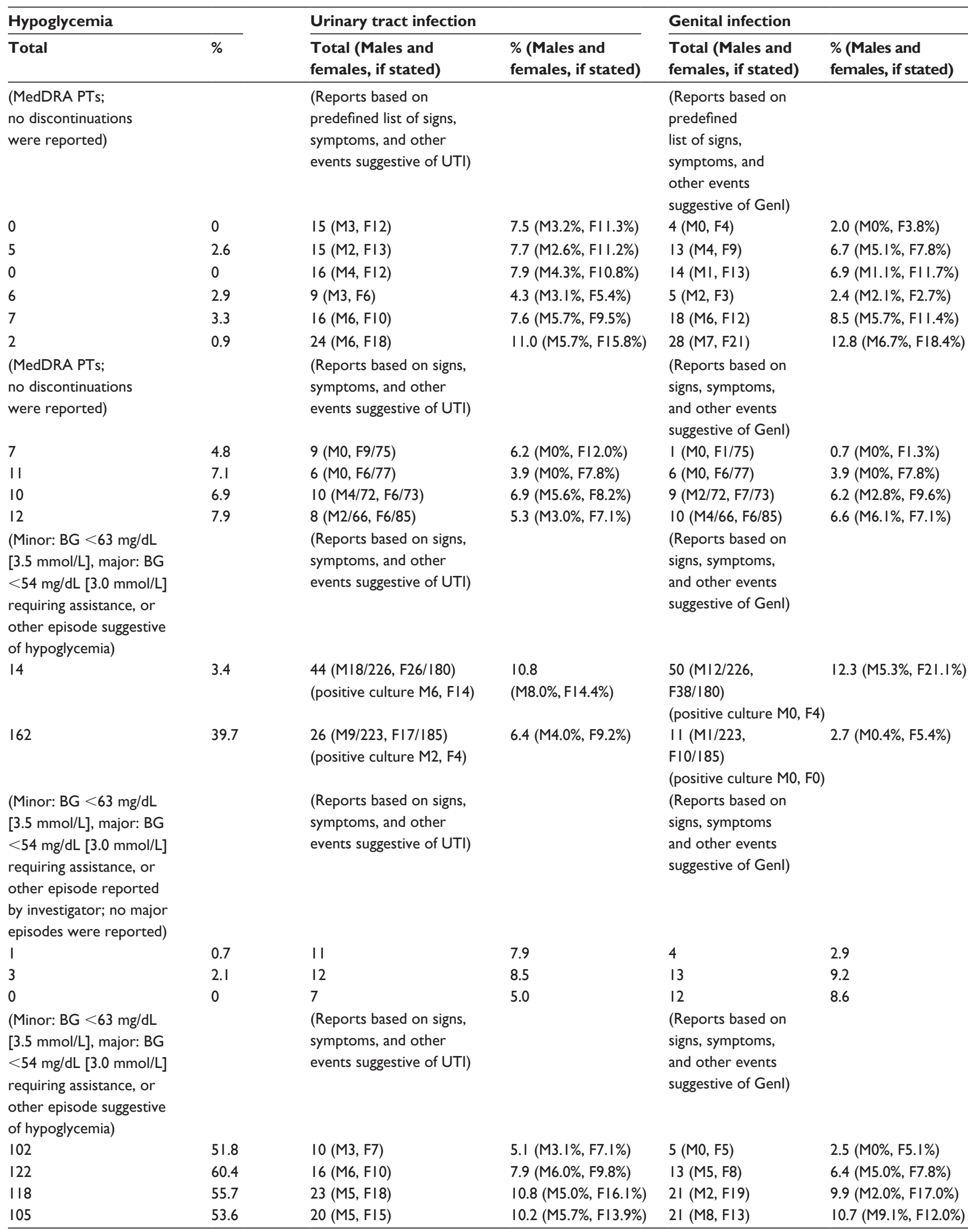

(Continued) 
Table S4 (Continued)

\begin{tabular}{lll}
\hline $\begin{array}{l}\text { Reference \& NCT ID (Study } \\
\text { number or acronym) }\end{array}$ & $\begin{array}{l}\text { Study } \\
\text { detail }\end{array}$ & Regimen \\
& & \\
\hline Kohan Kidney Int 2013'2 & Phase III, & AHAs including \\
NCT00663260 (MBI02029) & I04 week & INS \\
& $\begin{array}{l}\text { Renal } \\
\text { impairment }\end{array}$ & \\
& &
\end{tabular}

Jabbour Diabetes Care $2013^{13}$ NCT00984867 (DI690C000I0)

\section{Canagliflozin}

Stenlöf Diabetes Obes Metab $2013{ }^{14}$ NCTOI08I834

(CANTATA-M)
Phase III, 24 week

DDP4 inhibitor $(\mathrm{SITA}) \pm \mathrm{MET}$

24 week

24 week

Phase III, 26 week

Drug naïve, diet/exercise
$\mathbf{N}$ Treatment and
dose, $\mathrm{mg} /$ day

\begin{tabular}{ll}
$\begin{array}{l}\text { Adverse } \\
\text { events }\end{array}$ & $\begin{array}{l}\text { Serious adverse } \\
\text { events }\end{array}$ \\
\hline Total $\%$ & Total $\%$
\end{tabular}

$\begin{array}{llllll}84 & \text { Pbo } & 77 & 91.7 & 26 & 31.0 \\ 83 & 5 & 80 & 96.4 & 16 & 19.3 \\ 85 & 10 & 77 & 90.6 & 11 & 2.9\end{array}$

Cefalu Lancet 2013 $3^{15}$ NCT009688I 2 (CANTATA-SU)
Phase III, MET

52 week

$\begin{array}{ll}192 & \text { Pbo } \\ 195 & 100 \\ 197 & 300 \\ 1,450 & \end{array}$

483

485

482

1,284

\section{Pbo \\ DAPA}

584
Lavalle-González

Diabetologia $2013^{16}$

NCTOII 06677

(CANTATA-D)
Phase III, MET

52 week
Phase III,

52 week
Schernthaner Diabetes

Care $2013^{17}$

NCTOII378I 2

(CANTATA-D2)

\begin{tabular}{llllll}
377 & 300 & 289 & 76.7 & 24 & 6.4 \\
378 & SITA I00 & 293 & 77.5 & 21 & 5.6 \\
\hline
\end{tabular}


Number of patients with an adverse event of special interest

\begin{tabular}{|c|c|c|c|c|c|}
\hline \multicolumn{2}{|c|}{ Hypoglycemia } & \multicolumn{2}{|c|}{ Urinary tract infection } & \multicolumn{2}{|l|}{ Genital infection } \\
\hline Total & $\%$ & $\begin{array}{l}\text { Total (Males and } \\
\text { females, if stated) }\end{array}$ & $\begin{array}{l}\% \text { (Males and } \\
\text { females, if stated) }\end{array}$ & $\begin{array}{l}\text { Total (Males and } \\
\text { females, if stated) }\end{array}$ & $\begin{array}{l}\% \text { (Males and } \\
\text { females, if stated) }\end{array}$ \\
\hline
\end{tabular}

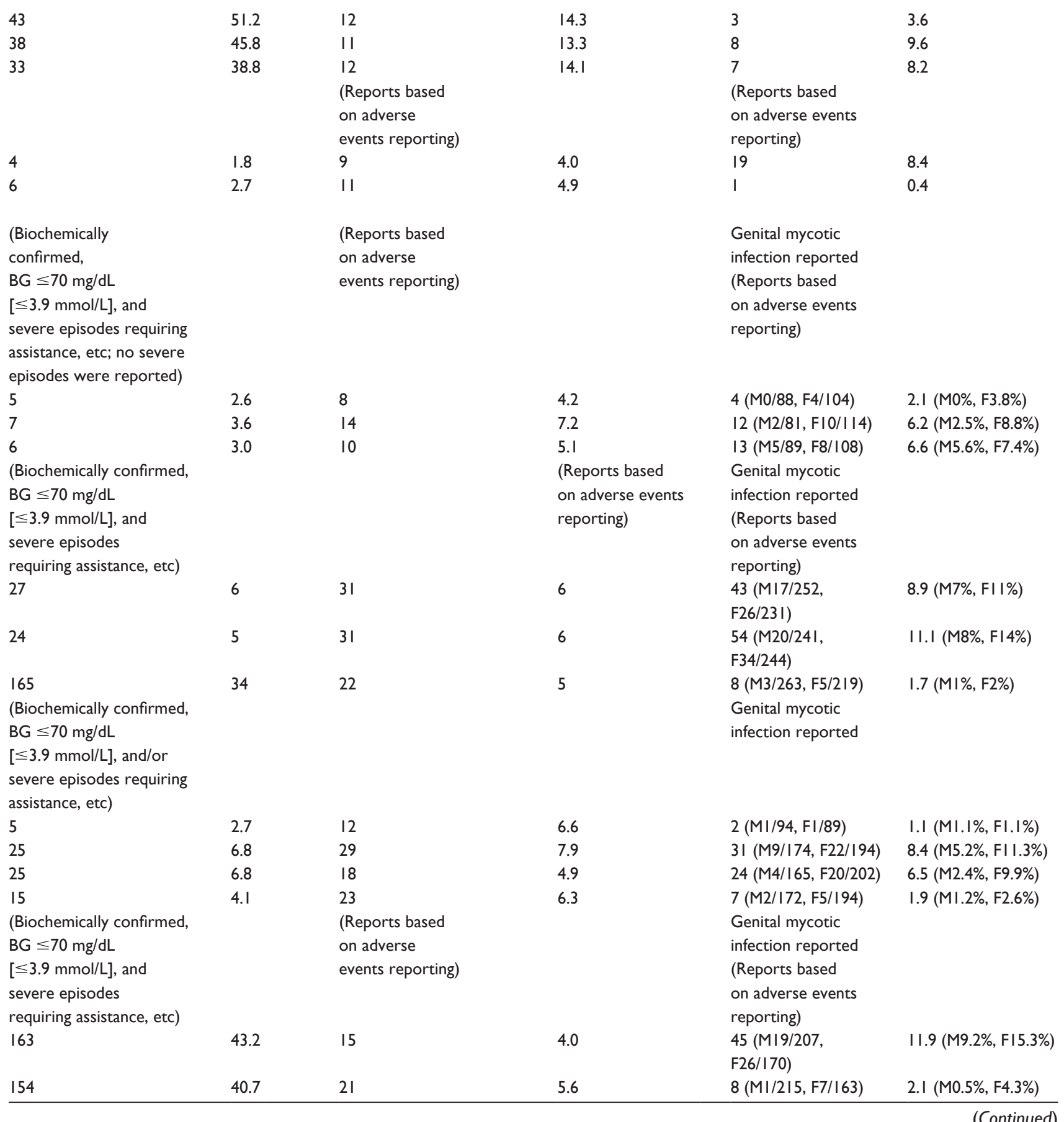


Table S4 (Continued)

\begin{tabular}{|c|c|c|c|c|c|c|c|c|}
\hline \multirow[t]{2}{*}{$\begin{array}{l}\text { Reference \& NCT ID (Study } \\
\text { number or acronym) }\end{array}$} & \multirow[t]{2}{*}{$\begin{array}{l}\text { Study } \\
\text { detail }\end{array}$} & \multirow[t]{2}{*}{ Regimen } & \multirow[t]{2}{*}{$\mathbf{N}$} & \multirow[t]{2}{*}{$\begin{array}{l}\text { Treatment and } \\
\text { dose, } \mathrm{mg} / \mathrm{day}\end{array}$} & \multicolumn{2}{|c|}{$\begin{array}{l}\text { Adverse } \\
\text { events }\end{array}$} & \multicolumn{2}{|c|}{$\begin{array}{l}\text { Serious adverse } \\
\text { events }\end{array}$} \\
\hline & & & & & Total & $\%$ & Total & $\%$ \\
\hline \multirow[t]{4}{*}{$\begin{array}{l}\text { Wilding Int J Clin Pract 20I } \\
\text { NCT0I I } 06625 \\
\text { (CANTATA-MSU) }\end{array}$} & $\begin{array}{l}\text { Phase III, } \\
26 \text { week } \\
\text { (+26 week } \\
\text { extension) }\end{array}$ & $\mathrm{MET}+\mathrm{SU}$ & 469 & & & & & \\
\hline & & 52 week & 156 & Pbo & 111 & 71.2 & 13 & 8.3 \\
\hline & & 52 week & 157 & 100 & 106 & 67.5 & 7 & 4.5 \\
\hline & & 52 week & 156 & 300 & 114 & 73.1 & 8 & 5.1 \\
\hline Forst Diabetes Obes Metab $2014^{19}$ & Phase III, & MET + TZD (PIO) & 342 & \multicolumn{2}{|l|}{ (Safety data reported } & & & \\
\hline \multirow[t]{4}{*}{ NCTOII 06690 (CANTATA-MP) } & $\begin{array}{l}26 \text { week } \\
(+26 \text { week } \\
\text { extension) }\end{array}$ & $\begin{array}{l}\text { (Pbo group switched } \\
\text { to SITA during } \\
26 \text { week extension) }\end{array}$ & & at week 52) & & & & \\
\hline & & & 115 & $\mathrm{Pbo} / \mathrm{SITA}$ & 88 & 76.5 & 6 & 5.2 \\
\hline & & & 113 & 100 & 79 & 69.9 & 8 & 7.1 \\
\hline & & & 114 & 300 & 87 & 76.3 & 7 & 6.1 \\
\hline \multirow{5}{*}{$\begin{array}{l}\text { Matthews Diabetologia }{ }^{20} \\
\text { NCT0I032629 (CANVAS, } \\
\text { INS sub-study) }\end{array}$} & Phase III, & INS & ।,708 & & & & & \\
\hline & $\begin{array}{l}\text { Sub-study } \\
\text { efficacy } \\
\text { duration } \\
\text { 18 week }\end{array}$ & $\geq 20$ units/day & & & & & & \\
\hline & & & 565 & Pbo & - & 59 & - & 6.4 \\
\hline & & & 566 & 100 & - & 63 & - & 5.5 \\
\hline & & & 587 & 300 & - & 65 & - & 4.9 \\
\hline \multirow{10}{*}{$\begin{array}{l}\text { Rosenstock Diabetes } \\
\text { Care } 2012^{21} \\
\text { NCT00642278 }\end{array}$} & Phase II, & MET & 451 & & & & & \\
\hline & 12 week & & & & & & & \\
\hline & & & & & & & & \\
\hline & & & 65 & Pbo & 26 & 40 & I & 2 \\
\hline & & & 64 & 50 & 32 & 50 & I & 2 \\
\hline & & & 64 & 100 & 30 & 47 & I & 2 \\
\hline & & & 65 & 200 & 26 & 40 & I & 2 \\
\hline & & & 64 & 300 & 26 & 41 & I & 2 \\
\hline & & & 64 & $300 \mathrm{BD}$ & 36 & 56 & I & 2 \\
\hline & & & 65 & SITA 100 & 23 & 35 & 0 & 0 \\
\hline \multirow{5}{*}{$\begin{array}{l}\text { Yale Diabetes Obes Metab } 2013^{22} \\
\text { NCT010644I4 }\end{array}$} & Phase III, & AHAs & 269 & & & & & \\
\hline & $\begin{array}{l}26 \text { week, } \\
\text { CKD }\end{array}$ & & & & & & & \\
\hline & & & 90 & Pbo & 67 & 74.4 & 16 & 17.8 \\
\hline & & & 90 & 100 & 71 & 78.9 & 10 & II.I \\
\hline & & & 89 & 300 & 66 & 74.2 & 10 & 11.2 \\
\hline \multirow{6}{*}{$\begin{array}{l}\text { Bode Hosp Pract } 2013^{23} \\
\text { NCT0II } 06651\end{array}$} & Phase III, & AHAs & 714 & & & & & \\
\hline & 26 week & & & & & & & \\
\hline & Elderly & & & & & & & \\
\hline & & & 237 & Pbo & 174 & 73.4 & 12 & 5.1 \\
\hline & & & 241 & 100 & 174 & 71.8 & 10 & 4.1 \\
\hline & & & 236 & 300 & 184 & 78.0 & 8 & 3.4 \\
\hline
\end{tabular}


Number of patients with an adverse event of special interest

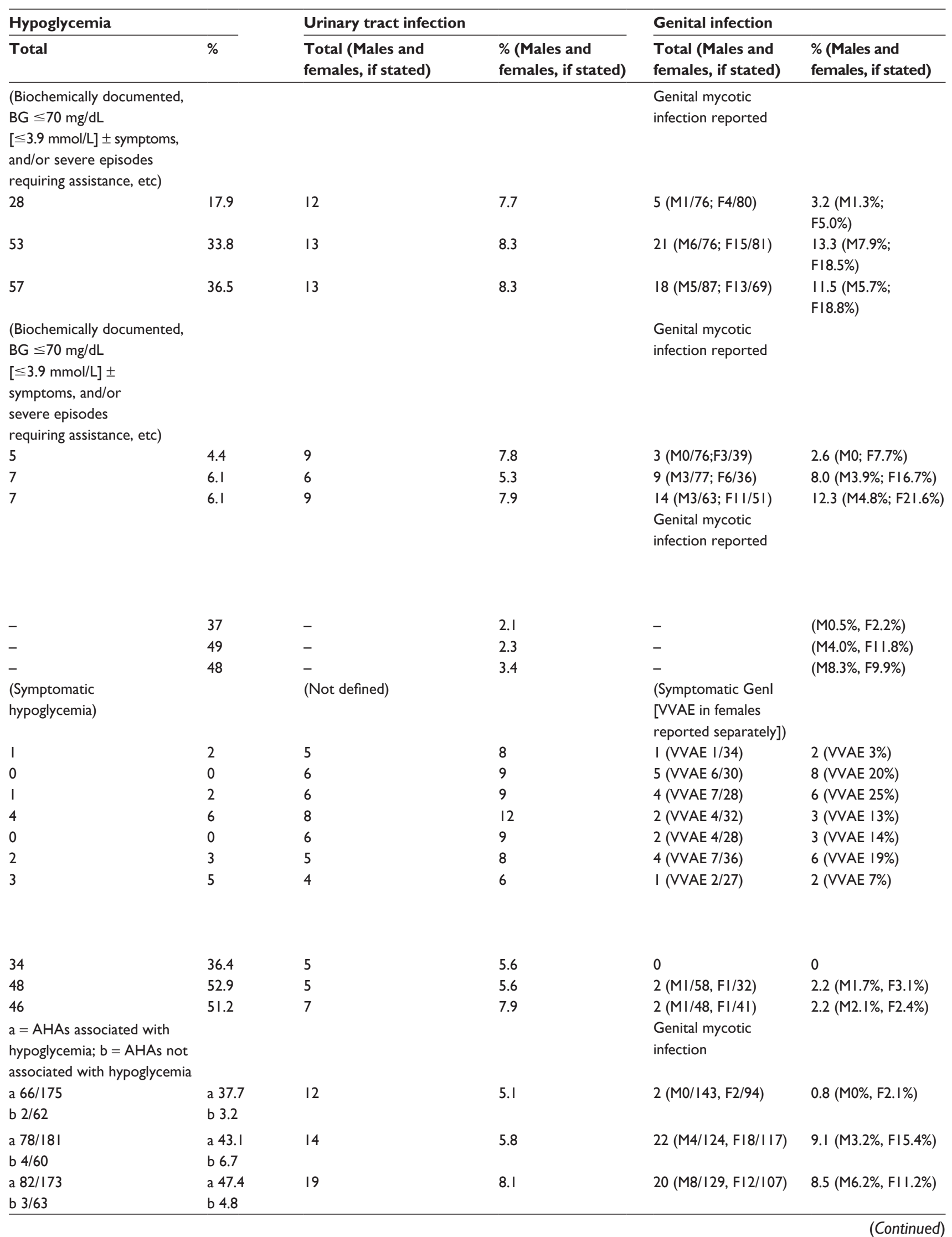


Table S4 (Continued)

\begin{tabular}{llllllll}
\hline $\begin{array}{l}\text { Reference \& NCT ID (Study } \\
\text { number or acronym) }\end{array}$ & $\begin{array}{l}\text { Study } \\
\text { detail }\end{array}$ & Regimen & N & $\begin{array}{l}\text { Treatment and } \\
\text { dose, mg/day }\end{array}$ & $\begin{array}{l}\text { Adverse } \\
\text { events }\end{array}$ & $\begin{array}{l}\text { Serious adverse } \\
\text { events }\end{array}$ \\
\cline { 3 - 6 } & & & Total & $\%$ & Total & $\%$
\end{tabular}

\section{Empagliflozin}

Roden Lancet Diab

Endo 201324

NCTOI I778I3 (1245.20)

Häring Diabetes $2013^{25}$

NCTOI I 59600 (1245.23)

Ferrannini Diabetes Care 201326 NCT0088I530 (I 245.24)

Häring Diabetes Care 201 $3^{27}$ NCTOI I 59600 (I245.23)

Kovacs

Diabetes Obes Metab $2013^{28}$ NCTOI21000 I

(1245.19)

Rosenstock

Diabetes $^{29}$

NCTOIOII 868

(1245.33)

Phase III, Drug naïve

24 week

Phase III, MET

24 week

Phase llb, Monotherapy

78 week or MET

monotherapy

or + MET + SITA

Phase III, $\quad$ MET + SU

24 week
207

217

213

229

224

223

223

637

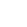

Pbo

10

25

SITA 100

Pbo

Pbo
10

25

106
109
56
166
166
56
666

$\begin{array}{ll}225 & \text { Pbo } \\ 225 & 10 \\ 216 & 25\end{array}$

Phase III, TZD (PIO)

24 week \pm MET

Phase Ilb,

INS

78 week

(dose not stated)

$\begin{array}{ll}165 & \text { Pbo } \\ 165 & 10 \\ 168 & 25 \\ 494 & \end{array}$

120

III

120

72.7

$67.3 \quad 7$

4.2

4.2

494
$170 \quad$ Pbo

$169 \quad 10$ 
Number of patients with an adverse event of special interest

\begin{tabular}{|c|c|c|c|c|c|}
\hline \multicolumn{2}{|l|}{ Hypoglycemia } & \multicolumn{2}{|c|}{ Urinary tract infection } & \multicolumn{2}{|l|}{ Genital infection } \\
\hline Total & $\%$ & $\begin{array}{l}\text { Total (Males and } \\
\text { females, if stated) }\end{array}$ & $\begin{array}{l}\% \text { (Males and } \\
\text { females, if stated) }\end{array}$ & $\begin{array}{l}\text { Total (Males and } \\
\text { females, if stated) }\end{array}$ & $\begin{array}{l}\% \text { (Males and } \\
\text { females, if stated) }\end{array}$ \\
\hline (Plasma glucose & & (MedDRA PTs & & (MedDRA PTs & (MedDRA PTs \\
\hline$\leq 70 \mathrm{mg} / \mathrm{dL}[\leq 3.9 \mathrm{mmol} / \mathrm{L}]$ & & consistent with UTIs) & & consistent with & consistent with UTIs) \\
\hline \pm requiring assistance; no & & & & Genls) & \\
\hline \multicolumn{6}{|l|}{ events required assistance) } \\
\hline I & $<1$ & I2 (M3/I24, F9/I05) & 5 (M2\%, F9\%) & 0 (M0/I24, F0/I05) & 0 \\
\hline I & $<1$ & I5 (M3/I42, FI2/82) & 7 (M2\%, FI5\%) & 7 (M4/I42, F3/82) & 3 (M3\%, F4\%) \\
\hline I & $<1$ & I2 (M2/I44, FI0/79) & 5 (MI\%, FI3\%) & 9 (M2/I44, F7/79) & 4 (MI\%, F9\%) \\
\hline I & $<1$ & II (M4/I4I, F7/82) & 5 (M3\%, F9\%) & $2(\mathrm{MI} / \mathrm{II}, \mathrm{FI} / 82)$ & I (MI\%, FI\%) \\
\hline \multicolumn{6}{|l|}{ (Plasma glucose } \\
\hline \multicolumn{6}{|l|}{$\leq 70 \mathrm{mg} / \mathrm{dL}[\leq 3.9 \mathrm{mmol} / \mathrm{L}]$} \\
\hline \multicolumn{6}{|l|}{ \pm requiring assistance; no } \\
\hline \multicolumn{6}{|l|}{ events required assistance) } \\
\hline- & 0.5 & - & 4.9 & - & 0 \\
\hline- & 1.8 & - & 5.1 & - & 3.7 \\
\hline- & 1.4 & - & 5.6 & - & 4.7 \\
\hline (Plasma glucose & & (MedDRA PTs & & (MedDRA PTs & \\
\hline$\leq 70 \mathrm{mg} / \mathrm{dL}$ & & consistent with UTIs) & & consistent with & \\
\hline$[\leq 3.9 \mathrm{mmol} / \mathrm{L}])$ & & & & Genls) & \\
\hline I & 0.9 & $4(\mathrm{M} 0, \mathrm{~F} 4)$ & 3.8 (M0\%, F7.0\%) & $5(\mathrm{M} 2, \mathrm{~F} 3)$ & 4.7 (M4.I\%, F5.3\%) \\
\hline 2 & 1.8 & $7(\mathrm{M} 4, \mathrm{~F} 3)$ & 6.4 (M7.0\%, F5.8\%) & $6(M 3, F 3)$ & 5.5 (M5.3\%, F5.8\%) \\
\hline 2 & 3.6 & $2(\mathrm{M} 0, \mathrm{~F} 2)$ & 3.6 (M0\%, F7. I\%) & $\mathrm{I}(\mathrm{MO}, \mathrm{FI})$ & I.8 (M0\%, F3.6\%) \\
\hline 3 & 1.8 & I5 (M2, FI3) & 9.0 (M2.4\%, FI5.7\%) & $5(\mathrm{M} 2, \mathrm{~F} 3)$ & 3.0 (M2.4\%, F3.6\%) \\
\hline 4 & 2.4 & $2 \mathrm{I}(\mathrm{M} 3, \mathrm{FI})$ & 12.7 (M3.4\%, F23.1\%) & $6(M 3, F 3)$ & 3.6 (M3.4\%, F3.8\%) \\
\hline 2 & 3.6 & $7(\mathrm{M} 3, \mathrm{~F} 4)$ & I2.5 (MI0.3\%, FI4.8\%) & 0 & 0 \\
\hline (Plasma glucose & & (MedDRA PTs & & (MedDRA PTs & \\
\hline$\leq 70 \mathrm{mg} / \mathrm{dL}[\leq 3.9 \mathrm{mmol} / \mathrm{L}]$ & & consistent with UTIs) & & consistent with & \\
\hline \pm requiring assistance; no & & & & Genls) & \\
\hline \multicolumn{6}{|l|}{ events required assistance) } \\
\hline 19 & 8.4 & $18(\mathrm{M} 3, \mathrm{FI})$ & 8.0 (M2.7\%, FI3.3\%) & $2(\mathrm{MI}, \mathrm{FI})$ & 0.9 (M0.9\%, F0.9\%) \\
\hline 36 & 16.1 & 23 (M3, F20) & I0.3 (M2.7\%, FI8.0\%) & 6 (MI, F5) & 2.7 (M0.9\%, F4.5\%) \\
\hline 25 & 11.5 & I8 (M0, FI8) & 8.3 (M0\%, FI7.5\%) & 5 (MI, F4) & 2.3 (M0.9\%, F3.9\%) \\
\hline (Plasma glucose $\leq 70 \mathrm{mg} / \mathrm{dL}$ & & (MedDRA PTs & & (MedDRA PTs & \\
\hline [ $\leq 3.9 \mathrm{mmol} / \mathrm{L}] \pm$ requiring & & consistent with UTIs) & & consistent with & \\
\hline assistance; no events & & & & Genls) & \\
\hline \multicolumn{6}{|l|}{ required assistance) } \\
\hline 3 & 1.8 & 27 (M6, F2I) & I6.4 (M8.2\%, F22.8\%) & $4(\mathrm{MI}, \mathrm{F} 3)$ & 2.4 (MI.4\%, F3.3\%) \\
\hline 2 & 1.2 & 28 (M3, F25) & 17.0 (M3.6\%, F30.5\%) & I4 (M6, F8) & 8.5 (M7.2\%, F9.8\%) \\
\hline 4 & 2.4 & $20(\mathrm{M} 2, \mathrm{FI} 8)$ & 11.9 (M2.4\%, F2I.7\%) & $6(\mathrm{MI}, \mathrm{F5})$ & 3.6 (MI.2\%, F6.0\%) \\
\hline \multicolumn{6}{|l|}{ (Plasma glucose $\leq 70 \mathrm{mg} / \mathrm{dL}$} \\
\hline \multicolumn{6}{|l|}{ [ $\leq 3.9 \mathrm{mmol} / \mathrm{L}] \pm$ requiring } \\
\hline \multicolumn{6}{|l|}{ assistance; } \\
\hline \multicolumn{6}{|l|}{2 cases [EMPA $25 \mathrm{mg}$ ] } \\
\hline \multicolumn{6}{|l|}{ required assistance) } \\
\hline- & 35.3 & - & 8.8 & - & 1.8 \\
\hline- & 36.I (dose & - & 14.8 & - & 7.7 \\
\hline & groups & & & & \\
\hline & pooled) & & & & \\
\hline- & - & - & 11.6 & - & 5.2 \\
\hline
\end{tabular}


Table S4 (Continued)

\begin{tabular}{llllllll}
\hline $\begin{array}{l}\text { Reference \& NCT ID (Study } \\
\text { number or acronym) }\end{array}$ & $\begin{array}{l}\text { Study } \\
\text { detail }\end{array}$ & Regimen & N & $\begin{array}{l}\text { Treatment and } \\
\text { dose, mg/day }\end{array}$ & $\begin{array}{l}\text { Adverse } \\
\text { events }\end{array}$ & $\begin{array}{l}\text { Serious adverse } \\
\text { events }\end{array}$ \\
\cline { 3 - 7 } & & & Total & $\%$ & Total $\%$
\end{tabular}

Ferrannini Diabetes Obes Metab

$2013^{30}$ NCT00789035 (I 245.9)

\section{Phase Ilb, \\ 12 week}

Drug naïve or
4-week washout

\begin{tabular}{|c|c|c|c|c|c|c|c|c|}
\hline & & & 82 & Pbo & 27 & 33 & 0 & 0 \\
\hline & & & 81 & 5 & 26 & 32 & 2 & 2.5 \\
\hline & & & 81 & 10 & 22 & 27 & 0 & 0 \\
\hline & & & 82 & 25 & 23 & 28 & I & 1.2 \\
\hline & & & 80 & MET (O/L) & 31 & 39 & 3 & 3.8 \\
\hline \multirow[t]{8}{*}{$\begin{array}{l}\text { Rosenstock Diabetes Obes Metab } \\
2013^{31} \text { NCT00749190 (I245.10) }\end{array}$} & $\begin{array}{l}\text { Phase Ilb, } \\
12 \text { week }\end{array}$ & MET & 495 & & & & & \\
\hline & & & 71 & Pbo & 26 & 36.6 & 2 & 2.8 \\
\hline & & & 71 & 1 & 21 & 29.6 & 0 & 0 \\
\hline & & & 71 & 5 & 26 & 36.6 & 3 & 4.2 \\
\hline & & & 71 & 10 & 30 & 42.3 & I & 1.4 \\
\hline & & & 70 & 25 & 25 & 42.3 & 2 & 2.9 \\
\hline & & & 70 & 50 & 34 & 48.6 & 3 & 4.3 \\
\hline & & & 71 & SITA I00 (O/L) & 25 & 35.2 & 0 & 0 \\
\hline \multirow{9}{*}{$\begin{array}{l}\text { Barnett Lancet Diab Endo 20I4 }{ }^{32} \\
\text { NCT0I I 6450I (1245.36) }\end{array}$} & Phase III, & AHAs & 741 & (Safety data & & & & \\
\hline & $\begin{array}{l}52 \text { week, } \\
\text { CKD }\end{array}$ & & & $\begin{array}{l}\text { reported at } \\
\text { week 52) }\end{array}$ & & & & \\
\hline & & Stage 2 CKD & 97 & Pbo & 83 & 87.4 & 11 & 11.6 \\
\hline & & & 98 & 10 & 86 & 87.8 & 6 & 6.1 \\
\hline & & & 97 & 25 & 78 & 80.4 & 7 & 7.2 \\
\hline & & Stage 3 CKD & 187 & Pbo & 156 & 83.4 & 23 & 12.3 \\
\hline & & & 188 & 25 & 156 & 83.4 & 22 & 11.8 \\
\hline & & Stage 4 CKD & 37 & Pbo & 31 & 83.8 & 10 & 27.0 \\
\hline & & & 37 & 25 & 34 & 91.9 & II & 29.7 \\
\hline
\end{tabular}

Notes: ${ }^{a}$ Data are presented as published (from randomized double-blind arms of each trial unless otherwise stated).

Abbreviations: AHA, anti-hyperglycemic agent; AM, ante meridiem (in the morning); BD, bis in die (twice per day); BG, blood glucose; BMI, body mass index; CANTATA, canagliflozin treatment and trial analysis; CANTATA-D2, dipeptidyl peptidase 4 inhibitor second comparator; CANTATA-M, metformin; CANTATA-MSU, metformin + sulfonylurea; CANTATA-SU, sulfonylurea; CANVAS, canagliflozin cardiovascular assessment study; CKD, chronic kidney disease; DAPA, dapagliflozin; DDP4, dipeptidyl

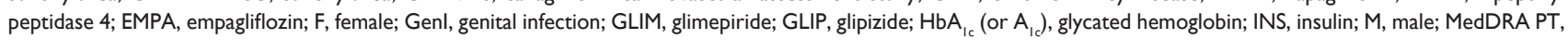
Medical Dictionary for Regulatory Activities Preferred Terms; MET, metformin; NCT ID, National Clinical Trials (US) identification (number); OAD, oral anti-diabetes drug; O/L, open label; Pbo, placebo; PG, plasma glucose; PIO, pioglitazone; PM, post meridiem (in the afternoon); SGLT2, sodium glucose co-transporter type 2; SITA, sitagliptin; $\mathrm{SU}$, sulfonylurea; TZD, thiazolidinedione; UTI, urinary tract infection; VVAE, vulvovaginal adverse event; XR, extended release formulation. 
Number of patients with an adverse event of special interest

\begin{tabular}{|c|c|c|c|c|c|}
\hline \multicolumn{2}{|l|}{ Hypoglycemia } & \multicolumn{2}{|c|}{ Urinary tract infection } & \multicolumn{2}{|l|}{ Genital infection } \\
\hline Total & $\%$ & $\begin{array}{l}\text { Total (Males and } \\
\text { females, if stated) }\end{array}$ & $\begin{array}{l}\% \text { (Males and } \\
\text { females, if stated) }\end{array}$ & $\begin{array}{l}\text { Total (Males and } \\
\text { females, if stated) }\end{array}$ & $\begin{array}{l}\% \text { (Males and } \\
\text { females, if stated) }\end{array}$ \\
\hline (Symptomatic or & & (MedDRA PTs & & (MedDRA PTs & \\
\hline \multirow[t]{2}{*}{ laboratory-defined) } & & consistent with UTIs) & & consistent with & \\
\hline & & & & Genls) & \\
\hline I & 1.2 & 1 & 1.2 & 0 & 0 \\
\hline 0 & 0 & 2 & 2.5 & 0 & 0 \\
\hline 0 & 0 & 1 & 1.2 & 3 & 3.7 \\
\hline 0 & 0 & 1 & 1.2 & 2 & 2.4 \\
\hline I & 1.2 & 2 & 2.5 & 0 & 0 \\
\hline (Defined by & & (MedDRA PTs & & (MedDRA PTs & \\
\hline \multirow[t]{2}{*}{ MedDRA PTs) } & & consistent with UTIs) & & consistent with & \\
\hline & & & & Genls) & \\
\hline 0 & 0 & 2 & 2.8 & 0 & 0 \\
\hline 0 & 0 & 2 & 2.8 & I & 1.4 \\
\hline 3 & 4.2 & 2 & 2.8 & 4 & 5.6 \\
\hline 0 & 0 & 3 & 4.2 & 7 & 9.9 \\
\hline 0 & 0 & 4 & 5.7 & 0 & 0 \\
\hline I & 1.4 & 3 & 4.3 & 2 & 2.9 \\
\hline 2 & 2.8 & 3 & 4.2 & 2 & 2.8 \\
\hline 23 & 24.2 & I5 (M5; FIO) & I 5.8 (M8.9\%; F25.6\%) & 6 (M2; F4) & 6.3 (M3.6\%; FI0.3\%) \\
\hline 26 & 26.5 & I4 (M5; F9) & I 4.3 (M8.3\%; F23.7\%) & 7 (M6; FI) & $7 . \mathrm{I}$ (MI0.0\%; F2.6\%) \\
\hline 22 & 22.7 & 9 (M2; F7) & 9.3 (M3.3\%; FI9.4\%) & 5 (M0; F5) & 5.2 (M0; FI3.9\%) \\
\hline 53 & 28.3 & 29 (M4; F25) & I 5.5 (M3.8\%; F30.9\%) & $2(\mathrm{MI} ; \mathrm{FI})$ & I.I (M0.9\%; FI.2\%) \\
\hline 52 & 27.8 & 31 (M6; F25) & I 6.6 (M5.6\%; F3I.3\%) & 5 (M2; F3) & 2.7 (MI.9\%; F3.8\%) \\
\hline 12 & 32.4 & 3 (M0; F3) & 8.I (M0; FI6.7\%) & 0 (M0; F0) & 0 (M0; F0) \\
\hline 14 & 37.8 & 7 (M2; F5) & I8.9 (M9.5\%; F3I.3\%) & I (M0; FI) & 2.7 (M0; F6.3\%) \\
\hline
\end{tabular}

\section{References}

1. List JF, Woo V, Morales E, Tang W, Fiedorek FT. Sodium-glucose cotransport inhibition with dapagliflozin in type 2 diabetes. Diabetes Care. 2009;32(4):650-657

2. Wilding JP, Norwood P, T'Joen C, Bastien A, List JF, Fiedorek FT. A study of dapagliflozin in patients with type 2 diabetes receiving high doses of insulin plus insulin sensitizers: applicability of a novel insulinindependent treatment. Diabetes Care. 2009;32(9):1656-1662.

3. Ferrannini E, Ramos SJ, Salsali A, Tang W, List JF. Dapagliflozin monotherapy in type 2 diabetic patients with inadequate glycemic control by diet and exercise: a randomized, double-blind, placebo-controlled, phase 3 trial. Diabetes Care. 2010;33(10): 2217-2224.

4. Bailey CJ, Iqbal N, T'Joen C, List JF. Dapagliflozin monotherapy in drugnaive patients with diabetes: a randomized-controlled trial of low-dose range. Diabetes Obes Metab. 2012;14(10):951-959.
5. Bailey CJ, Gross JL, Pieters A, Bastien A, List JF. Effect of dapagliflozin in patients with type 2 diabetes who have inadequate glycaemic control with metformin: a randomised, double-blind, placebo-controlled trial. Lancet. 2010;375(9733):2223-2233.

6. Bolinder J, Ljunggren O, Kullberg J, et al. Effects of dapagliflozin on body weight, total fat mass, and regional adipose tissue distribution in patients with type 2 diabetes mellitus with inadequate glycemic control on metformin. J Clin Endocrinol Metab. 2012;97(3):1020-1031.

7. Henry RR, Murray AV, Marmolejo MH, Hennicken D, Ptaszynska A, List JF. Dapagliflozin, metformin XR, or both: initial pharmacotherapy for type 2 diabetes, a randomised controlled trial. Int J Clin Pract. 2012;66(5):446-456.

8. Strojek K, Yoon KH, Hruba V, Elze M, Langkilde AM, Parikh S. Effect of dapagliflozin in patients with type 2 diabetes who have inadequate glycaemic control with glimepiride: a randomized, 24-week, double-blind, placebo-controlled trial. Diabetes Obes Metab. 2011;13(10):928-938. 
9. Nauck MA, Del Prato S, Meier JJ, et al. Dapagliflozin versus glipizide as add-on therapy in patients with type 2 diabetes who have inadequate glycemic control with metformin: a randomized, 52-week, double-blind, active-controlled noninferiority trial. Diabetes Care. 2011;34(9):2015-2022.

10. Rosenstock J, Vico M, Wei L, Salsali A, List JF. Effects of dapagliflozin, an SGLT2 inhibitor, on $\mathrm{HbA}(1 \mathrm{c})$, body weight, and hypoglycemia risk in patients with type 2 diabetes inadequately controlled on pioglitazone monotherapy. Diabetes Care. 2012;35(7):1473-1478.

11. Wilding JP, Woo V, Soler NG, et al. Long-term efficacy of dapagliflozin in patients with type 2 diabetes mellitus receiving high doses of insulin: a randomized trial. Ann Intern Med. 2012;156(6):405-415.

12. Kohan DE, Fioretto P, Tang W, List JF. Long-term study of patients with type 2 diabetes and moderate renal impairment shows that dapagliflozin reduces weight and blood pressure but does not improve glycemic control. Kidney Int. 2014;85(4):962-971.

13. Jabbour SA, Hardy E, Sugg J, Parikh S. Dapagliflozin is effective as add-on therapy to sitagliptin with or without metformin: a 24-week, multicenter, randomized, double-blind, placebo-controlled study. Diabetes Care. 2014;37(3):740-750.

14. Stenlöf K, Cefalu WT, Kim KA, et al. Efficacy and safety of canagliflozin monotherapy in subjects with type 2 diabetes mellitus inadequately controlled with diet and exercise. Diabetes Obes Metab. 2013;15(4):372-382.

15. Cefalu WT, Leiter LA, Yoon KH, et al. Efficacy and safety of canagliflozin versus glimepiride in patients with type 2 diabetes inadequately controlled with metformin (CANTATA-SU): 52 week results from a randomised, double-blind, phase 3 non-inferiority trial. Lancet. 2013;382(9896):941-950.

16. Lavalle-González FJ, Januszewicz A, Davidson J, et al. Efficacy and safety of canagliflozin compared with placebo and sitagliptin in patients with type 2 diabetes on background metformin monotherapy: a randomised trial. Diabetologia. 2013;56(12):2582-2592.

17. Schernthaner G, Gross JL, Rosenstock J, et al. Canagliflozin compared with sitagliptin for patients with type 2 diabetes who do not have adequate glycemic control with metformin plus sulfonylurea: a 52-week randomized trial. Diabetes Care. 2013;36(9):2508-2515.

18. Wilding JP, Charpentier G, Hollander P, et al. Efficacy and safety of canagliflozin in patients with type 2 diabetes mellitus inadequately controlled with metformin and sulphonylurea: a randomised trial. Int J Clin Pract. 2013;67(12):1267-1282.

19. Forst T, Guthrie R, Goldenberg R, et al. Efficacy and safety of canagliflozin over 52 weeks in patients with type 2 diabetes on background metformin and pioglitazone. Diabetes Obes Metab. 2014;16(5):467-477.

20. Matthews DR, Fulcher G, Perkovic V, et al. Efficacy and safety of canagliflozin (CANA), an inhibitor of sodium glucose co-transporter 2 (SGLT2), added-on to insulin therapy +/- oral agents in type 2 diabetes. Abstract 764. Diabetologia. 2012;55(Suppl 1):S314.

21. Rosenstock J, Aggarwal N, Polidori D, et al. Dose-ranging effects of canagliflozin, a sodium-glucose cotransporter 2 inhibitor, as add-on to metformin in subjects with type 2 diabetes. Diabetes Care. 2012;35(6):1232-1238.

22. Yale JF, Bakris G, Cariou B, et al. Efficacy and safety of canagliflozin in subjects with type 2 diabetes and chronic kidney disease. Diabetes Obes Metab. 2013;15(5):463-473.
23. Bode B, Stenlöf K, Sullivan D, Fung A, Usiskin K. Efficacy and safety of canagliflozin treatment in older subjects with type 2 diabetes mellitus: a randomized trial. Hosp Pract (1995). 2013;41(2):72-84.

24. Roden M, Weng J, Eilbracht J, et al. Empagliflozin monotherapy with sitagliptin as an active comparator in patients with type 2 diabetes: a randomised, double-blind, placebo-controlled, phase 3 trial. Lancet Diabetes Endocrinol. 2013;1(3):208-219.

25. Häring HU, Merker L, Seewaldt-Becker E, Weimer M, Meinicke T. Empagliflozin as add-on to metformin for 24 weeks improves glycemic control in patients with type 2 diabetes (T2DM). Diabetes. 2013; 62(Suppl 1):Abstract 1092-P.

26. Ferrannini E, Berk A, Hantel S, et al. Long-term safety and efficacy of empagliflozin, sitagliptin, and metformin: an active-controlled, parallelgroup, randomized, 78-week open-label extension study in patients with type 2 diabetes. Diabetes Care. 2013;36(12):4015-4021.

27. Häring HU, Merker L, Seewaldt-Becker E, et al. Empagliflozin as add-on to metformin plus sulfonylurea in patients with type 2 diabetes. A 24-week, randomized, double-blind, placebo-controlled trial. Diabetes Care. 2013;36(11):3396-3404.

28. Kovacs CS, Seshiah V, Swallow R, et al. Empagliflozin improves glycaemic and weight control as add-on therapy to pioglitazone or pioglitazone plus metformin in patients with type 2 diabetes: a 24-week, randomized, placebo-controlled trial. Diabetes Obes Metab. 2014;16(2):147-158.

29. Rosenstock J, Jelaska A, Kim G, Broedl UC, Woerle HJ. Empagliflozin as add-on to basal insulin for 78 weeks improves glycemic control with weight loss in insulin-treated (T2DM). Diabetes. 2013;62(Suppl 1): Abstract 1102-P.

30. Ferrannini E, Seman L, Seewaldt-Becker E, Hantel S, Pinnetti S, Woerle H. A phase IIb, randomised, placebo-controlled study of the SGLT2 inhibitor empagliflozin in patients with type 2 diabetes. Diabetes Obes Metab. 2013;15(8):721-728.

31. Rosenstock J, Seman LJ, Jelaska A, et al. Efficacy and safety of empagliflozin, a sodium glucose cotransporter 2 (SGLT2) inhibitor, as add-on to metformin in type 2 diabetes with mild hyperglycaemia. Diabetes Obes Metab. 2013;15(12):1154-1160.

32. Barnett AH, Mithal A, Manassie J, et al. Efficacy and safety of empagliflozin added to existing antidiabetes treatment in patients with type 2 diabetes and chronic kidney disease: a randomised, double-blind, placebo-controlled trial. Lancet Diabetes Endocrinol. 2014;2(5):369-384.

33. Yamamoto Y, Kawanishi E, Koga Y et al. N-Glucosides as human sodium-dependent glucose cotransporter 2 (hSGLT2) inhibitors. Bioorg Med Chem Lett. 2013 15;23(20):5641-5645.

34. Powell DR, Smith M, Doree D, et al. LX2761, an SGLT1 inhibitor restricted to the intestine, improves glycaemic control in mice. Diabetologia. 2013;56(1):S399 Abstract 995.

35. Young AA, Liu Y, McNulty D et al. Synergistic glucose-lowering effects of SGLT1- and ASBT-inhibitor combinations in ZDF rats. Diabetologia 2013;56(Suppl 1):S399 Abstract 994.

36. hang L, Wang Y, Xu H et al. Discovery of 6-deoxydapagliflozin as a highly potent sodium-dependent glucose cotransporter 2 (SGLT2) inhibitor for the treatment of type 2 diabetes. Med Chem. 2014;10:304-317.
Drug Design, Development and Therapy

\section{Publish your work in this journal}

Drug Design, Development and Therapy is an international, peerreviewed open-access journal that spans the spectrum of drug design and development through to clinical applications. Clinical outcomes, patient safety, and programs for the development and effective, safe, and sustained use of medicines are a feature of the journal, which

\section{Dovepress}

has also been accepted for indexing on PubMed Central. The manuscript management system is completely online and includes a very quick and fair peer-review system, which is all easy to use. Visit http://www.dovepress.com/testimonials.php to read real quotes from published authors. 